\title{
LONG SHIFTS, SHORT RESTS AND VULNERABILITY TO SHIFT WORK
}

\author{
John Axelsson
}

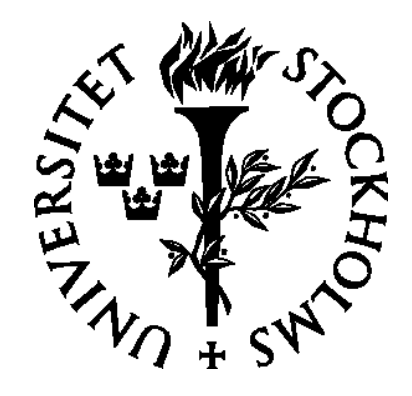

Department of Psychology, Stockholm University

National Institute of Psychosocial Medicine

Stockholm 2005 
Long shifts, short rests and vulnerability to shift work

(C) John Axelsson, 2005

ISBN-91-7155-054-2

Department of Psychology, Stockholm University, Sweden

National Institute of psychosocial Medicine, Stockholm, Sweden

Prited by Reproprint AB, Stockholm, Sweden 


\section{To my Darlings}

"I love fools' experiments, I am always making them." Charles Darwin 
Doctoral Dissertation

Department of Psychology, Stockholm University

National Institute for Psychosocial Medicine

\section{Abstract}

At the same time as many urban economies are developing into 24-hour societies it is becoming popular amongst shift workers to compress their working hours. This is done by working longer shifts $(>8 \mathrm{~h})$ and/or restricting free time $(<16 \mathrm{~h})$ in between shifts - the main reasons are to gain longer bouts of free time and extra free weekends. However, there is a limited knowledge of the effects of such arrangements on sleep and wakefulness. Thus, the main purposes of the present thesis were to evaluate the effects of long working hours (in the form of $12 \mathrm{~h}$ shifts) and short recovery periods. Another aim was to evaluate possible mechanisms that could suggest why some individuals develop problems with shift work while others do not.

We used a combination of methods - sleep diaries, wake diaries, blood samples and objective measures of sleep and cognitive performance - across whole or large parts of shift schedules to evaluate acute effects of particularly demanding working periods, as well as the total effects of a shift cycle. Study I evaluated the effect of changing from an $8 \mathrm{~h}$ - to a $12 \mathrm{~h}$-shift system. Study II evaluated the effects of long shifts in a shift schedule with both $8 \mathrm{~h}$ - and $12 \mathrm{~h}$-shifts. Study III evaluated the effects of several consecutive short recovery periods (8-9h of recovery) and whether satisfaction with ones' work hours was associated to problems with sleep and sleepiness. Study IV evaluated whether endocrinological markers of catabolic (cortisol) and anabolic (testosterone) activity changed across a shift sequence and whether satisfaction were related to them. Study V was a laboratory simulation of the effects of a short recovery period ( $4 \mathrm{~h}$ of sleep) and whether a short nap could counteract any detrimental effects.

There was no convincing evidence for $12 \mathrm{~h}$ shifts inducing more problems with sleep and sleepiness than $8 \mathrm{~h}$ shifts. With regard to recovery time between shifts, the shortest recovery times (only 8h) seriously shortened sleep duration and increased sleepiness, while $12 \mathrm{~h}$ of recovery (between two consecutive 12h shifts) was judged as having no or limited effects on acute measures. The problems with the shortest recovery periods were worse in a schedule with several consecutive shifts and less pronounced in a schedule with few consecutive shifts. With regard to individual differences, it was found that subjects being dissatisfied with their working hours were vulnerable to short recovery periods, which was evident by less sufficient sleep and an accumulation of sleepiness across work periods with limited recovery time. Interestingly, these problems disappeared when they were allowed to recover after the work period. In addition, dissatisfied male shift workers had lower testosterone levels at the end of work periods, indicating disturbed anabolic activity. The simulated quick return supported that curtailed sleep affected sleepiness and performance and that a short nap could counteract these effects temporarily.

It is concluded that long shifts (up to $12 \mathrm{~h}$ ) may be acceptable, whereas short recovery time ( $8 \mathrm{~h}$ or less) is not. Most of the problems with short recovery periods were related to short sleep and sleepiness, and there is, clearly, a subgroup of workers that suffer more from this than others. It is argued that insufficient sleep and low testosterone levels (in males) might be key factors for developing shift intolerance, mainly by reducing the capacity to recover from shift work.

Keywords: Sleep, alertness, sleepiness, shiftwork, compressed working hours, long shifts, $12 \mathrm{~h}$ shifts, quick returns, quick change-overs, tolerance 


\section{Svensk Sammanfattning}

Andelen skiftarbetare med komprimerade arbetstider har ökat under de senaste decennierna. Avhandlingen syfte är att undersöka effekterna om hur långa arbetspass (12-timmarsskift) och korta vilotider (kortare än 16-timmar) påverkar sömn och vakenhet hos skiftarbetare. Vi ville även undersöka varför vissa klarar att arbeta skift med minimala problem medan andra har kraftiga problem (problem som är relaterade till senare ohälsa).

Totalt 5 publicerade studier ingår i avhandlingen. Studierna använder ett flertal mätmetoder: sömndagböcker, vakenhetsdagböcker, blodprover, samt objektiva mått på sömn, vakenhet och prestation.

Sammanfattningsvis har långa arbetspass (12 timmar) endast marginella effekter på trötthet och sömn under dessa arbetsförhållanden. Det större antalet vilodagar kan i vissa fall medföra en förbättrad totalsituation (hälsa, trötthet, sömn). Vidare medför korta vilotider ( 8 timmar) en avsevärd sömnförkortning och trötthet. Dessa problem blev värre i ett skiftschema med flera efterföljande arbetspass och lindrigare i schema med få efterföljande pass. "Icke toleranta" skiftarbetare (i samband med ett skift schema med flera korta vilotider mellan arbetspassen) hade betydligt mer problem med sömn och vakenhet än toleranta skiftarbetare. Problemen hos "icke toleranta" ackumulerade under arbetsperioder och försvann under lediga dagar. En möjlig mekanism till dessa problem kan var ett större sömnbehov och lägre testosteronnivåer (hos män) vilket speglar deras problem att hinna återhämta sig när vilotiden var kort medan det gick bra under ledig tid. Ett motmedel vid reducerad sömn är en kortare kompletterande sömn (tupplur) som återställer mycket av vakenhet och funktionsförmåga. 


\section{List of Original Papers}

The present thesis is based on the following studies, which will be referred to by their Roman numerals.

\section{I}

Lowden A, Kecklund G, Axelsson J, Akerstedt T.

Change from an 8-hour shift to a 12-hour shift, attitudes, sleep, sleepiness and performance. Scand J Work Environ Health. 1998;24 Suppl 3:69-75.

\section{II}

Axelsson J, Kecklund G, Akerstedt T, Lowden A.

Effects of alternating 8- and 12-hour shifts on sleep, sleepiness, physical effort and performance.

Scand J Work Environ Health. 1998;24 Suppl 3:62-8.

\section{III}

Axelsson J, Akerstedt T, Kecklund G, Lowden A.

Tolerance to shift work-how does it relate to sleep and wakefulness?

Int Arch Occup Environ Health. 2004 Feb;77(2):121-9. Epub 2003 Nov 11.

\section{IV}

Axelsson J, Akerstedt T, Kecklund G, Lindqvist A, Attefors R.

Hormonal changes in satisfied and dissatisfied shift workers across a shift cycle.

J Appl Physiol. 2003 Nov;95(5):2099-105. Epub 2003 Jul 25.

V

Gillberg M, Kecklund G, Axelsson J, Akerstedt T.

The effects of a short daytime nap after restricted night sleep.

Sleep. 1996 Sep;19(7):570-5. 


\section{Contents}

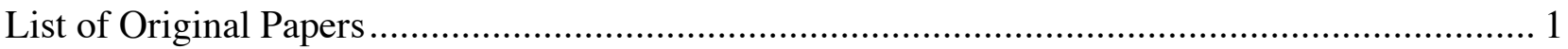

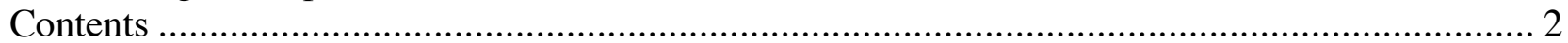

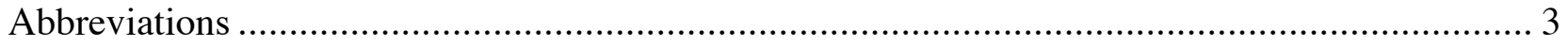

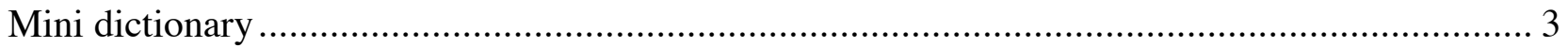

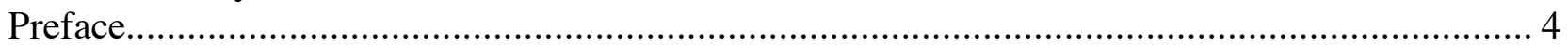

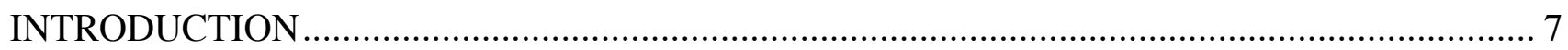

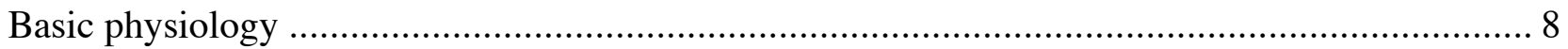

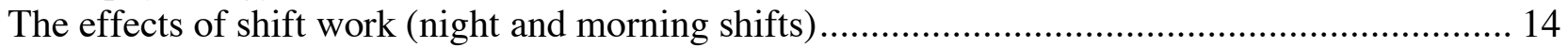

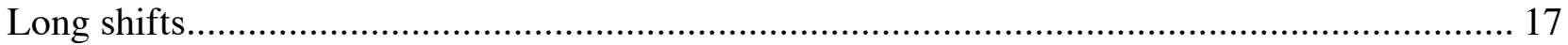

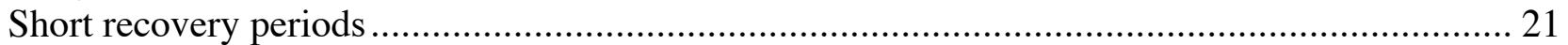

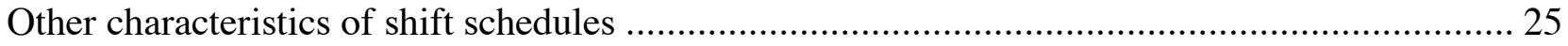

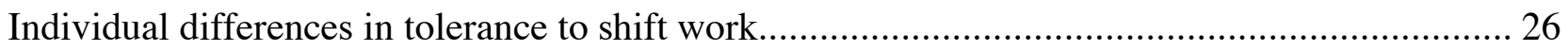

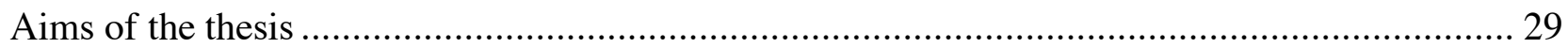

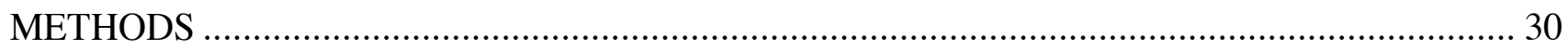

Design of the studies............................................................................................................. 30

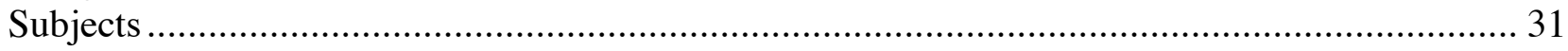

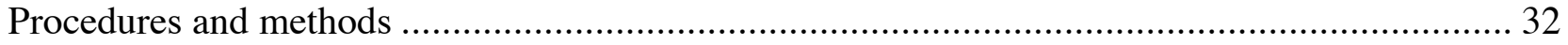

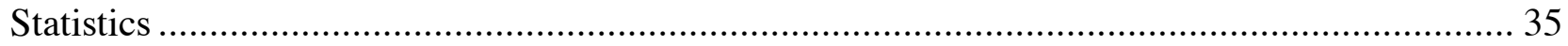

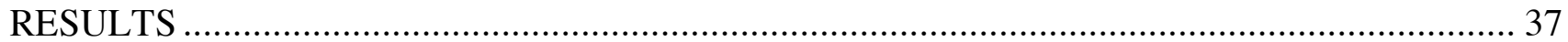

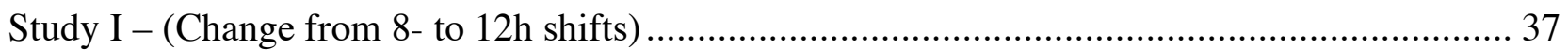

Study II - (Alternating 8- and 12h shifts in the same schedule) ……………............................... 39

Study III - (Tolerance to shift work with short recovery periods) .......................................... 41

Study IV - (Hormonal changes across a shift cycle)........................................................... 42

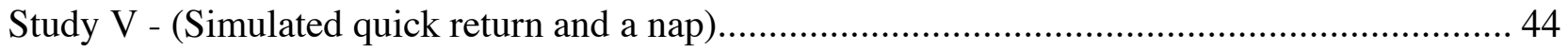

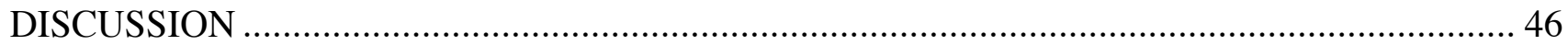

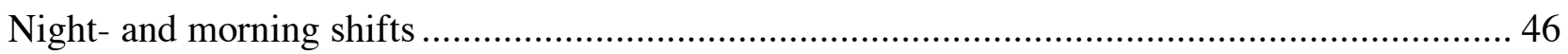

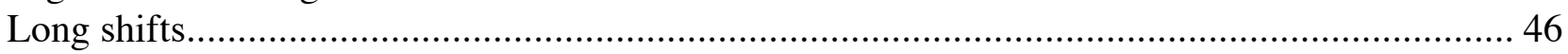

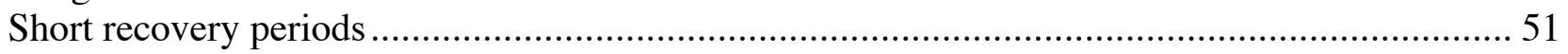

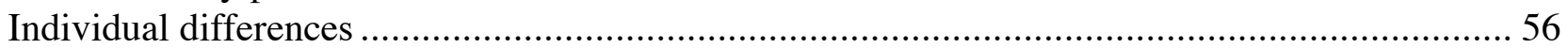

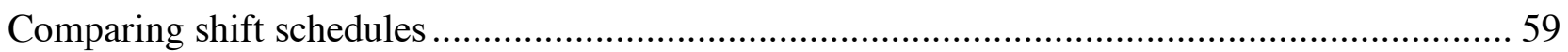

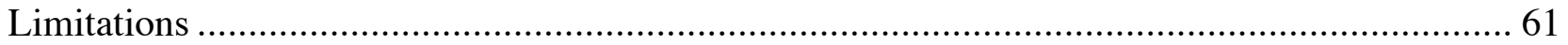

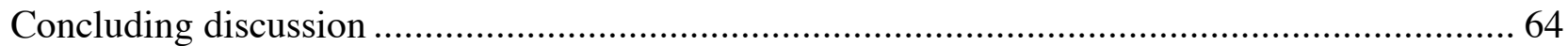

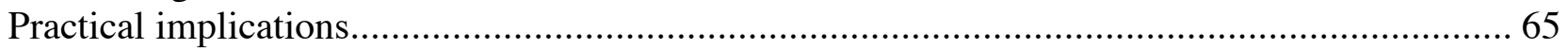

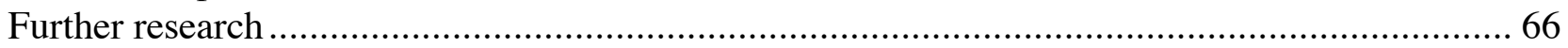

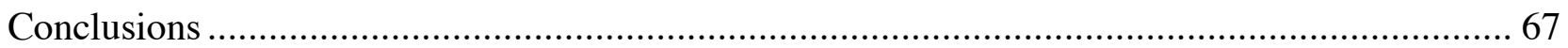

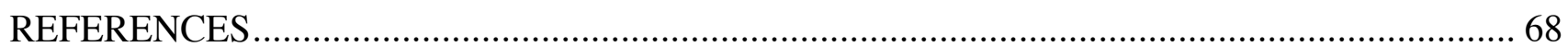




\section{Abbreviations}

$\begin{array}{ll}\text { A-shift } & \text { Afternoon shift } \\ \text { BMI } & \text { Body Mass Index (weight/length }{ }^{2} \text { ) } \\ \text { D-shift } & \text { Day shift } \\ \text { EEG } & \text { electroencephalogram } \\ \text { e.g. } & \text { exemple gratia (for example) } \\ \text { EMG } & \text { electromyogram } \\ \text { EOG } & \text { electrooculogram } \\ \text { etc. } & \text { etcetera; and other unspecified things of the same class } \\ \text { EU } & \text { European Union } \\ \text { h } & \text { hour } \\ \text { HPG } & \text { hypothalamus - pituarity - gonadal system } \\ i . e . & \text { id est (that is) } \\ \text { KDT } & \text { Karolinska Drowsiness Test } \\ \text { KSD } & \text { Karolinska Sleep Diary } \\ \text { KSS } & \text { Karolinska Sleepiness Scale } \\ \text { KSQ } & \text { Karolinska Sleep Questionnaire } \\ \text { M-shift } & \text { Morning shift } \\ \text { MSLT } & \text { Multiple Sleep Latency Test } \\ \text { MWT } & \text { Maintenance of Wakefulness Test } \\ \text { NREM-sleep } & \text { Non REM sleep (=stage 1-4) } \\ \text { N-shift } & \text { Night shift } \\ \text { REM-sleep } & \text { Rapid Eye Movement sleep } \\ \text { RT } & \text { Reaction time test } \\ \text { SCN } & \text { Suprachiasmatic nucleus (Hypothalamic nucleus with a } \approx 24 h \text { periodicity) } \\ \text { SSS } & \text { Stanford Sleepiness Scale } \\ \text { TIB } & \text { time in bed (lights out until rising) } \\ \text { TST } & \text { total sleep time (time asleep) } \\ \text { VAS } & \text { visual analogue scale } \\ \text { VT } & \text { Vigilance test }\end{array}$

\section{Mini dictionary}

$\begin{array}{ll}\text { acrophase } & \text { maximum of a period (here circadian period) } \\ \text { amplitude } & \text { difference between the maximum and the minimum of a period } \\ \text { anabolic } & \text { restorative processes (i.e. related to the synthetic phase of metabolism) } \\ \text { endogenous } & \text { originating from within the organism } \\ \text { entrain } & \text { to determine or modify the circadian phase or period } \\ \text { homeostasis } & \text { the ability or tendency to maintain internal equilibrium } \\ \text { nadir } & \text { the minimum of a period } \\ \text { period (circadian) } & \text { usually 24h } \\ \text { polysomnography } & \text { the monitoring of EEG, EOG and EMG during sleep } \\ \text { quick return } & \text { quick change-over, only 8-9h of free time between shifts } \\ \text { trough } & \text { the minimum of a period } \\ \text { Zeitgebers } & \text { external time cues setting the circadian system }\end{array}$




\section{Preface}

"Reality is merely an illusion, albeit a very persistent one."

Albert Einstein

At last, after long time and many doubts, this thesis is terminated. It was not an easy journey, nor was it entirely filled with pleasure. Nevertheless, it is done.

The purposes of this preface is to inform the reader of the content of this thesis - in a feeble hope that it can support any digestible information about its subject - and to acknowledge some of those who have contributed to its mere existence.

With regard to the time it took to write, it should be a masterpiece. Unfortunately, it is not, and I can only hope that that it can provide the reader with new knowledge and generate ideas for future research. If I am lucky, it may even improve working life if some of its guidelines are adopted.

Firstly, I have to warn any plausible (and implausible) reader that I do not write like Dan Brown or JK Rawling, rather the opposite. It will take a fare share of determination to read it from cover to cover. On the other had, it may also be used as a cure for insomnia. I will therefore try to guide the interested reader of what parts could be most rewarding.

For the scientific nerd, I have no other suggestion, than to skip this section and go right ahead. For the rest of you, I suggest that you flick through the "Contents" of the introduction, and focus on finding any interesting subject that may be palatable. For non-researchers, don't even try to read the Methods or the Results section, they are merely there to show what we have done, if its ethical, and selected analyses of the data. However, the conclusions include the results in a rewritten form and may even contain fragments of new knowledge. Personally, and after rereading this thesis for the eleventeenth time (a well used term by my 4 year old daughters), I can only find support in Albert Einstein words "If you are out to describe the truth, leave elegance to the tailor".

Now to the more important matters. I wish to express my sincere gratitude to all those who have contributed to the completion of this thesis. But no matter how many I list, some will be forgotten. I just hope for forgiveness,

I would like to thank my supervisor, Torbjörn Akerstedt for his inspiration and support. Not only has he guided me through inconceivable amounts of data, he has also spent vast amount of time reading my manuscripts - firstly trying to save them, and after sound thought often rewritten them. He certainly stood the test of time.

I owe comparable amounts of gratitude to my secondary supervisor and friend, Göran Kecklund. He has been less involved in the final parts of the thesis, but he was my first real mentor in the field of 
research and his door has always been open. His path was not the easiest one, but the one of finding the truth. Without his inspiration and endless discussions, I would often have chosen an easier path.

My first contact with sleep research was Mats Gilberg. He is not only a meticulous scientist, he is also a magician - I still don't know how he managed to publish that first study I carried out in the lab. In fact, it turned out really well, and holds a significant part of this thesis. Without him, I would have been something completely different, perhaps not even a man of science.

I have spent many long days with Arne Lowden. He has always made them feel short, whether they have been in the jungle or in deep pine forests of Småland. I am fortunate to have been in his company for so long.

During my years at IPM, I have had enormous support, from one of the least scientific persons I knew (at least then) Cristian Portin. However, he has always challenged my intellect in most peculiar ways. His frankness has not always been entirely pleasant, although always revitalizing. Only his Finnish charm has been able to penetrate the thickest walls at our Institution.

I am indebted to my colleagues and scientific collaborators - Anna Dahlgren, Paolo DonOffrio, Mirjam Ekstedt, Clair Eriksen, Kiarash Fathi, Michael Ingre, Kerstin Jeding, Juha Keinanen, Mats Lekander, Mona Martinsson, Jens Nilsson, Helena Pernler and Marie Söderström. You have all contributed in the most unimaginable and improbable ways of our present research, even though you have mostly not contributed to the studies of the present thesis - they were all carried out in an earlier century.

I am grateful to all other co-workers, particularly Anne Lindqvist and Reine Attefors, for your contribution in the field.

I will also thank the rest of the staff at our institution for your help with everyday issues.

I am also grateful to Adam Fletcher, Cameron van Den Heuvel, Drew Dawson and the rest of the Sleep and Fatigue lab at the Queen Elisabeth Hospital in Adeliade, Australia, for your invitation and hospitality. Likewise I am thankful to Jim Horne, Lousie Reyner, Stuart Baulk, Diane Flateley and Hillary Kemp at the sleep laboratory in Loughborough, England for your warm welcome.

I am sincerely thankful to all the participants, without you, this thesis would be superficial.

To my friends, I regret that I haven't had more time to enjoy your company. To Rickard, did you manage to finish your examination before me?

I am forever grateful to my family, for having had patience with me during times when I have given priority to work. Especially my wife Suzanne, for her love, proofreading and endless patience. She has provided me with an atmosphere of love and possibilities and has accepted changes with enthusiasm. I am truly yours. 
My children, Sophia, Isabelle and Michael, for your love and for letting me know the wonderful feeling of being a father. It is never ever boring around any of you. I hope you will go open-minded out into the world of possibilities.

To my parents Leif and Anita Axelsson, who have helped with everything from babysitting to being guinea-pigs.

My sister Jenny Axelsson, who also contributed to many of my studies, when my own energy has been running low.

This work has been supported by the Swedish Work Environment Fund; the Department of Psychology Stockholm University; the Institution of Psychosocial Medicine, and STINT

"Only dull people are brilliant a breakfast."

Oscar Wilde 


\section{INTRODUCTION}

"My most horrible memory is when I thought I was a hummingbird after working 96-hours straight."

$\mathrm{Apu}$

According to the last European Union (EU) survey on working conditions, approximately $24 \%$ of the population work on a regular 8-hour schedule during daylight hours (07.00-18.00) and 5 days per week, while almost $30 \%$ have atypical schedules (weekend work and irregular schedules), with Finland and Sweden being close to 50\%. (Boisard et al., 2002). Seventeen per cent are engaged in shift work and $14 \%$ have long shifts (at least 10h) on a regular basis (Boisard et al., 2002; Stevens et al., 2004). Even though a wide variety of shift systems exist, the term "shift work" will, for simplicity, in the present thesis refer to all work hours that include night work.

At the same time as many urban economies are developing into 24-hour societies it is becoming increasingly popular amongst shift workers to compress their working hours by extending shifts and/or decreasing time for recovery between shifts (Duchon and Smith, 1993; Kogi, 1995). The reduced possibilities to recover in compressed working schedules may impose a great risk for adverse acute and long-term effects, but are still poorly understood. For instance, how do long shifts, in particular at night, and short recovery periods influence the quantity and/or quality of sleep, alertness and performance in individuals with such working schedules? And which are the biological mechanisms behind these influences?

The present thesis focuses on the issues above and on why individuals differ in tolerance to shift work. Perhaps the major contribution of the present papers concerns the methodological approach the present studies are based on diary studies with a longitudinal approach rather than epidemiological data. This is particularly obvious in the field of long shifts, where a substantial amount of epidemiological studies are published. The benefits of studying short rest periods and individual differs are more obvious, as the understandings of these issues are still in their infancy.

The introduction contains a series of reviews; that covers basic physiological processes - that are necessary for understanding the effects of shift work - as well as the effects of various aspects of shift work. The introduction ends with the aims of the thesis. This is followed by a description of the methods and the results of the individual papers. The thesis ends with a discussion that tries to integrate the results from the different studies. The aim was to provide a more generalised picture of the issues of long shifts, short recovery periods and individual differences in tolerance.

The key reviews (long shifts, short recovery and individual differences) include peer-reviewed papers published 2000 and earlier. Later articles are included in reviews of non-key issues (i.e. basic physiology) and in the discussion. 


\section{Basic physiology}

To survive and remain healthy, the human body has to keep a balance between different processes within the organism (Ader et al., 1990; Anisman et al., 1996; Mason, 1959). This regulation involves many systems that interact on various levels (Ader et al., 1995; Besedovsky and del Rey, 1999), and we have evolved intricate processes to keep the different systems within certain boundaries. These, so called, "homeostatic systems" (homeostasis referring to "balance" or steady state) are vital and allows the individual to retain a physiological and behavioural stability despite environmental fluctuations (McEwen, 1998). For example, strong reciprocal homeostatic drives exist for activity and rest within different systems of the body, the alterations between wakefulness and sleep is one of the most prominent one. Furthermore, the homeostatic systems are regulated by several endogenous biological rhythms. Many of the problems associated with shift work are related to a conflict between irregular work hours and the circadian system, but also with the homeostatic drive for sleep. The basics of circadian systems, sleep and wakefulness are hence reviewed below.

\section{The Circadian System}

Humans and animals have precise and persistent rhythms in many behavioural, physiological, metabolic, cellular, and molecular parameters that, although influenced by the environment, are generated by an internal clock (Aschoff, 1967, 1978; Klein et al., 1991; Meijer and Rietveld, 1989; Minors and Waterhouse, 1981; Takahashi, 1993). This clock runs, even in the absence of external time cues such as light, with a period of approximately 24 hours, and has thus been named the "circadian clock" (circadian = around a day) (Czeisler et al., 1999). This "master" clock governs circadian oscillators in peripheral cells throughout the body (Balsalobre et al., 2000; Hastings et al., 2003) and more or less all physiology and behaviour is affected (Rusak and Zucker, 1979). It is the reliable alterations of day and night of the earth that most living organisms, e.g. animals, plants and even bacteria, have adjusted their behaviour and physiology to (for reviews see (Hastings et al., 2003; Ishida et al., 1999; Panda et al., 2002).

It is this "master" clock, situated in the hypothalamic suprachiasmatic nucleus (SCN) of the midbrain, that synchronizes processes throughout our body, and direct them to suit behaviours related to a diurnal living (Aschoff, 1964, 1978; Dijk and Czeisler, 1994; Klein et al., 1991; Rusak and Zucker, 1979). These rhythms promote activity during the day and sleep during the night (Aschoff, 1964; Dijk and Czeisler, 1994). Perhaps even more importantly, circadian rhythms prepare us for the regular changes of light-darkness before they actually occur (Panda et al., 2002; Schultz and Kay, 2003). The apparent purpose of the circadian system is to prepare us (by directing many processes) for day-light even before sunrise. Even though much more work is needed before we can develop an understanding of the interactions between the different timing mechanisms (Hastings et al., 2003), it is clear that humans are designed for a diurnal life style.

The characteristics of the circadian system are often described using period (usually 24h), the "acrophase" (maximum), the trough or "nadir" (the minimum), and the amplitude (difference between the maximum and the minimum). An important feature of the circadian clock is that it is set (entrained) by external time cues, also called Zeitgebers (Aschoff, 1979; Kryger et al., 1994). 
The most potent Zeitgeber is light, as the purpose of the rhythm is to adjust us to the changes of light and darkness (Lewy et al., 1985; Moore, 1995). Other zeitgebers, like sleep, temperature, food and social interaction, may also affect the phase of the clock (Daan and Aschoff, 2001; Stokkan et al., 2001; Wever, 1979), but their influences are probably of less importance as long as we are exposed to normal daylight (Koller et al., 1994). Nevertheless, there is a variation in diurnal types, and the norm is that evening types (later phase) have fewer problems with shift work than morning types (with an earlier phase) (Bohle and Tilley, 1989; Härmä et al., 1988a).

The circadian nadir (low point) or minimum of body temperature (one of the most important "rhythms" in this context as it reflects the overall metabolic rate) and alertness normally occurs around 4-6h in the morning, and the maximum around 16-18h in the late afternoon (Aschoff, 1965; Czeisler et al., 1980; Folkard et al., 1985). Entrainment by light is more efficient (=greater time change) the closer it is applied to the minimum of the rhythm (Moore-Ede et al., 1982). Light before the minimum (around subjective dusk) will have a delaying effect while light after the minimum (near subjective dawn) will advance the rhythm (Lewy et al., 1983).

\section{Sleep}

Disturbed sleep is perhaps the major consequence of shift work. This section presents an overview of the functions of sleep and methods for sleep measurement. Sleep is essential and provides us with rest and recovery from the day's "wear and tear". Reduced or disrupted sleep results in increased sleepiness and reduced well-being the following day (Horne, 2000). Even though most sleep researchers feel that the need for sleep indicates an essential function (Tobler, 2000) - similar to the need for food or water - several theories have been proposed for the homeostatic function of sleep: the classical restorative one (Adam and Oswald, 1984; Horne, 1988), energy saving (Zepelin and Rechtschaffen, 1974), thermoregulatory (McGinty and Szymusiak, 1990), host responses to infections (Krueger and Majde, 1995; Krueger et al., 2001), learning (Karni et al., 1994; Stickgold et al., 2000), and memory consolidation (Maquet, 2000).

Processes that are directly promoted by sleep are, for example, a general increase in anabolic activity throughout the body (Adam and Oswald, 1977), replenishment of energy depots in the central nervous system (Benington and Heller, 1995; Porkka-Heiskanen et al., 1997), a generalised increase of protein synthesis (Adam and Oswald, 1977; Nakanishi et al., 1997; Ramm and Smith, 1990), cortical plasticity (Frank et al., 2001), and elicitation of certain forms of long-term potentiation (Bramham et al., 1994). Hence, there is probably not a single reason of why we sleep, but several.

Sleep is measured with the help of polysomnography (the monitoring of multiple variables of physiological activity during sleep, like electroencephalography, electrooculography and electromyography, =EEG, EOG, EMG), certain behavioural aspects and/or self-ratings (Bloch, 1997; Carskadon and Dement, 1989). The output from polysmonography is used to divide sleep into several stages - stage 1, 2, 3, 4 (NREM-sleep=non rapid eye-movement sleep) and REM-sleep (rapid eye movement sleep) - which alternate in a very characteristic and regular pattern of sleep cycles of approximately 90-100 minutes (Bloch, 1997; Dement and Kleitman, 1957; Hobson, 1999; 
Rechtschaffen and Kales, 1968). Polysomnography is the "gold standard", which - despite a fast technological development - is still a very expensive and time demanding technique (Bloch, 1997); and hence mostly used in clinical and laboratory settings. In addition, it is also invasive, in the sense that it disturbs sleep to some degree (Agnew et al., 1966; Rechtschaffen and Verdone, 1964).

Also motor rest/activity measured by actigraphs (measuring wrist activity) is used to define sleep/wakefulness (Mullaney et al., 1980). Actigraphy has several benefits and drawbacks compared to polysomnographic data (Cole et al., 1992). Actigraph measures are more economically viable, less obtrusive and subjects can easily be followed for longer periods (Sadeh et al., 1995). Actigrahps have been used to measure shift workers since the mid 80's (Torsvall et al., 1987), and several studies have shown a reasonably good relationship between actigraphy and polysomnographic measures of sleep (Cole et al., 1992; Mullaney et al., 1980; Sadeh et al., 1989), but also with subjective ratings (Lockley et al., 1999; Reyner and Horne, 1995). However, actigraphy is less valid than the "gold standard" itself; as it only differentiates between waking and sleeping; and it is, for example, possible that actigraphy does not discriminate entirely between sleep and motionless wakefulness (Reid and Dawson, 1999; Reyner and Horne, 1995).

The simplest way to measure sleep is basically to ask people how they sleep. The easiest and most economically viable method is the sleep questionnaire, which is a reasonable tool to describes overall sleep quality, sleepiness and occurrence of some sleep disturbances (Douglass et al., 1994; Johns, 1992). Sleep diaries are preferred when we want to evaluate how sleep varies on a day-today basis (Spielman et al., 2000). Even though several aspects of subjective sleep are difficult to assess (Carskadon et al., 1976), many polysomnographic characteristics show a good correlation to subjective evaluations of sleep (Hoch et al., 1987; Kecklund and Åkerstedt, 1996; Kryger et al., 1991; Spiegel, 1981; Åkerstedt et al., 1994b).

\section{Sleep regulation}

Shift work interferes strongly with normal sleep regulation (see below). The research field of how sleep is regulated has received a lot of attention and has also provided many important findings. It has been shown that sleep regulation is highly integrated with our physiology at many levels (immune, neuroendocrine, thermoregulatory, energy metabolism etc.) of which each has complex oscillating feedback mechanisms that are interacting with each other as well as with the circadian timekeeping system. Despite the complexity of the processes involved, only two major regulatory mechanisms determine sleep length, sleep propensity (the likelihood of falling asleep) and sleep structure: a circadian component and a homeostatic component (Borbély, 1982; Daan et al., 1984). The circadian system promotes sleep during the circadian low ( \pm 6 hours around the trough) and interferes with sleep around the acrophase (Dijk and Czeisler, 1994). Wakefulness shows the reverse pattern. A main purpose of the circadian system is to consolidate sleep to the night time and wakefulness to the day time. These consolidating properties, are further maintained by arousing effects at dawn and sleep inducing properties at dusk.

The homeostatic regulation of sleep is a result of the balance between sleep and wakefulness; the longer we are awake - the more we need to sleep - and the longer we sleep - the less we need to 
continue sleeping (Borbély, 1998). One interesting aspect of the sleep homeostasis is that prolonged wakefulness results in deeper and longer sleep (Berger and Oswald, 1962; Borbély et al., 1981; Dijk et al., 1990; Webb and Agnew, 1971; Åkerstedt and Gillberg, 1986). The practical outcome of the circadian influences is that the length of sleep is considerably affected by bed time - going to bed in the early morning reduces sleep length while a bed time in the late afternoon often result in very long sleep durations (Åkerstedt and Gillberg, 1981a).

It is still debated how much sleep we need to recover fully. Several studies have considered the amount of sleep that is required to function normally (Carskadon and Roth, 1991; Gillberg and Åkerstedt, 1994; Johnson, 1981), but none have conclusively determined a minimum sleep requirement. Some researchers have raised concerns that we are chronically sleep deprived (Bonnet and Arand, 1995; Levine et al., 1988), at least during weekdays (Webb and Agnew, 1975), but others claim that we do fine with as little sleep as 4.5h-6h (Horne, 1988), and that extending sleep, above the normal $7.5 \mathrm{~h}$, only generates marginal positive effects on wakefulness and performance at the same time as it disturbs following sleep episodes (Harrison and Horne, 1996). A likely explanation for the different views is the large variation in sleep need (Ferrara and de Gennaro, 2001).

\section{Factors modifying sleep}

Sleep is not only influenced by time-of-day (circadian regulation) and homeostatic processes, but also by environmental factors (such as noise), psychosocial factors (such as stress), diseases (such as sleep apnea) and lifestyle related factors (like consumption of alcohol, coffee (caffeine) and pharmaceutical substances) have strong influences on sleep (Bliwise, 1993; Carskadon and Dement, 1989; Eberhardt et al., 1987). In addition, age and sex also have great impact on sleep. Age is perhaps the most obvious mediator on sleep as duration, sleep content, and the occurrence of sleep problems vary extensively across a life span (Bliwise, 1993; Carskadon, 1990; Carskadon and Dement, 1989; Dijk et al., 1999; Foret et al., 1981). Generally, sleep time decreases with age at the same time as sleep problems increase (Bliwise, 2000; Carskadon and Dement, 1989; Reyner and Horne, 1995; Van Cauter et al., 2000). This is partly related to that many age-related diseases affect sleep (Bliwise, 1993, 2000) and that elderly may be more sensitive to the arousing effects of the circadian system in the morning (Dijk et al., 2000).

With respect to sex, women sleep longer and report more sleep problems than men (Bixler et al., 1976; Lindberg et al., 1997; Reyner and Horne, 1995). It is likely that the effects of menstrual cycle, being pregnant, breast feeding, having small children, menopause, and higher rates of depression are the cause of some of these problems (Bixler et al., 1976; Driver, 1996). Moreover, stress disturbs sleep as it arouses the individual and inhibits sleep initiation and continuation (Bonnet and Arand, 1997; Foret et al., 1981; Opp, 1995; Åkerstedt, 1987). It should be noted that it is not only a large variation in exposure to sleep disturbing mediators, but also a variation in susceptibility to such mediators. 


\section{Wakefulness/Sleepiness}

Pronounced sleepiness is a typical characteristic amongst most shift workers. Sleepiness is usually seen as a "drive towards sleep" (Carskadon and Dement, 1982a) and the subjective part is believed to act as a "messenger" to the conscious mind to begin the bedtime ritual. Increased sleepiness is related to performance deficits and may affect many work-related tasks (Dinges and Kribbs, 1991; Johnson, 1982). Several authors have concluded that sleepiness (or fatigue) is the cause of mistakes and accidents in a series of different occupations (Mitler et al., 1988; Åkerstedt, 1991), particularly in the transport sector where most evaluations have been carried out (Horne and Reyner, 1995; Hänecke et al., 1998; Åkerstedt, 2000).

Sleepiness is, like sleep, to a large extent regulated by sleep/wake homoeostasis and the circadian system (Babkoff et al., 1991; Carskadon and Dement, 1982b; Folkard and Åkerstedt, 1991). The homeostatic effect on sleepiness is a result of prior sleep length and quality, and disturbed (or restricted) sleep results in increased sleepiness (Carskadon and Roth, 1991). Sleepiness follows the circadian temperature, although not without exceptions. For example, both sleepiness and sleep tendencies (both napping and short sleep latency) have an additional afternoon peak, a so called "post-lunch dip", which coincides with the peak of temperature (metabolism) in the late afternoon (Broughton, 1975; Carskadon and Dement, 1979; Zulley and Campbell, 1985). In addition, one of the most crucial aspects of sleepiness is the subject's ability to reverse sleepiness with effort (Broughton, 1982).

The strong influences of circadian and homeostatic factors were validated by studies of truck and train drivers where sleepiness could be predicted with high accuracy (r2>.70) (Åkerstedt and Folkard, 1995). However, there are large individual differences and models based on those parameters are mainly for predicting sleep and sleepiness on group levels. Other factors affecting sleepiness, and hence performance, are sleep inertia - which is the drop of alertness directly upon awakening - and contextual or environmental aspects (Dement and Carskadon, 1982; Folkard and Åkerstedt, 1987; Kjellberg, 1977a, 1977c). The latter includes the nature of the situation, which can have arousing as well as sleep inducing properties (Cluydts et al., 2002; Horne and Pettit, 1985). Although interesting, motivating and stimulating tasks can mask (suppress the underlying sleepiness) latent sleepiness and performance - monotony, heavy meals, warm rooms and boredom can make it worse (Dement and Carskadon, 1982; Dinges and Kribbs, 1991; Horne, 2000; Horne and Pettit, 1985; Kjellberg, 1977a, 1977c; Wilkinson, 1961). One example of environmental influence is that bright light during simulated night $(\mathrm{N})$-shifts improves alertness and performance and can help in shifting the circadian system (Campbell and Dawson, 1990; Dawson and Campbell, 1991).

Although, sleepiness/alertness can be measured "objectively" (with the Multiple Sleep Latency Test (MSLT), the Maintenance of Wakefulness Test (MWT) and polysomnography (Carskadon and Dement, 1982a; Fruhstorfer et al., 1977; Mitler et al., 1982), all these techniques are very intrusive in the work environment and the present studies will only consider self-ratings of sleepiness. Selfratings usually involve indicating one's sleepiness on a scale from very alert to very sleepy using a 
100mm visual analogue scale (VAS) (Folstein and Luria, 1973), or Likert type scales with each step anchored with a written label, like the Stanford Sleepiness Scale (SSS) (Hoddes et al., 1973) or the Karolinska sleepiness scale (KSS) (Åkerstedt and Gillberg, 1990).

There are several reasons for measuring subjective sleepiness. Firstly, it is a sound indicator of how a person is affected by homeostatic and circadian influences. The more a shift system is in conflict with these processes, the more sleepiness will rise. Shift work sleepiness can therefore be seen as an indicator of the impact of a shift schedule on a person's biology. In this perspective, sleepiness will be a product of circadian influences, disturbed sleep and long waking hours - indirectly reflecting how well the workers can recuperate during these circumstances. Secondly, subjective sleepiness is closely related to physiological sleepiness and behavioural indicators of sleepiness (i.e. performance) (Åkerstedt and Gillberg, 1990). Thirdly, sleepiness is closely related to health, and increased sleepiness can be seen as indicators of ill-health and poor well-being. Fourthly, it seems reasonable that sleepiness is a sound indicator of a persons "functioning level". In this sense, it doesn't matter to what degree sleepiness is a result of circadian pressure and homeostatic drive, or of individual and contextual factors (like motivation and boredom), the importance is the level of sleepiness. The fact that increased sleepiness is related to poorer productivity and increased accident risk suggests that sleepiness can be seen as a marker of how well the workers are doing their job. An additional reason is that objective measures of sleepiness are not feasible in field studies. Objective measures of sleepiness are expensive, seriously affected by artefacts (disturbances), disturb the worker and are very time consuming to analyse. Taken together, sleepiness is an indicator of the workers functioning level as well as of disturbed recuperation (i.e. sleep) or if they work at the wrong time of the day. The present thesis will use sleepiness to judge the effects of different shift work characteristics.

\section{Fatigue}

In shift work research, fatigue and sleepiness have often been used interchangeably. This has led to confusion over some of the results and the underlying mechanisms. A main reason for this confusion is the lack of consensus and a clear definition of fatigue. In our filed of research, fatigue is often measured with a single question at the same time as it has several dimensions, of which sleepiness is one. Other suggested dimensions are mental fatigue, physical discomfort, lack of motivation, lack of energy and general fatigue (Åhsberg, et al., 2000). To increase the complexity, the causes of fatigue stretch from lack of energy and "time on task" to immune activation. In the latter, fatigue is an adaptive response to infections and different diseases (so called "sickness behaviour"). To simplify the issue, sleepiness is the drive for sleep while fatigue can be seen as a signal from the body that we should end the ongoing activity, whether it is physical activity, mental activity or just being awake.

It is not an easy job to disentangle sleepiness from fatigue in previous studies. The reviews of the present thesis will therefore focus on sleepiness, but will also include studies of fatigue for practical reasons. However, if we want to understand the underlying mechanisms, future studies will have to distinguish between the two concepts as well as adopting strict distinctions amongst various measures of fatigue, and choose the most appropriate for the study issue. 


\section{The effects of shift work (night and morning shifts)}

"Shiftwork is probably bad for the heart, almost certainly bad for the head and definitely bad for the gut"

Monk and Folkard, 1992

\section{Background}

Even though humans have adapted and survived in a variety of environments, new environments are still introduced. One such peculiar introduction is shift work and other irregular work arrangements, according to which the individuals regularly have to work during the night and sleep during the day. These behaviours are related to disturbed sleep, sleepiness and health problems and the following paragraphs are focusing on these problems in shift workers.

\section{Problems}

Disturbed sleep is more common amongst shift workers than among day workers (Aanonsen, 1964; Knauth and Rutenfranz, 1982; Kogi, 1982; Tepas et al., 1981; Wyatt and Mariott, 1953; Åkerstedt and Gillberg, 1981b). Most disruptions are experienced in connection to N-shifts, day sleep is typically curtailed by 2-3 hours or more (Foret and Lantin, 1972; Tilley et al., 1982; Torsvall et al., 1981; Åkerstedt et al., 1991). Also morning (M)-shifts are associated with shortened and disturbed sleep (Folkard et al., 1989; Kecklund and Åkerstedt, 1995; Knauth et al., 1980; Torsvall et al., 1981; Åkerstedt et al., 1991; Akerstedt et al., 1990). The earlier the start time of the M-shift the shorter is the sleep, mainly because of the poor flexibility in adjusting the bed time to the start of the M-shift (Folkard and Barton, 1993; Foret and Lantin, 1972; Knauth et al., 1980). Sleep in connection to afternoon (A)-shifts is often extended, or at least of similar duration as sleep between days off (Folkard and Barton, 1993; Åkerstedt and Gillberg, 1981b).

Recovery sleeps are often prolonged as the shift workers have to compensate for the accumulating sleep debt that they have developed across the work period. However, the first recovery sleep after a series of N-shifts is often severely curtailed (Knauth et al., 1980). Partly because many shift workers voluntarily shorten the first recovery sleep in an attempt to adapt back to a normal sleep/wake rhythm; and partly because the circadian system disturb recovery sleep while the circadian system is adjusting back to normal. Although most shift workers occasionally use naps, only about a third use them regularly (Knauth and Rutenfranz, 1981; Tepas, 1982). The main reason is to compensate a rising sleep dept and the prevalence of naps increase if prior sleep duration is shorter (Rosa, 1993; Åkerstedt and Torsvall, 1985). However, many shift workers claim to use naps in a prophylactic manner (Rosa, 1993).

Studies on self-rated sleepiness as well as psychophysiological measures of wakefulness show that severe sleepiness is a major problem amongst shift workers (Mott et al., 1965; Thiis-Evensen, 1958; Torsvall and Åkerstedt, 1983; Torsvall et al., 1986; Verhaegen et al., 1981; Åkerstedt, 1988, 1991, 1995; Åkerstedt et al., 1983; Åkerstedt et al., 1982, 1987). Sleepiness is often so severe that many workers fall asleep involuntarily (Åkerstedt, 1988). In addition, M-shifts are accompanied by 
increased sleepiness, but to a lesser extent (Kecklund et al., 1997; Åkerstedt et al., 1983). Experimental studies have shown that the repetition of curtailed sleep leads to an accumulation of sleepiness that may reach severe levels (Carskadon and Dement, 1981; Dinges et al., 1997), but accumulations of problems has not yet been confirmed in shift workers. A consequence of severe sleepiness is that performance is affected (Dinges and Kribbs, 1991; Åkerstedt, 1988; Åkerstedt et al., 1994a), which, in turn, compromises safety (Dinges, 1995; Åkerstedt, 1988). Several evaluations have shown sleepiness to increase the risk for accidents (Hamelin, 1987; Harris, 1977; Horne and Reyner, 1995; Langlois et al., 1985; Mitler et al., 1988).

There is extensive evidence that shift work, including night work, increases the risk for developing both psychological (Bohle and Tilley, 1989; Scott et al., 1997) and physiological health problems (Andlauer, 1960; Koller, 1983). The most well established links exist between shift work and increased risk for cardiovascular heart disease (Bøggild and Knutsson, 1999; Kawachi et al., 1995; Tenkanen et al., 1998) and gastrointestinal disorders (Tuchsen et al., 1994). In addition, there is also support for a link between shift work and clinical sleep disorders (Guilleminault et al., 1982), breast cancer (Davis et al., 2001; Hansen, 2001; Schernhammer et al., 2001) and several forms of reproductive problems (Ahlborg et al., 1996; Axelsson et al., 1984; Axelsson and Rylander, 1989; Nurminen, 1998). Moreover, the risk increases with the number of years exposed to shift work (Knutsson et al., 1986; Verhaegen et al., 1986), which seems logical if exposure to shift work is a risk factor. This may explain why older shift workers have particularly poor health (Koller, 1983). On the other hand, there is also support for shift work to impose no or few health risks (for review see (Harrington, 1978), and there is, still, a controversy whether shift work increases mortality (Harrington, 1978; McNamee et al., 1996; Taylor and Pocock, 1972; Virtanen and Notkola, 2002).

Self-ratings of general well-being is also poorer amongst shift workers than day workers (Åkerstedt and Torsvall, 1978), and it is likely that their suffering is related to turnover, absenteeism and productivity (Burke, 1970; Locke, 1976; Petty et al., 1984). Their degree of suffering will be reflected in the attitude, i.e. satisfaction, with the present work hours, and this is evidenced in several studies of satisfaction in relation to individual factors, organisational issues, social/family life, free time, health problems, sleepiness, sleep disturbances, sleep flexibility and the ability to overcome drowsiness (Dirkx, 1987; Escribà-Agüir, 1992; Kundi et al., 1980; Lavie et al., 1989; Nachreiner, 1975; Patkai and Dahlgren, 1981; Wedderburn, 1967; Wedderburn, 1981). The effect is to some degree reversible, as attitudes improve in those changing back to day work (Åkerstedt and Torsvall, 1978).

\section{Reasons}

Both $\mathrm{N}$ - and M-shifts require behaviours that conflict with the circadian system, which leads to problems with processes under circadian influence. And sleep and sleepiness are strongly regulated by the circadian system. Day sleeps (after a N-shift) are severely curtailed because circadian regulation increases metabolism in the morning and this interferes with sleep duration (Czeisler et al., 1980). The short sleep results in prolonged waking hours, but may be compensated by a nap in the afternoon/evening ( $\AA$ kerstedt and Torsvall, 1985). Waking hours are particularly long before the first $\mathrm{N}$-shift, where a worker often is awake for up to 16 hours before coming to work. 
Taken together, N-shifts are pressured by sleepiness from the circadian system, from short sleep and from long waking hours. Most M-shifts are affected by an early start (interfering with the low point of the circadian system), short sleep, and often disturbed sleep (mainly because the early awakening is related to disturbed sleep). Morning (M) shifts may also be affected by sleep inertia if the worker is sleeping close to the work site, but this has not been under systematic study. However, M-shifts are not preceded by a long waking span and the homoeostatic drive for sleep is hence small in the early part of the day. In addition, A-shifts interfere with sleep/wake behaviour, but then with timing of sleep, rather than sleep length. The fact that neither sleep nor sleepiness is a problem when working afternoon (A) shifts suggest that slight delays of sleep and wakefulness can be made with few complaints.

It is reasonable to believe that the main causes of increased morbidity are the disruptions of sleep/wake-behaviour and circadian rhythms, typical of shift work. For example, shift work sleep is related to disturbed endocrinology (Weibel and Brandenberger, 1998) and it is possible that anabolic activity (restorative processes) is impaired. However, the risk is probably multifactorial and factors like poor eating behaviour and fewer social contacts - both being related to morbidity are disturbed in shift workers (for review see (Bøggild and Knutsson, 1999). The clashes between different behaviours and the circadian system may lead to desynchronisation between different time keeping systems. Desynchronisation occurs when different functions in the body adopt different periodicities in their oscillation. This can occur when different tissues are deprived of regulatory signals from the SCN (Hastings et al, 2003), but the predominant reason is contradictory information of conflicting zeitgebers (i.e. light-darkness) to the SCN (Aschoff, 1978). A consequence of being awake at night is that one is exposed to light during the "window" when light has strong entraining effects. For example, a night worker exposed to light before the minimum will delay his/her rhythm. However, the night worker will also be exposed to light after the circadian nadir, particularly when going home after the shift (Koller et al., 1994). Thus, the night worker will receive conflicting signals when working nights. The contradictory input may result in an incomplete adjustment of the circadian system (Wegmann et al., 1985), which may result in a flattened rhythm (Patkai et al., 1977). It was suggested already in the 60's that internal desynchronisation may be harmful in the long run (Aschoff et al., 1967).

\section{Summary}

The fact that shift work, and night work in particular, is in conflict with the circadian system results in several distinctive problems amongst shift workers: disturbed sleep, sleepiness and increased risk for developing health problems. Problems are worst in connection to N-shifts, but M-shifts are also affected to a large extent, and least problems are experienced during A-shifts. While the reasons of sleep and sleepiness in relation to type of shift are well understood, it still remains to find the mechanisms through which shift work increases disease susceptibility. 


\section{Long shifts}

\section{Background}

There are two main methods to cover the 24-hour window with personnel, either three 8-hour shifts, or two 12-hour shifts. 10h work shifts are also used, but they are less common and not used to cover the entire $24 \mathrm{~h}$ window. Normal $8 \mathrm{~h}$ shifts are often extended when there are increased demands for productivity, for example by overtime, deadlines, being on-call. There is not any data available on the prevalence of long shifts, but the general impression is that they are increasingly popular. The main argument for long work shifts is the attractiveness of the resulting more days off, especially weekends, for the employee (Duchon and Smith, 1993; Kogi, 1985; Rosa, 1995). An additional advantage may be that less time and money has to be spent on commuting since fewer days are worked. The popularity amongst workers and the extensive use of long work hours suggest that both management and employees believe the advantages outweigh the disadvantages. On the other hand, it could, perhaps, also be argued that the drawbacks of extended work shifts are largely unknown or ignored by these groups.

\section{Problems}

The main concerns with extended shifts are severe sleepiness (or fatigue), poorer performance and safety (Duchon and Smith, 1993; Rosa, 1995; Smith et al., 1998a). Most worries are related to long N-shifts (Hamelin, 1987), even though 12h day (D) shifts have been shown to increase sleepiness in the afternoon (Tucker et al., 1998b). Another problem is that $12 \mathrm{~h}$ shifts may cause dissatisfaction with work hours and problems to carry out social arrangements (Todd et al., 1993). It has also been put forward that $12 \mathrm{~h}$ shifts cause lower productivity, higher turnover, problems to cover a portion of a subsequent shift, reduced ability of overtime, problems with hand-over between shifts, a greater need for reorientation when coming back after days off and exacerbated communication difficulties due to less contacts with managers (Gillespie and Curzio, 1996; Rosa and Bonnet, 1993; Smith et al., 1998a; Smith et al., 1998c; Tepas, 1985).

Rosa and co-workers conducted a series of field studies and warned against fatigue in $12 \mathrm{~h}$ shifts, particularly at night (Rosa, 1991; Rosa and Bonnet, 1993; Rosa and Colligan, 1989). However, their results of $12 \mathrm{~h}$ shifts contain a mixture of findings - problems with sleep, sleepiness and performance - but also better sleep, less sleepiness and better performance. For example, one study reported 441 vs. 353 minutes of total sleep time in favour of 12h N-shifts (Rosa and Bonnet, 1993). An explanation could be the small sample sizes, the peculiar designs and problems with participation in their studies. Nevertheless, there are several articles supporting problems with fatigue and performance in 12h shift systems (Hamelin, 1987; Mitchell and Williamson, 2000). For example, a deterioration of patient care amongst nurses is well established (Reid et al., 1993; Todd et al., 1989; Vik and MacKay, 1982), but similar results have been shown in other occupational settings, particularly within the transport sector (Hamelin, 1987; Kecklund and Åkerstedt, 1993). 
A few studies from the beginning of the last century showed a gradual reduction of the output over the 12-hour period and Osborne pointed out that the last four hours were particularly affected on a self-paced task (Osborne, 1919; Vernon, 1920). Both reported improvements in productivity after the introduction of 8-hour shifts. Still, these studies involved not only long shifts but also very long total work hours. More recent studies have reported increased sleepiness, a declining performance and increased probability for accidents at the end of long shifts in manufacturing workers, air traffic controllers, truck drivers and studies of large populations (Ellingstad and Heimstra, 1970; Grandjean et al., 1971; Hamelin, 1987; Hänecke et al., 1998; Kecklund and Åkerstedt, 1993). The last period of the $\mathrm{N}$-shift is often followed by fatigue and periods with difficulties concentrating (Hamelin, 1987; Mitchell and Williamson, 2000; Ugrovics and Wright, 1990). Macdonald and coworkers showed fatigue and sleepiness to increase with higher work load, but only in $12 \mathrm{~h}$ shifts (Macdonald and Bendak, 2000).

There is also evidence for a lack of negative effects or even a presence of positive effects of $12 \mathrm{~h}$ shifts on sleep length, sleep quality and subjective levels of sleepiness/fatigue (Fields and Loveridge, 1988; Gillespie and Curzio, 1996; Mills et al., 1983; Peacock et al., 1983; Smith et al., 1998a; Smith et al., 1998b; Tucker et al., 1996; Tucker et al., 1998b; Washburn, 1991). Even amongst those with high physical work load (Duchon et al., 1994). Most improvements occur during M-shifts rather than N-shifts (Tucker et al., 1996; Tucker et al., 1998b; Williamson et al., 1994), but may be due to later change-over times (07.00h instead of $06.00 \mathrm{~h}$ ). In a study by Mills and colleagues (Mills et al., 1983) 12h shifts worsened both fatigue and performance at the same time as sleep was improved, which suggests that extended shifts inflict more fatigue and increase the need for sleep.

In a study of control room workers, Knauth and co-workers concluded that a shift system with $10 \mathrm{~h}$ D-shifts followed by a single 14h N-shift was unacceptable (Knauth et al., 1995). However, the schedule was popular amongst the workers and performance was not significantly affected.

A series of laboratory studies have also shown $12 \mathrm{~h}$ shifts to induce fatigue (Colquhoun et al., 1968a, 1968b, 1969; Rosa et al., 1985). The latter carried out an experiment with 6 young males working either a 4 -days*12h- or $6 * 8 \mathrm{~h}$ work week and found more fatigue and worse performance in the $12 \mathrm{~h}$ work week, particularly at the end of shifts. However, this study only included a few males, only D-shifts and used a very liberal p-level of 0.10 , and the finding of the consistent decline of performance could be due to different ending times of the different shifts.

The literature suggests a link between long working hours to adverse health, like cardiovascular disease, diabetes and mental health problems (for reviews see (Spurgeon et al., 1997; van der Hulst, 2003). However, the larger part of these studies are related to overtime, which makes it difficult to determine whether the effects are due to extended working hours or increased stress associated with the reason for overtime. When excluding the literature of overtime (only including scheduled extended work hours while the total work hours are the same), it is evident that negative findings exist (Iskra-Golec et al., 1996), but the majority of the literature support no or few health problems with extended shifts compared to $8 \mathrm{~h}$ shift systems (Frese and Semmer, 1986; Smith et al., 1998a; Tucker et al., 1996). In fact, several studies report better health (Duchon et al., 1994; 
Lees and Laundry, 1989; Mitchell and Williamson, 2000; Williamson et al., 1994). One explanation is that the build up of fatigue may be reduced in $12 \mathrm{~h}$ shift systems as the sequence of consecutive $\mathrm{N}$-shifts are often reduced compared to 8h shift systems (Williamson et al., 1994).

\section{Reasons}

The problems with sleep, sleepiness/fatigue and performance in relation to extended shifts are mainly due to time awake, time on task/fatigue and limited/restricted time for recovery. Another possible reason for problems with extended shifts is the conflict with the circadian system (most long work hours will intrude on times when the circadian system is promoting sleep), but this is less likely as this conflict is not worse in $12 \mathrm{~h}$ shift systems than in $8 \mathrm{~h}$ shift systems, as the same $24 \mathrm{~h}$ time window is covered; and the extra $4 \mathrm{~h}$ occur in the afternoon and early evening.

Laboratory studies using forced desynchronisation protocols have shown sleepiness to increase with time awake independently of time of day (Dijk et al., 1992; Folkard and Åkerstedt, 1991). The time spent awake will automatically increase in equivalence to delayed and lengthening of working hours, and it is important to recognise that $12 \mathrm{~h}$ work shifts involve more than $12 \mathrm{~h}$ of activity or wakefulness (Smith et al., 1998a). Consequently, time for household responsibilities and recovery are restricted and pushed to odd hours. The time spent awake differs according to shift type, a $12 \mathrm{~h}$ $\mathrm{N}$-shift often starts 10-12h after rising, while the M-shift is often preceded by 1-2h of wakefulness. $\mathrm{N}$-shifts are, hence, associated with extensive time awake, often more than $20 \mathrm{~h}$ of wakefulness. Notably, reduction of prior sleep will also result in prolonged waking spans. Moreover, long working hours are also related to increased exposure to other sources of work place stress (Knauth, 1993) and toxins; and it is questionable if it is possible to generalise the effects of long working hours across populations and job types - as the effects seem to interact with different situations, demands, and cultural norms (Spurgeon et al., 1997), which may explain why some individuals report more problems with $12 \mathrm{~h}$ shifts than others. For example, it has been shown that stress at work - which is highly variable between occupations and work places - is a potentially strong risk factor amongst shift workers (Frese and Semmer, 1986), that may be extra harmful in $12 \mathrm{~h}$ shift systems (Iskra-Golec et al., 1996).

The longer a task is carried out, the more fatigue will develop (Fields and Loveridge, 1988; Fröberg, 1985). Thus, 12h shifts will in general induce more fatigue than shorter shifts, if work demands are the same. The effect of time on task (or fatigue) is in its nature similar to time awake, but while time awake is related to the alterations of wakefulness/sleep, fatigue is the unwanted effects due to continued exercise of a particular task (Craig and Cooper, 1992). However, the two effects are difficult to separate from each other as both depend on time. The development of fatigue is coupled to the exhaustion - or imbalance of resources needed to perform activity - of one or several particular systems within our body, like physical exhaustion, the ability to concentrate or keeping high vigilance (Aaronson et al., 1999; Konz, 1998). The type of work is, hence, very important for the development of fatigue, and higher levels of work load increase the rate at which fatigue accumulates (Konz, 1998; Macdonald and Bendak, 2000). A ratio can be calculated between the maximum acceptable work time and physical workload ( $\mathrm{Wu}$ and Wang, 2002). Indeed, the combination of higher workload and 12h workdays produce more fatigue (Macdonald and Bendak, 
2000). Mital and co-workers showed that a work pace at $28-29 \%$ of the maximal oxygen capacity, for an 8-hour workday, and 23-24\%, for a 12-hour workday, was manageable without exertion (Mital, 1984). The nature of the mental workload is also important for the occurrence of fatigue. Both mentally overloading and underloading work tasks are very demanding and may inflict fatigue as well as a larger need for recovery (Konz, 1998). Examples of activities with mental overload are tasks demanding both high concentration and attention, like simultaneous translation, and underloading tasks are monitoring in control rooms, watch-keeping systems at sea, and driving vehicles (cars, trucks, trains and aeroplanes) (Konz, 1998). It has been recommended to avoid work tasks that are physically heavy or highly monotonous (Knauth, 1993; Tepas, 1985), but there is a lack of data from real life settings and the relationships between sleepiness/fatigue and contextual factors are poorly understood. Evidently, the type of work and the consequences of poor performance are important ingredients for determination of whether 12-hours shifts should be used.

One implication of extending working hours to $12 \mathrm{~h}$ is that it limits time for recovery (short recovery times are further reviewed in the next section) from normally $15-16 \mathrm{~h}$ to $12 \mathrm{~h}$. This has obvious consequences for sleep time (and social responsibilities) and risks for an increasing sleep debt across consecutive shifts. Even though it is reasonable that the longer bouts of work (the number of consecutive shifts) without free days would cause more strain and risks for accumulation of problems (Knauth, 1993; Smith et al., 1998a; Wallace and Greenwood, 1995) the only empirical finding suggests that the distribution of leisure time in $12 \mathrm{~h}$ shift systems are of minor importance (Tucker et al., 1999). Hence, there is a need for more empirical data on the relationship between sleep and accumulation of problems in shift systems with long shifts.

In addition, $12 \mathrm{~h}$ shift systems include $50 \%$ more free days, which increases the possibility to recover properly between work periods. The improved possibility to recover between work periods is a likely explanation for less problems with sleep and fatigue in some $12 \mathrm{~h}$ shifts systems. The important issue is whether $12 \mathrm{~h}$ of recovery is sufficient between shifts (if they are not accumulations of problems would occur) and whether the extra free days are sufficient for proper recovery (Iskra-Golec et al., 1996). As Craig stated "the two important aspects of fatigue: the effects of continued performance at the task itself, and longer lasting effects or after-effects that carry over to subsequent performance (Craig and Cooper, 1992)

\section{Summary}

The considerable difference between studies may be due to the different characteristics amongst schedules, work tasks and involvement of workers. However, the large variation in study design is perhaps of even greater importance. Most studies are based on surveys, which have used retrospective ratings when comparing populations in similar or different occupational settings. The generalisations from survey studies are often limited by the fact that they compare different populations when job type differs and considerable selection processes amongst the populations are involved (Daniel and Potasova, 1989; Parkes, 1999). The accuracy of retrospective ratings for particular phenomena can also be questioned (Spielman et al., 2000). In addition, many studies contain small sample sizes, poor participation rates, incomplete data sets, poor description of the shift schedules, lack or miss a relevant control group. Several studies have also been carried out 
closely after the introduction of a new schedule, and few health problems could therefore be expected to have developed. Furthermore, most studies have focused on the development of fatigue and productivity rather than sufficient recovery and accumulations of problems. The use of laboratory studies have several problems, it is easier to control for unwanted effects flawing your data, but one has to be careful generalising results from such artificial conditions. The new development of realistic simulator studies have improved the validity of laboratory performance measures considerably.

To summarize, it is still a controversy whether $8 \mathrm{~h}$ shifts are preferable to $12 \mathrm{~h}$ shifts (Duchon and Smith, 1993; Smith et al., 1998a). The lack of consistent results calls for further studies of extended shifts with control groups and with a within-group design - individuals switching between 8 and $12 \mathrm{~h}$ shifts, rather than comparing different groups. In addition, one also needs to evaluate longer periods, it is, for example, important to try to evaluate the total impact of the whole shift cycle - not only a few work shifts.

\section{Short recovery periods}

\section{Background}

The importance of adequate recovery on a daily basis was highlighted already in the beginning of the last century; Vernon stated "what must be avoided at all costs is that excess of fatigue from which the worker does not fully recover as the result of a good nights rest" (Vernon, 1920) arguing that we need to keep a balance between work (and other sources of) induced fatigue and sufficient recovery. Unfortunately, few researchers have studied recovery in a methodical manner.

A normal full-time worker obtains about 15-16 hours of free time each day, as most jobs start around 8 or 9 am and last for about 8-9 hours. During free time, the workers have to travel to and from work, eat several meals, unwind, sleep, maintain hygiene, and carry out other household and social responsibilities. Important to note is that sleep latency and travel times vary extensively between individuals and work sites. Obviously, the shorter the free time, the less time there is for sleep and to carry out these tasks/duties.

Free time may be shortened by overtime, 12h-shift systems (only allowing 12 hours of free time), quick returns (only allowing 8-9 hours off between shifts), watch-keeping systems at sea (mainly 6-on, 6-off; 4-on, 4-off; and 4-on, 8-off) and "irregular shift schedules" (common in the transport sector) (Cabon et al., 1991; Knauth, 1993). This thesis will not cover the effects of overtime or watch-keeping systems, but the impact from the other working schedules - with focus on quick returns - on sleep and sleepiness are reviewed below.

The previous chapter reviewed the impact of $\mathbf{1 2 h}$ shifts on sleep and sleepiness, and the only additional comments are that such systems may not only induce fatigue, but also limit recovery times (free time is limited to $11-12 \mathrm{~h}$ instead of 15-16h). A possible consequence is that equal, or even longer sleep duration, may be insufficient to counteract the increased strain by longer shifts, 
and the balance between fatigue and recovery in schedules with extended shifts has yet to be evaluated in a systematic manner.

Studies evaluating irregular shift systems showed that short recovery periods reduce sleep duration in ground transport drivers and train drivers (Cabon et al., 1991; Foret and Lantin, 1972). However, it was reported that this was an effect of the start time of the rest period, not to the amount of recovery time. It is clear that more field studies are needed to clarify how free time affects sleep and subsequent sleepiness.

The so-called "quick returns" (around $8 \mathrm{~h}$ of free time between shifts) are used to change the type of shift, for example from a series of $\mathrm{N}$-shifts to a period of $\mathrm{M}$-shifts. This compresses working hours and the major benefit is extra free time outside the work period. Each quick return gives 8 extra hours of continuous free time between work periods, but at the cost of severely curtailed free time between shifts, $8 \mathrm{~h}$ instead of $16 \mathrm{~h}$. Table 1 shows how quick returns affect sleep duration, but also illustrates the limited knowledge on the subject.

Table 1. How free time affects sleep duration (shown as: sleep duration/free time) and sleepiness (fatigue) in different schedules with quick returns (sleep duration/free time). - =not measured in the article; ?=not known/reported; h=hours

\begin{tabular}{llllllll}
\hline & & \multicolumn{7}{c}{ Quick return between: } & Effect on \\
Occupation & invited & responders & $\mathrm{M} / \mathrm{N}$ & $\mathrm{N} / \mathrm{A}$ & $\mathrm{A} / \mathrm{M}$ & sleepiness & study method \\
\hline rotary workers (Saitoh) & 268 & $?$ & - & $4-5 \mathrm{~h} / 7$ & - & strong & $?$ \\
police officers (Totterdel) & 41 & 19 & - & $5.1 \mathrm{~h} / 8$ & - & no effect & survey \\
manufacturing workers (Tucker) & $?$ & 143 & - & $5.2 / ?$ & - & minor & survey \\
nurses - with children (Kurumatani) & - & 18 & $1.8 \mathrm{~h} / 7.5 \mathrm{~h}-$ & - & - & time budget \\
nurses - no children (Kurumatani) & - & 46 & $2.6 \mathrm{~h} / 7.5 \mathrm{~h}-$ & - & - & time budget \\
air traffic contollers (Cruz) & $?$ & 24 & $2.4 / 8 \mathrm{~h}$ & - & $5.1 / 8 \mathrm{~h}$ & - & diary/actigraphy \\
police officers (Kanuth) & 120 & $?$ & $3 \mathrm{~h} / 9 \mathrm{~h}$ & - & $6.5 \mathrm{~h} / 9$ & - & time budget \\
non shift workers (Della Rocco) & $?$ & 20 & $3.7 / 9.5 \mathrm{~h}$ & $5.8 / 9.5 \mathrm{~h}$ & - & diary/actigraphy \\
nurses - with children (Kurumatani) & - & 14 & $2.1 \mathrm{~h} / 11.5 \mathrm{~h}$ & - & - & time budget \\
nurses - no children (Kurumatani) & - & 30 & $3.4 \mathrm{~h} / 11.5 \mathrm{~h}$ & - & - & time budget \\
\hline
\end{tabular}

Preliminary results (not published in a peer reviewed paper) from Saito and Kogi, of 268 rotating workers, showed that a quick return between a N-shift (ending at 04.00h) and D-shift (starting at $11.00 \mathrm{~h}$ ) reduced sleep to $4-5 \mathrm{~h}$ (Saito and Kogi, 1978). Sleep would have been even shorter if the employer had not provided a dormitory at the working site. The result was more fatigue during the D-shift than the preceding N-shift. They also reported that the workers wanted to remove the quick return because the benefits of the extra free time were cancelled by an increased need for compensatory sleep. However, there were no descriptions of the shift schedule, participation rate, statistical procedures, mean levels, or design.

In a survey study of 41 police officers, comparing a newly introduced rapidly rotating shift schedule - including one quick return after the last N-shift, with a traditional and slowly rotating shift schedule, Totterdel and Folkard found the average amount of sleep to be equal in the two shift systems (Totterdell and Folkard, 1990). The quick return curtailed sleep to 5h, which is less sleep than between continuous N-shifts (6h in the old slowly rotating shift system), but equal to the sleep after the last $\mathrm{N}$-shift (5h). In addition, they found no general effect of the total shift system on fatigue, but noted that the preference between the two shift systems varied considerably between locations. 
In a time budget study of 120 policemen across 8 days, Knauth and co-workers reported that that quick returns (with 9h off) between M- and N-shifts shortens day sleep to only $3 \mathrm{~h}$ (Knauth et al., 1983). The quick return (9h off) between A- and M-shifts reduced sleep duration to 6.5h, compared to more than $8 \mathrm{~h}$ between consecutive A-shifts in a weekly rotating shift schedule. The slowly rotating shift schedule also included quick returns, but most policemen took a day off to avoid it.

That afternoon sleep (between M- and N-shifts) is severely curtailed is supported by another time budget study of 180 nurses (Kurumatani et al., 1994), who also showed the day sleep (between Mand N-shifts) to be $3 \mathrm{~h}$ with free time being $7.5 \mathrm{~h}$ between the shifts. Free time between shifts was strongly correlated to sleep duration $(\mathrm{r}=0.95)$; the shorter recovery time, the shorter sleep (Kurumatani et al., 1994). The authors concluded that we need at least $16 \mathrm{~h}$ of free time to get $7-8 \mathrm{~h}$ of sleep. However, their strong correlation is partly due to the fact that the shortest free time (7.5h) occurred during the day and the longest free time $(30 \mathrm{~h})$ occurred after N-shifts - which was followed by an evening shift 30 hours later - and hence including both a nap and a recovery sleep. Thus, this study failed to consider the input from the circadian system (making it particularly difficult to sleep in the afternoon), as well as the obvious fact that longer bouts of free time include several sleep episodes. It would have been interesting if the study had included quick returns at other times (i.e. during the night or the morning) and no more than one sleep episode.

Surprisingly, in a survey study of 261 industrial and service workers, Barton and colleagues found more sleep problems in connection to A-shifts in advancing schedules without quick returns than in schedules with quick returns (Barton and Folkard, 1993). There was no difference with respect to chronic fatigue, but schedules with quick returns caused poorer physical health, less job satisfaction and more social and domestic disruption. Despite few significant differences, they concluded schedules with quick returns to be most problematic among those evaluated. However, the inconclusive data are hard to interpret as none of the shift schedules are described, or which quick returns were included, or the free time between shifts, nor the change-over times between shift types. One also has to be cautious with generalisations as the study did not report the response rates. In addition, the study did not include ratings of sleepiness, the only question of fatigue concerned chronic fatigue, and ratings were made for the entire shift period. This makes conclusions on the acute effects of quick returns speculative.

Another survey study of more than 600 workers, of which 143 had a schedule including quick returns (with retrospective ratings of sleep and sleepiness) found few effects of quick returns (Tucker et al., 2000). They found schedules with quick returns to shorten day sleep between N- and A-shifts to $5.2 \mathrm{~h}$ instead of more than $6 \mathrm{~h}$ between consecutive $\mathrm{N}$-shifts. However, this comparison was never made and the only analysis of a "quick return sleep" was against the last daytime sleep, after a series of $\mathrm{N}$-shifts (4.9-5.6h). It is well known that this sleep is severely curtailed (Knauth et al., 1980), since the workers want to be able to fall asleep in the evening and return back to diurnal living as quickly as possible. That this "quick return sleep" was too short was supported by increased sleep duration between the following A- shifts (8.8h), compared to other schedules (8.18.2h) (Tucker et al., 2000). Their analysis of retrospective sleepiness ratings found that sleepiness, in general, deteriorated faster in schedules with quick returns, but not specifically in relation to the 
quick returns. This suggests that the effects of quick returns are not acute, but more chronic in nature. However, there were no other measures that could support a chronic effect of quick returns (i.e. psychological- or physiological health or social disruptions). In contradiction to these findings, it is likely that the quick return inflicted acute effects on sleep and sleepiness, but the nature of retrospective sleepiness ratings may not be ideal for measuring this (even though shortened sleep was found), and it is possible that acute effects are confounded by this type of method. In addition, generalisations about quick returns are difficult as timing and duration were not described. Moreover, the conclusions of that study are limited to one type of quick return, as only schedules with quick returns between $\mathrm{N}$ - and A-shifts were included. Furthermore, there is support for quick returns (between $\mathrm{N}$ - and A-shifts) to increase the risk for accidents in steel manufacturing workers (MacDonald et al., 1997).

In a series of reports for the Federal Aviation Administration (FAA), Della Rocco and colleagues have measured air traffic controllers and non-shift workers in the field as well as in experimental settings (Cruz, 1995, Della Rocco, 1995, Della Rocco 1996). Taken together, their data support that quick returns have slight negative effects on sleep duration and performance. In a more recent study, they reported that $50 \%$ of air traffic controllers (working shifts with quick returns) complain of severe fatigue or exhaustion, and gastrointestinal disturbances was a common problem (Cruz et al., 2000).

No study has yet evaluated a system including several consecutive quick returns, but longitudinal partial sleep deprivation experiments suggests that sleepiness may accumulate across shifts (Carskadon and Dement, 1981; Carskadon and Roth, 1991; Dinges et al., 1997; Webb and Agnew, 1974). The only existing data on several consecutive quick returns are reported by Smith (Smith et al., 1998a) after personal correspondence with Jaffe (1994) that workers working in a shift schedule with two consecutive quick returns had worse sleep quality and health than workers in a $12 \mathrm{~h}$ shift system.

\section{Limitations and conclusions}

The time budget studies included time spent in different activities and did not include ratings of sleepiness, fatigue or performance (Knauth and Rutenfranz, 1982; Kurumatani et al., 1994). Of the survey studies, one is preliminary, and none made any attempts to evaluate the total burden of the shift schedule (Knauth and Rutenfranz, 1982; Saito and Kogi, 1978). Most studies evaluating sleepiness/fatigue/performance or the effect of the total work period are based on retrospective survey data (Barton and Folkard, 1993; Totterdell and Folkard, 1990; Tucker et al., 2000). The FAA studies included both diaries as well as actigraphy, and showed slight effects on sleep duration and performance. The reports showed the acute effects of a particular shift sequence (AAMMN and AAMMM) in comparison to working straight M- or D-shifts (DDDDD or MMMMM). The reports did not include systematic measures of sleepiness or if any accumulations occurred across a sequence of shifts or the shift schedule (Cruz, 1995, Della Rocco, 1995, Della Rocco 1996). In addition, none of these reports have yet been published in any peer-reviewed journals. 
It has been shown that the shorter the free time, the shorter the sleep (Kurumatani et al., 1994), and recovery periods of about $8 \mathrm{~h}$ reduce sleep with about 1 hour. This may seem little, but should be seen in relation to that sleep in connection to shift work is already severely curtailed. Sleep periods between $\mathrm{M}$ - and N-shifts are most drastically shortened, but there is a minimal need for sleep at this time (they have slept prior the M-shift), and it is likely that managing a nap at all before the N-shift is more important than its duration. It is probable that short recovery periods before A-shifts and Mshifts are more important as these sleep periods are main sleep episodes and there are few possibilities to take counteracting naps. The risk of accumulation of problems across shifts and work periods seems high since there is limited time to recover during a work period.

The evaluations of subsequent wakefulness are more inconclusive. Preliminary data from Saito et al (Saito and Kogi, 1978) support the impression of severe fatigue on the subsequent D-shift, but no or minor effects where found with retrospective ratings of fatigue and sleepiness, when comparing shift schedules (Totterdell and Folkard, 1990; Tucker et al., 2000). At the same time, most authors recommend avoiding quick returns (Kecklund and Åkerstedt, 1995; Knauth, 1993; Knauth et al., 1983; Knauth and Rutenfranz, 1982; Saito and Kogi, 1978).

\section{Summary}

On the whole, we know little of the relationships between disturbed sleep and subsequent sleepiness at the working place. There is some consistency in that sleep is curtailed, even though some may disagree. A main reason may be that the time of day affects sleep-duration. There is a need to better evaluate the effects of the different types of quick returns, particularly those where the workers have to manage a main sleep period in between shifts. In what ways are these sleep periods curtailed and disturbed? It is also an inconsistency in whether quick returns impose sleepiness on subsequent shifts. If that is the case, it would clearly be shown if one evaluated the acute effects of two consecutive quick returns. Another question is whether recovery time is sufficient after such "stressful" work periods or whether problems accumulate across the shift cycle.

Apart from comparing different parts of the shift schedule, it may also be fruitful to measure sleepiness across the entire shift schedule and compare with other schedules. This may yield a better understanding of the total burden of different shift systems. Finally, polysomnographic studies of short sleep - with similar sleep times as in a quick return - in controlled environments may shed new light upon how subsequent alertness and performance is affected.

\section{Other characteristics of shift schedules}

There are some fundamental characteristics that are important for tolerance to shift work in addition to the ones already described. They include timing of shifts, direction of rotation between shifts, speed of rotation, distribution of leisure time, the number of consecutive (N- or M-) shifts, duration of work periods and the shift cycle (Knauth, 1993; Knauth and Rutenfranz, 1982). None of these are part of the focus of the present thesis, but the most well researched issues are briefly summarized for completeness. 
The timing of shifts are important for sleep duration and subsequent sleepiness (Folkard and Barton, 1993; Kecklund and Åkerstedt, 1995; Kecklund et al., 1997; Knauth, 1993). The most critical change over time occur between the $\mathrm{N}$ - and the $\mathrm{M}$-shift and has hence rendered most attention. The conflict lies in that the N-shift should end as early as possible, while the M-shift should start as late as possible (Folkard and Barton, 1993). It seems a reasonable compromise to start the M-shift around $07.00 \mathrm{~h}$ in the morning.

There is still a controversy whether the direction of rotation should be advancing (backwards rotating; = changing from $\mathrm{N}$ - to A-shift, from $\mathrm{A}$ - to $\mathrm{M}$ or from $\mathrm{M}$ - to $\mathrm{N}$-shift) or delaying (forwards rotating, and the opposite shift changes) (Barton and Folkard, 1993; Barton et al., 1994; Czeisler et al., 1982; Knauth, 1996; Tucker et al., 2000; Turek, 1986). Despite recent findings of few differences between advancing and delaying shift schedules, it seems that delaying shift schedules are to prefer, particularly when advancing schedules include quick returns. However, the speed of the rotation and the amount of consecutive days are important mediators.

With respect to speed of rotation, Knauth concluded that rapidly rotating shift schedules should be favoured to slowly rotating ones as they reduce time for re-adaptation after a series of $\mathrm{N}$-shift, are more popular and limit any accumulations of a sleep deficit (Knauth and Kiesswetter, 1987; Knauth and Rutenfranz, 1982).

It is difficult to draw any distinct conclusions of the effects of the distribution of leisure time within the schedule. Most convincing evidence of an accumulation of problems concern a deteriorating performance across consecutive N-shifts (Patkai et al., 1977; Tilley et al., 1982; Wilkinson et al., 1989). However, it seems to have little effect on health and well-being (Barton et al., 1995), and having a recovery day between a series of $\mathrm{D}$ - and $\mathrm{N}$-shifts seems to be of minor importance (Tucker et al., 1999), even if the latter study did not include shift systems with more than 2 successive Nshifts. Nonetheless, the consensus is that it is important to limit the amount of continuous shifts to minimise the risk for accumulations of problems (Knauth, 1993; Smith et al., 1998a; Wallace and Greenwood, 1995).

\section{Individual differences in tolerance to shift work}

\section{Background}

While some shift workers develop problems within a few months, others thrive and stay healthy throughout their working lives (Härmä, 1993). One reason why we still don't know more about tolerance to shift work is probably that the negative effects of shift schedules, including night work, are not uniform (Harrington, 1978; Rutenfranz et al., 1977), partially because shift work is a multivariate phenomenon, including all sorts of more or less "odd" work hours". Another reason may be the large individual variation in tolerance to irregular work hours (Folkard and Monk, 1981; Åkerstedt and Torsvall, 1981b). Hence, tolerance to shift work is dependent on different characteristics amongst shift schedules as well as on individual characteristics. Better knowledge of these aspects may yield better possibilities for successful interventions. 
Individual properties traditionally associated with tolerance are: diurnal type (Costa et al., 1989; Härmä et al., 1994a; Åkerstedt and Torsvall, 1981a), circadian amplitude (Reinberg et al., 1980), sleep flexibility (Costa et al., 1989; Folkard et al., 1979), age (Bonnet and Rosa, 1987; Härmä et al., 1994b), physical fitness (Härmä et al., 1988a; Härmä et al., 1988b), gender (Beermann, 1995; Oginska et al., 1993), the ability to overcome drowsiness (Folkard et al., 1979), neuroticism (Härmä et al., 1988a; Parkes, 1994), social and domestic aspects (Gadbois, 1981; Monk, 1988). Most of these studies have, however, shown very weak links, and there is a lack of knowledge of the connections between individual characteristics and tolerance to shift work (Nachreiner, 1998; Åkerstedt, 1999). One of the most prominent findings concerns the connection between disturbed sleep and shift work intolerance (Lavie et al., 1989). However, further work is needed if we want to understand what individual aspects/mechanisms that are critical for shift work tolerance.

Despite the fact that a substantial proportion of workers stop working shifts already within the first year (Thiis-Evensen, 1958), many workers develop problems around the age of 40-50 (Koller, 1983; Torsvall et al., 1981). It is difficult to know whether these problems are due to age or exposure as these variables are closely tied together. Another complicating factor is that age is normally related to more sleep disturbances, both via alterations of the sleep process itself and via age related diseases (Bliwise, 2000). On the other hand, older workers have been shown to be less sensitive to acute sleep deprivation in experimental studies (Fröberg et al., 1972; Webb and Agnew, 1974) as well as during night work (Härmä et al., 1994b). The latter study also showed that the older workers felt more refreshed after the first and the second $\mathrm{N}$-shifts despite shorter sleep times. The increased resistance to sleepiness, amongst older workers is supported by findings showing that their performance is less affected by disturbed sleep (Bonnet and Rosa, 1987). These results are contradictory to the development of shift related health problems, and may suggest that tolerance would increase by age. On the other hand, it is also possible that acute resistance to sleep deprivation and sleepiness is not linked to long-term health.

The moderate levels of problems found in many shift working groups is partly due to the "healthy worker" effect. This self-selection processes is the result of selection into shift work - some workers are less likely to start shift work - and out of shift work - those with problems are more likely to drop out, leaving the healthiest workers (Andlauer, 1960; Bruusgaard, 1969; Knutsson and Åkerstedt, 1992; Koller et al., 1978; Mott et al., 1965; Åkerstedt and Fröberg, 1976). As a result, many cross sectional studies will find no or few differences between shift workers and day workers with respect to morbidity. Even though there are several other reasons for leaving shift work prematurely (Frese and Okonek, 1984), a consequence is that "drop-outs" report worse health than day- or shift workers (Aanonsen, 1959; Angersbach et al., 1980; Koller et al., 1978).

It is likely that problems amongst shift workers are related to turnover, absenteeism and productivity (Burke, 1970; Frese and Okonek, 1984; Locke, 1976; Petty et al., 1984). In turn, the degree of suffering is reflected in the attitude, i.e. satisfaction to the present work hours, and this is evidenced in several studies of satisfaction in relation to individual factors, organisational issues, social/family life, free time, health problems, sleep disturbances, sleep flexibility and the ability to overcome drowsiness (Dirkx, 1987; Escribà-Agüir, 1992; Kecklund et al., 2000; Kundi et al., 1980; Lavie et al., 1989; Nachreiner, 1975; Patkai and Dahlgren, 1981; Wedderburn, 1967; Wedderburn, 
1981). In the studies above, problems are, as expected, related to dissatisfaction, but there are only two studies that have tried to tease out, in a multivariate fashion, which major shift related factors determine satisfaction (Iskra-Golec, 1993; Kecklund et al., 2000). The first study included only a few sleep characteristics and individual factors (Iskra-Golec, 1993), while the second found that sleepiness was the only significant predictor of dissatisfaction with the shift schedule (Kecklund et al., 2000). It seems reasonable that satisfaction with work hours reflects how well the workers are coping with the shift system, and that this may be related to the main problems with shift work sleep and sleepiness.

Besides looking at the different aspects of shift work that are harmful, we also wanted to shed light on biological mechanisms involved in the development of shift work intolerance. We believed that a fruitful way would be to compare tolerant and intolerant shift workers and follow them over time. Accordingly, we evaluated if intolerant shift workers were differently affected by working a shift cycle than tolerant ones. The fact that shift work can be seen as a stressor and that sleep is important for anabolic activity (Adam and Oswald, 1977) made us focus on the endocrine differences between satisfied (tolerant) and dissatisfied (intolerant) shift workers working a particularly stressful shift schedule that was extremely rapidly rotating and included several consecutive quick returns. The variables for comparison were selected from key indicators of catabolic (cortisol) and anabolic activity (testosterone), both are closely related to stress and sleep (Luboshitzky et al., 2002; Luboshitzky et al., 2000; Schiavi et al., 1992; Yehuda et al., 1993; Åkerstedt et al., 1980). In addition, prolactin was measured because of its sensitivity to sleep and stress (Noel et al., 1972; Spiegel et al., 1996; Van de Kar and Blair, 1999), but also for its importance as a regulator of immune function and cellular osmosis (Freeman et al., 2000). Thus, the present thesis compared satisfied and dissatisfied shift workers with respect to major anabolic and catabolic hormones, and whether they were differently affected by working a shift cycle.

\section{Summary}

All in all, there is a large individual variation in tolerance to shift work and far from all shift workers develop severe health problems. It is largely unknown why some are more tolerant than others. Such knowledge may help to advise potential shift workers, but, more importantly, comparison of groups with different tolerance may help us understand more about the mechanisms behind problems caused by shift work. There is clearly a need for studies comparing groups of different tolerance of shift work. This also includes physiological variables. Among them are, for example, cortisol and testosterone, representing catabolic and anabolic processes. 


\section{Aims of the thesis}

The present thesis aimed to assess the effects of long shifts, short recovery periods, and what factors being important for tolerance to shift work. The following were the main research issues:

1) To assess the effects of long working hours (12h shifts) on sleep and sleepiness using day-today ratings and control groups. It was intended to measure the effects on each day to find particularly problematic periods of a shift schedule as well as to evaluate the effect of the entire shift period. (Study I-III).

2) To assess the effects of short recovery periods in different schedules. Day-to-day measures made it possible to assess whether acute and accumulative effects occur (Study I-IV).

3) To try a new way of obtaining a total measure of sleepiness of the entire shift period reflecting the total strain induced by a particular shift system (Study I-III).

4) To assess the effects of short sleep (simulating a quick return between A- and M-shifts) on subsequent sleepiness and performance in a controlled environment (Study V).

5) To compare "resilient" and vulnerable shift workers with respect to the most obvious problems in shift workers, sleep and sleepiness. The aim was to find what aspects of shift work that are most problematic for intolerant workers, and the nature of the intolerant shift workers problems. Another aim was to evaluate if tolerance to shift work is related to major biological parameters of anabolic (testosterone) and catabolic (cortisol) processes. (Study III and IV). 


\title{
METHODS
}

\author{
"If we knew what it was we were doing, \\ it would not be called research, would it?"
}

Albert Einstein

\section{Design of the studies}

The design of the studies and the measured variables are presented in table 2. Study I-IV are the result of three field studies of shift workers. All 5 studies have a within-group design. Study I compares the same group of shift workers in two different schedules (a change from an 8-hour to a 12-hour shift schedule). A smaller group of day workers are used as a control/comparison group. Study II compares shifts with different length (8- vs $12 \mathrm{~h}$ shifts) in the same shift schedule. The schedule included 8-hour shifts during weekdays and 12-hour shifts during weekends (Fri-Sun). The design in study III includes both a within and a between groups approach. The within group perspective evaluates the effect of working an entire shift cycle (comparing the first work period in the shift cycle with the last). The two between group approaches were men vs. women, and satisfied (with their work hours) vs. dissatisfied ones. Study IV is based on the same material as study III, but here satisfied and dissatisfied men are evaluated with respect to hormonal changes across a shift cycle. In addition, Study IV also has a correlational approach, evaluating the relationship between hormone levels and questionnaire ratings of health symptoms and sleep characteristics. Study V, which is the sole experimental study in this dissertation, has 3 conditions. The main aims were 1) to evaluate the effects of curtailed sleep on objective and subjective parameters of sleepiness; and 2) to evaluate whether a short daytime nap could counteract any detrimental effects of curtailed sleep.

Study I-III also had the additional within factor "type of shift/day", evaluating differences between N-shifts, A-shifts, M-shifts, and when appropriate recovery days, and/or other days off. Moreover, all the studies, except IV, had another within factor, "time of day", which evaluates how sleepiness develops across each $24 \mathrm{~h}$ window.

Table 2. Summary of the designs and the measured variables of the studies

\begin{tabular}{|c|c|c|c|c|c|c|c|}
\hline Study & Design & $\begin{array}{l}\text { No. of } \\
\text { conditions }\end{array}$ & $\begin{array}{l}\text { Subjective } \\
\text { sleep }\end{array}$ & $\begin{array}{l}\text { Objective } \\
\text { sleep }\end{array}$ & $\begin{array}{l}\text { Subjective } \\
\text { sleepiness }\end{array}$ & $\begin{array}{l}\text { Perfor- } \\
\text { mance }\end{array}$ & other \\
\hline I & within-group & $2 \mathrm{w}$ & KSD & actigraphy & KSS & RT & \\
\hline II & within-group & $2 \mathrm{w}$ & KSD & no & KSS & $\mathrm{RT} / \mathrm{VT}$ & physical effort \\
\hline III & W \& B-groups & $2 \mathrm{w} / 2 \mathrm{~b} * 2 \mathrm{~b}$ & KSD & actigraphy & KSS & RT & \\
\hline IV & W \& B-groups & $2 \mathrm{w} / 2 \mathrm{~b}$ & no & no & no & no & hormones \\
\hline V & within group & $3 \mathrm{w}$ & KSD & EEG & KSS & $\mathrm{RT} \& \mathrm{VT}$ & EEG/EOG \\
\hline
\end{tabular}

A problem with most field studies, is that they permit limited conclusions of causality. Although one of the field studies is pseudo-experimental (study I), the strongest conclusions may be drawn 
from study $\mathrm{V}$, where the independent variable was manipulated in a controlled manner and subjects were analysed in the sleep laboratory in a cross-over design. Study II-IV are more descriptive in nature.

\section{Subjects}

Study I-IV included shift workers, although a smaller subgroup of day workers was included in study I. In study I-II, all shift workers were asked to participate in the studies. The only exclusion criteria were whether they could participate in the study protocol, if they managed to avoid too many deviations from the shift schedule or if they failed to fill out the sleep/wake diaries. In study II, all 76 shift workers were invited to participate in the study protocol, but 27 were excluded (as they chose not participate, changed to day work, went on long time sick leave or pregnancy leave). The remaining 49 went through the study protocol, but another 18 had to be excluded from the analysis because of incomplete data or too many deviations from the normal shift schedule (changed shifts with colleagues, much overtime, holidays and sick-leave), leaving 27 men (mean age $=38 \pm 2$ ) and 4 women (mean age $29 \pm 2$ ) for analyses.

In study III, participation was based on the shift workers' satisfaction with their work hours. To maximize variation in satisfaction we invited those highly satisfied or dissatisfied with their work hours (both men and women). The study included: 31 satisfied shift workers of which 11 were women, (men with a mean age of $43 \pm 2$ years, women $38 \pm 3$ ) and 25 dissatisfied shift workers, 9 women (mean age men $=39 \pm 2$, women $=44 \pm 4$ years). In study IV, 62 out of the 269 full time male shift workers were invited to participate in two health examinations. The groups in the present study were 42 men, of which 22 were satisfied (mean age $=44 \pm 2$ years, satisfaction with work hours $=5.0 \pm .0$ ) and 20 dissatisfied $(41 \pm 2$ years, satisfaction $=2.4 \pm .2)$. The 8 participants in study $\mathrm{V}$ were students or employees at our research institute and were all in good health and had no sleep problems. Table 3 presents a summary of some of the background information.

Table 3. Number of- subjects invited, subjects participating, subjects analysed, age and sex. In study I, 20 shift workers decided to participate in a meeting with those $(n=34)$ who had responded to the questionnaire, which had a response rate of $85 \%$. Ten volunteers participated in Study V, but two subjects (both women) were excluded due to pregnancy and disease.

\begin{tabular}{llllllll}
\hline Study & $\begin{array}{l}\text { subjects } \\
\text { invited }\end{array}$ & $\begin{array}{l}\text { subjects } \\
\text { participating }\end{array}$ & $\begin{array}{l}\text { subjects } \\
\text { analysed }\end{array}$ & Women & Men & Mean age & Age range \\
\hline I & $(34)$ & 20 & 14 & 3 & 11 & 39 & $25-57$ \\
II & 76 & 49 & 31 & 4 & 27 & 37 & $24-57$ \\
III & 100 & 62 & 56 & 20 & 36 & 40 & $25-61$ \\
IV & 62 & 42 & 42 & 0 & 42 & 42 & $25-61$ \\
V & 10 & 10 & 8 & 0 & 8 & 32 & $24-45$ \\
\hline
\end{tabular}




\section{Procedures and methods}

\section{General Procedure}

In study I, a questionnaire (Karolinska Sleep Questionnaire=KSQ) was distributed to all shift workers at a chemical plant in Stenungsund. In a second step, the shift workers were informed that we wanted to include half of them in an "intensive study", where they were studied thoroughly during approximately 2 weeks of their shift schedule. The intensive study included a sleep/wake diary (Karolinska Sleep Diary=KSD), actigraphy and a performance test (all described in following sections). Twenty shift workers and 11day workers agreed to participate.

In study II, all shift workers working at a power plant in Stockholm, were invited to participate in the intensive study. Included in the analysis were 27 men and 4 women that filled out a questionnaire, a KSD and a wake diary during an entire shift cycle. All participants also carried out a 10-minute reaction time test or a 10-minute vigilance test at the end and the beginning of $12 \mathrm{~h}$ and $8 \mathrm{~h} \mathrm{~N}$ - and M-shifts.

The questionnaire was distributed to all shift workers working at a paper and pulp factory in Hyltebruk. Based on the shift workers' satisfaction with their work hours (rated in the questionnaire) two subgroups were chosen. To maximize variation in satisfaction, we invited those who were either highly satisfied or dissatisfied with their work hours (both men and women). Two subgroups, women working part time (20 randomly chosen) and a group of electricians (all 10) having a different rotation of the schedule, also participated in the study protocol, but are not included in the present papers. All participants filled out the sleep/wake diary during the entire shift schedule. They wore actigraphs during the first and the last work period of the shift cycle as well as the first 4 days of their week off. A reaction time test was performed at the beginning and at the end of each shift during the first and last work period of the shift cycle. All shift workers that were asked to participate in the intensive study were also asked to perform two health examinations, one during the first M-shift of the shift cycle and one during the last M-shift. Study III involved analysis of all fulltime workers with respect to measures of sleep, sleepiness and performance. Study IV included all men that participated in the two health examinations.

In study $\mathrm{V}$, the participants were carefully instructed about the study protocol and had to follow a strict sleep schedule prior the participation in the sleep laboratory. The sleep schedule before entering the laboratory was $23.00 \mathrm{~h}$ to 07.00 during baseline, and $00.00 \mathrm{~h}$ to $04.00 \mathrm{~h}$ during the two other conditions. Participants also had had to abstain from caffeine beverages, alcohol and medicine at least 24 hours before entering the laboratory. Subjects came to the laboratory at $08.00 \mathrm{~h}$ and left the laboratory at $16.00 \mathrm{~h}$. The day in the laboratory included application of electrodes (EEG and EOG) at $08.00 \mathrm{~h}$, performing 3 test batteries, lasting 45 minutes, starting at $09.00 \mathrm{~h}, 11.15 \mathrm{~h}$ and 15.00h. A 30-minute nap was also introduced at 10.45 during one of the short sleep conditions. 


\section{Questionnaire}

All studies included the Karolinska Sleep Questionnaire (KSQ) (Kecklund and Åkerstedt, 1992) even though parts of it varied between studies. The questionnaire also contained questions about background, sleep characteristics, the work situation, social factors, health symptoms (including sleep items) and well-being.

The questions concerning sleep problems were "snoring", "exhausted upon awakening", and the indices: " disturbed sleep" (containing "difficulties falling asleep", "repeated awakenings", "disturbed sleep", "premature awakening"); and "sleepiness problems" (containing "sleepiness during work/leisure", "involuntary falling asleep at work", "involuntary falling asleep during leisure time" and "have to fight against sleep to stay awake"); all used the response alternatives 1=always, $2=$ mostly/several times a week, $3=$ sometimes/several times per month, $4=$ seldom, $5=$ never (during the last 6 months). Other items were "diurnal-type" (1=profound evening type - 4=profound morning type (Torsvall and Åkerstedt, 1980)), "habitual sleep need" (hours and minutes) and "sufficient sleep?" (1=No, far from sufficient $-5=$ Yes, definitely sufficient). In addition, the questionnaire included questions on whether sleep was disturbed in connection with day sleep (after the N-shift) or before the M-shift; the questions concerned if sleep was "disturbed", "insufficient" and the feeling of "not being well rested" (scales ranging from $1=$ never $-5=$ always). The shift workers also rated their need for recovery after a work period (how many night sleep periods were needed to recover, $1=$ one sleep, $2=$ two sleeps, $3=3$ or more) and as well as their general health ( $1=$ very poor $-5=$ very good). Study IV used questionnaire data to compare complaints and sleep characteristics with levels of hormones.

The questionnaire also included a question of satisfaction with ones work hours, phrased "How satisfied are you with your present work hours?" (1=very dissatisfied, $2=$ dissatisfied, $3=$ neither dissatisfied nor satisfied, $4=$ satisfied, $5=$ very satisfied).

\section{Sleep diary}

All studies included subjective ratings of sleep using the Karolinska Sleep Diary (KSD) (Åkerstedt et al., 1994b, 1994c). The KSD was rated after each main sleep period and after each nap, it contained questions about bed times, rise times, sleep latency, sleep quality, ease of falling asleep, calm sleep, slept throughout, ease of awakening, sufficient sleep and well rested. A sleep quality index (SQI) was calculated using the items "sleep quality" (phrased "how was your sleep?"), "ease falling asleep", "calm sleep" and "slept throughout". The response alternatives ranged from 1 ("problems" or "very poor") to 5 ("no problems at all" or "very good"). SQI has been shown to correlate with objective parameters such as sleep efficiency and slow wave sleep (Kecklund and Åkerstedt, 1997). Thus, poor sleep quality is associated with less SWS (slow wave sleep) and lower sleep efficiency. The KSD also included questions concerning medication, caffeine intake, whether anything particular had happened during the night and how they were awakened. 


\section{Wake diary}

The wake diaries differed slightly between studies as they had to suit different types of shift schedules. All subjects were instructed to rate their sleepiness on the Karolinska Sleepiness Scale (KSS) (Åkerstedt and Gillberg, 1990) every 2-3 hours awake (in study I-III) and every hour (study $\mathrm{V})$, both during work and free time. The KSS is a 9-point verbally anchored scale with the response alternatives 1-very alert, 3-alert, 5-neither alert nor sleepy, 7-sleepy but no problems staying awake, and 9-very sleepy, fighting sleep, an effort to keep awake (the intermediate steps have no verbal anchoring). The KSS is highly correlated with physiological sleepiness (Åkerstedt and Gillberg, 1990).

In study II, physical effort and exertion was rated on Borg's CR-10 scale (a category ration scale with $0=$ nothing at all; $0.5=$ extremely weak; $1=$ very weak; $2=$ weak; $3=$ moderate, $5=$ strong, $7=$ very strong, 10=extremely strong) every second hour (Borg, 1990).

The second part of the wake diary included questions describing the work period. They had to estimate the proportion of the shift they had felt different symptoms (or the entire day during free time). The symptoms were: "bad mood", "stress", "mental strain", "heavy eyelids", gravel-eyed", irresistible sleepiness", difficult keeping eyes open", difficulties focusing attention", "periods when you were fighting sleep". The symptoms describing severe sleepiness formed the a scale of Accumulated Time with Sleepiness (ATS, (Gillberg et al., 1994))

To obtain an understanding of the total impact of the shift system on sleepiness (diary ratings) for the entire shifts cycle the ratings were first averaged across the waking span of each day and then summed for workdays, days-off, and all days, respectively. Unmeasured days (mainly study I) were estimated by interpolation.

\section{Performance}

In study I-III and V the participants had to perform a single visual reaction time test (RT-test). The present RT-test is based on tests developed by Lisper and colleagues (Lisper and Kjellberg, 1972) and Wilkinson (Wilkinson and Houghton, 1982). The test (length=6-minutes in study III and 10minutes in the others) was presented on a handheld computer $\left({ }^{\mathrm{TM}}\right.$ PSION LZ, Psion PLC, London, UK) and was carried out in the normal work environment. Sixteen signals per minute were presented at random intervals (with an inter-stimulus interval of 2-7 seconds). Reaction times were in study I analysed with respect to median reaction times and $10 \%$ slowest reaction times and study II analysed with respect to mean reaction times and 10\% slowest. In study III, the presented analysis was based on mean reaction times after transformation of the raw reaction-time data $(1 / \mathrm{x})$ to counteract difference in variance or skewness (Dinges, 1992). For clarity, the mean values were transformed back $(1 / \mathrm{x})$ to be presented in milliseconds. In study III, a reaction time longer than 0.5 seconds was considered being a performance lapse (Dinges et al., 1997). There were, unfortunately, no RT-results from study V due to technical problems. 
Study II and V also included a visual vigilance test presented on a computer screen. The task consisted of a yellow dot (5mm in diameter) that jumped in a chronological order between 13 fixed positions in a clock-wise manner around a circle $(70 \mathrm{~mm}$ in diameter). The dot was visible for 0.45 seconds in each position with an interstimulus length of 0.45 seconds. The subjects should mark (as quick as possible) with a mouse click, when the interstimulus period increased with 0.30 seconds and the dot skipped a position. The signals occurred in a pseudo-random order with a length of 2-60 seconds. The test shows a high correspondence with subjective sleepiness (Gillberg et al., 1994). The vigilance task was 10-minutes in study II and 38-minutes in study V. All subjects had practiced on the different tests before entering the study protocol.

\section{Blood parameters}

In study IV, fasting blood samples were drawn by a nurse between $07.00 \mathrm{~h}$ and $09.00 \mathrm{~h}$ on the Mshift during the first and the last $\left(7^{\text {th }}\right)$ work period (from September 1996 to late spring 1997). The samples were centrifuged within 2 hours and serum was directly frozen and analysed with respect to cortisol, prolactin and testosterone (Calab, Nova Medical Sweden). Serum cortisol and serum testosterone were analyzed using ELIZA (Boehringer Mannheim, Germany with a fully automatic immunoassay system ES 700, Boehringer Mannheim, Germany). The total intra- and inter assay coefficient of variability $(\mathrm{CV}) \%$ for cortisol was $<8.0 \%$ and for testosterone $<5.0 \%$. Prolactin was analyzed with a two-site chemiluminometric immunoassay with an Automated Chemiluminescence Systems (ACS:180, Ciba Corning Diagnostic Corp, Medfield, MA, USA). The total CV\% was $<10 \%$.

\section{Statistics}

All studies evaluated changes within groups of the same individuals, but study III and IV also compared differences between groups of individuals with the same shift schedule. In addition, study I had a comparison group of day workers. For measures within individuals (groups) we used Analysis of Variance (ANOVA, all studies) for repeated measures (Winer, 1971) and for analysis between groups we used "grouping" of factorial ANOVA's (study I, III, IV). When several days or hours were compared (study I-III and V), the results were corrected for violation of the assumption of equal variances and covariances. Study I and III used the Greenhouse method (Greenhouse and Geisser, 1959) and study II and V used the Huynh-Feldt's epsilon (e) correction (Huynh and Feldt, 1976), both adjusting the degrees of freedom. Post-hoc comparisons of means for comparable days of hours were made with the help of Newman-Keuls t-test in study I and V, and with the help of orthogonal contrasts in study II.

Study II, IV and parts of the discussion of the thesis also aimed to test the relationship between variables. Study IV included correlations while study II included a test with a "least square dummy" variable regression model (all ratings pooled, using all data points=1791) to find the relationship between variables. The method is more thoroughly described by Totterdel and co-workers (Totterdell et al., 1994), but the main purpose is to eliminate the differences in "rated level" between individuals by using a set of n-1 dummy variables that represents each participant. The "net result" is the "correlational mean" for all subjects own correlation between a certain set of 
variables. The relationship, between those variables, within each subject - is calculated without interference from other subjects' ratings. The discussion includes a few logarithmic regressions to illustrate the non-linear dependency between variables. Study IV also included a set of stepwise multiple regression analyses to find the best predictors of the dependent variable.

The p-level was set to 0.05 , except in study III and IV where a stricter p-level of 0.01 was set due to the many "analyses" performed. The stricter p-level was used to minimise the risk of "mass significance" (type I-errors). 


\section{RESULTS}

"If rats are experimented on they will develop cancer."

Morton's Law

\section{Study I- Change from an 8-hour shift to a 12-hour shift, attitudes, sleep and performance}

Study I was conducted to evaluate whether 12-hour shifts differ from 8-hour shifts with respect to sleep, alertness and performance. Thirty-four shift workers, working at a chemical plant, responded to a questionnaire before and 10 months after the change from an 8-hour shift to a 12-hour shift. Fourteen of these workers (randomly chosen) were followed with a sleep/wake diary for select parts of their shift schedules (underlined in the schedules). They also performed a 10-minute visual reaction time task at the beginning and end of shifts. The A-M and N-A changes were "quick returns" with only 8-hours off between shifts. Shift changes occurred at 06-14-22h in the 8-hour shift schedule and at 06 and $18 \mathrm{~h}$ in the 12-hour shift schedule. A group of nine day workers at the same plant served as a control/comparison group.

8h shift schedule: + AMMMM+++NNNNAA+++AAMMM++++NNNAA+++

12h shift schedule: $\mathrm{NN}+++++\mathrm{DD}++\mathrm{NNN}++++\mathrm{DDD}++\mathrm{NN}+++++\mathrm{DD}+++$

$\mathrm{N}=$ Night shift, $\mathrm{A}=$ Afternoon shift, $\mathrm{M}=$ Morning shift, $\mathrm{D}=$ Day shift, $+=$ Day off

A set of two-way ANOVA's (Analysis of Variance) with one between factor (shift- vs. day workers) and one within factor (time 1 vs. time 2). was used to evaluate the effects of the shift change.

Questionnaire data showed that the shift workers were more satisfied with their 12-hour shift schedule compared with the 8-hour schedule $(\mathrm{p}<.05)$. Seventy-seven percent were in favour of the new $12 \mathrm{~h}$ schedule, which also increased time for social interaction $(\mathrm{p}<.05)$. The $12 \mathrm{~h}$ schedule also improved the feeling of being well rested upon awakening and shortened the time it took to recover after a period with $\mathrm{N}$-shifts. However, the $12 \mathrm{~h}$ shift schedule made it more costly to be away from work (one sick day is more costly as the salary per day has increased by 50\%) and reduced the contact between shift teams. The quick return, in the $8 \mathrm{~h}$ shift schedule, increased difficulties with sleep and sleepiness $(\mathrm{p}<.05)$.

Results from the sleep diary showed that the $12 \mathrm{~h}$ schedule improved quality of sleep (during both the N-shift and the D-shift sequences, $\mathrm{p}<.01)$ and lowered sleepiness during D-/M-shifts $(\mathrm{p}<.05)$. An improvement of sleep length and of the awakening index was seen during $12 \mathrm{~h}$ D-shifts compared to M-shifts in the $8 \mathrm{~h}$ schedule $(\mathrm{p}<.05)$. The $12 \mathrm{~h}$ shift schedule did not affect performance, but decreased napping markedly. 
All ratings of sleepiness were averaged across a shift cycle to provide a measure of the total load of the schedule. The shift change significantly decreased overall sleepiness from $5.0 \pm .2$ to $4.6 \pm .2$ amongst shift workers $(\mathrm{p}<.01)$. Also day workers decreased their sleepiness, from $3.8 \pm .2$ to $3.2 \pm .2$ across the same time frame $(\mathrm{p}<.01)$. The improvements were mainly related to less sleepiness during work, but shift workers also experienced less sleepiness during days off in the new $12 \mathrm{~h}$ schedule (days off, shift workers $=4.2 \pm .2$, day workers $=3.2 \pm .2, \mathrm{p}<.001$ ).
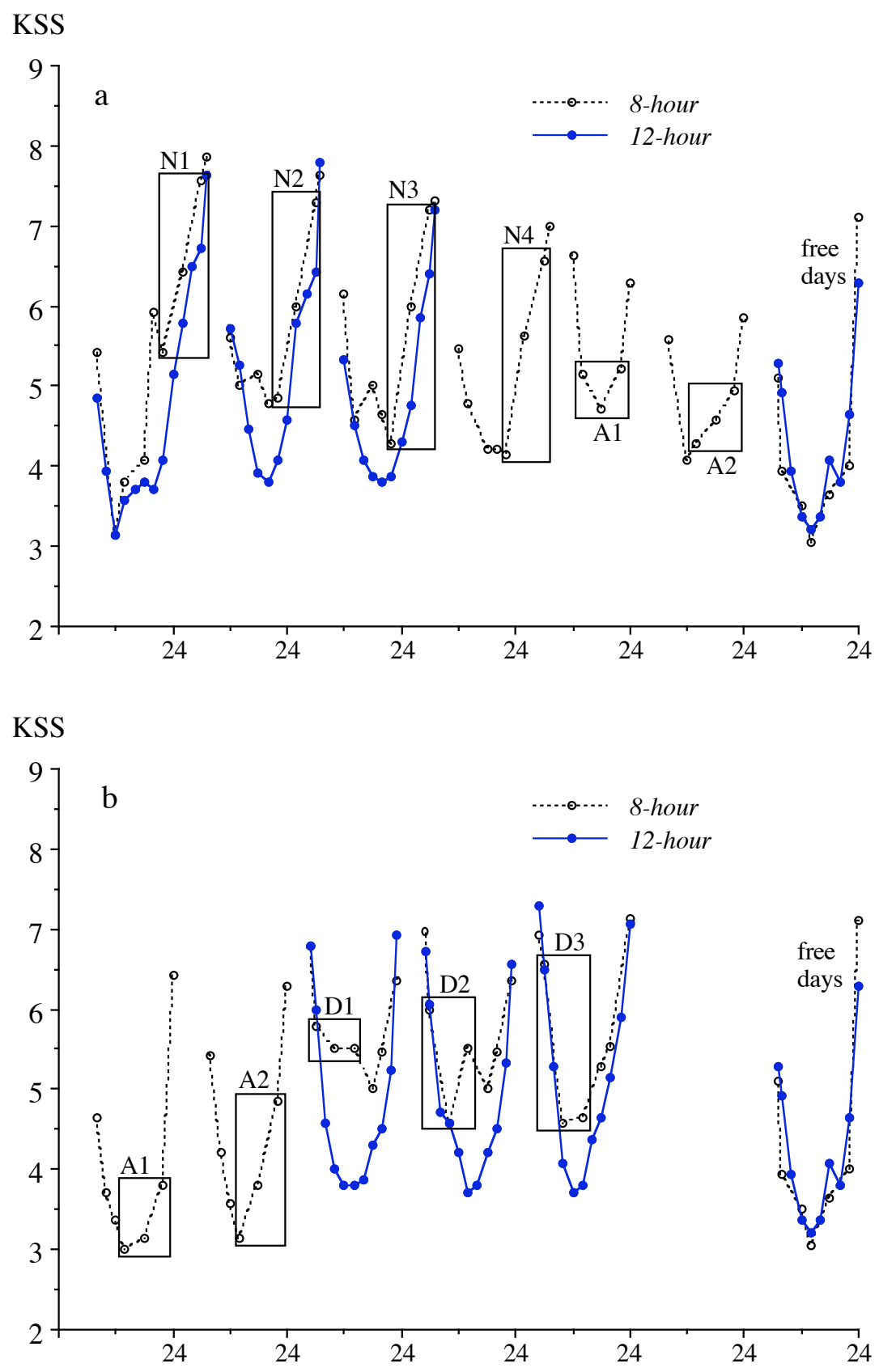

Figure $1 \mathrm{a}$ and $\mathrm{b}$. Mean ratings of sleepiness across two work periods in the old $8 \mathrm{~h}$ shift schedule and the new 12h shift schedule. Fig 1a includes a series of N-shifts (and two A-shifts in the 8h shift schedule). Fig $1 \mathrm{~b}$ includes a series of M-shifts (named D-shifts). The $8 \mathrm{~h}$ shift schedules also includes two previous A-shifts. 
In summary, the change from the $8 \mathrm{~h}$ - to the $12 \mathrm{~h}$ shift schedule was an improvement with regard to most aspects. It was suggested that the main reasons were: shorter work periods; longer sequences of days off with better possibilities to recover properly; fewer types of shifts (easier planning) and the elimination of quick returns. It was emphasized that the results may differ in settings with higher work load.

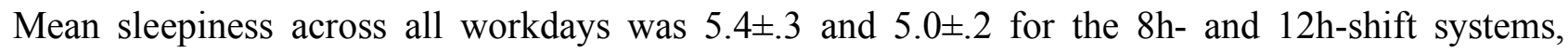
respectively. This decreased to $4.4 \pm .2$ during days off for both schedules, and the total sleepiness

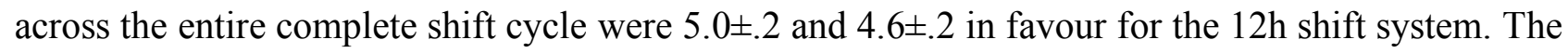
comparison group of day workers only filled in the sleep diaries for 4 days (th-su) and an average of the two measurement periods was calculated, sleepiness during workdays $3.7 \pm .2$, days off $3.3 \pm .3$,

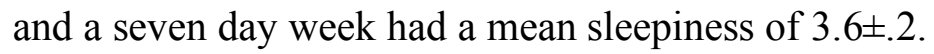

\section{Study II - Effects of alternating 8-and 12 hour shifts on sleep, sleepiness, physical effort and performance}

The aim of Study II was to compare $12 \mathrm{~h}$ shifts during weekends with $8 \mathrm{~h}$ shifts during weekdays with respect to sleep, alertness and performance. All shift workers $(n=76)$ at a power plant in Stockholm were invited. Twenty-seven abstained or could not participate (changed to day work, changed employment or pregnancy). Of the remaining 49 subjects another 18 had to be excluded from the analysis because of too many deviations from schedule (changed shifts with colleagues, too much overtime, holidays and sick leave). Included in the analysis of the KSQ-questionnaire and a KSD-diary during an entire shift cycle were 27 men and 4 women. In addition, about half of the subjects carried out a 10 -min reaction time test and the rest carried out a 10-minute vigilance task. The tests were performed at the beginning and at the end of both $8 \mathrm{~h}$ - and $12 \mathrm{~h} \mathrm{~N}$ - and D-shifts. The shift cycle (comprising of 42 days and 6 shift teams) included $12 \mathrm{~h}$ shifts Fri - Sun and $8 \mathrm{~h}$ shifts Mon - Thu (presented below). Shift changes occurred at $07.00 \mathrm{~h}-15.00 \mathrm{~h}-23.00 \mathrm{~h}$ for $8 \mathrm{~h}$ shifts and at $07.00 \mathrm{~h}-19.00 \mathrm{~h}$ for $12 \mathrm{~h}$ shifts. Commuting times were on average $40 \mathrm{~min}$.

shift schedule: AAAA+++/MMMMnNN/++++ $\mathrm{A}=$ Afternoon shift, $\mathrm{M}=$ Morning shift, $\mathrm{N}=$ Night shift, $\mathrm{D}=$ Day shift $(07.00 \mathrm{~h}-16.00 \mathrm{~h}),+=$ day off.

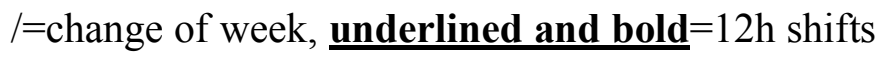

The data were analyzed with repeated measures analysis of variance (ANOVA) using 2, 3 or 4 within-group factors. The main effects were shift type (N- vs M-shifts), shift length (8h- vs. 12h shifts), shift sequence $\left(1^{\text {st }}, 2^{\text {nd }}\right.$, and $3^{\text {rd }}$ shift in a row $)$, and when appropriate, time of day.

Frequency of naps, ease of awakening and physical effort (CR-10) were the only variables that differed due to length of shift (8h vs. 12h). It was easier to rise in connection with $12 \mathrm{~h}$ shifts $(p<.05)$. More naps $(p<.05)$ were taken in connection to $8 \mathrm{~h}$ shifts and physical effort was lower during $12 \mathrm{~h}$ shifts $(\mathrm{p}<.001)$. A few variables changed across the sequence of shifts. Naps and physical effort decreased across the sequence $(p<.01)$. At the same time, problems with difficulties awakening $(\mathrm{p}<.01)$ and unrefreshing sleep $(\mathrm{p}<.05)$ accumulated and were worse at the end of the work period. There were no main effects for total sleep time (TST) nor sleep quality. 
Apart from the obvious differences in sleepiness according to type of shift, there was a significant interaction between shift length and shift type. Compared to $8 \mathrm{~h}$ shifts, $12 \mathrm{~h}$ shifts inflicted more sleepiness during $\mathrm{N}$ shifts, but less sleepiness during $\mathrm{D}$ shifts $(\mathrm{p}<.001)$. One was less sleepy at $12.00 \mathrm{~h}, 14.00 \mathrm{~h}$ and $16.00 \mathrm{~h}$ and sleepier at $24.00 \mathrm{~h}, 02.00 \mathrm{~h}$ and $04.00 \mathrm{~h}$ when working $12 \mathrm{~h}$ shifts compared to $8 \mathrm{~h}$ shifts. Moreover, physical effort was lower during $12 \mathrm{~h}$ shifts than $8 \mathrm{~h}$ shifts, and sleep was longer before $12 \mathrm{~h}$ D shifts than before $8 \mathrm{~h} \mathrm{M}$ shifts.

In an attempt to find out whether the differences in sleepiness levels (between $8 \mathrm{~h}$ and $12 \mathrm{~h}$ shifts) could be due to the differences in physical effort, we stratified subjects with respect to physical effort and sleep length before the D-shift. The subgroup with the same level of physical effort on $8 \mathrm{~h}$ and $12 \mathrm{~h}$ shifts did not differ with respect to sleepiness either. However, the subgroup that had lower physical effort during $12 \mathrm{~h}$ shifts was also sleepier during these extended shifts. A similar analysis was carried out to evaluate whether sleep length before the D-shift affected shift sleepiness. The group who slept equally long before their D-shifts (either it was $8 \mathrm{~h}$ or $12 \mathrm{~h}$ shifts), were equally alert on the subsequent shift. Subjects sleeping longer before $12 \mathrm{~h} \mathrm{D}$-shifts (compared to $8 \mathrm{~h}$ M-shifts) were also more alert the following shift.

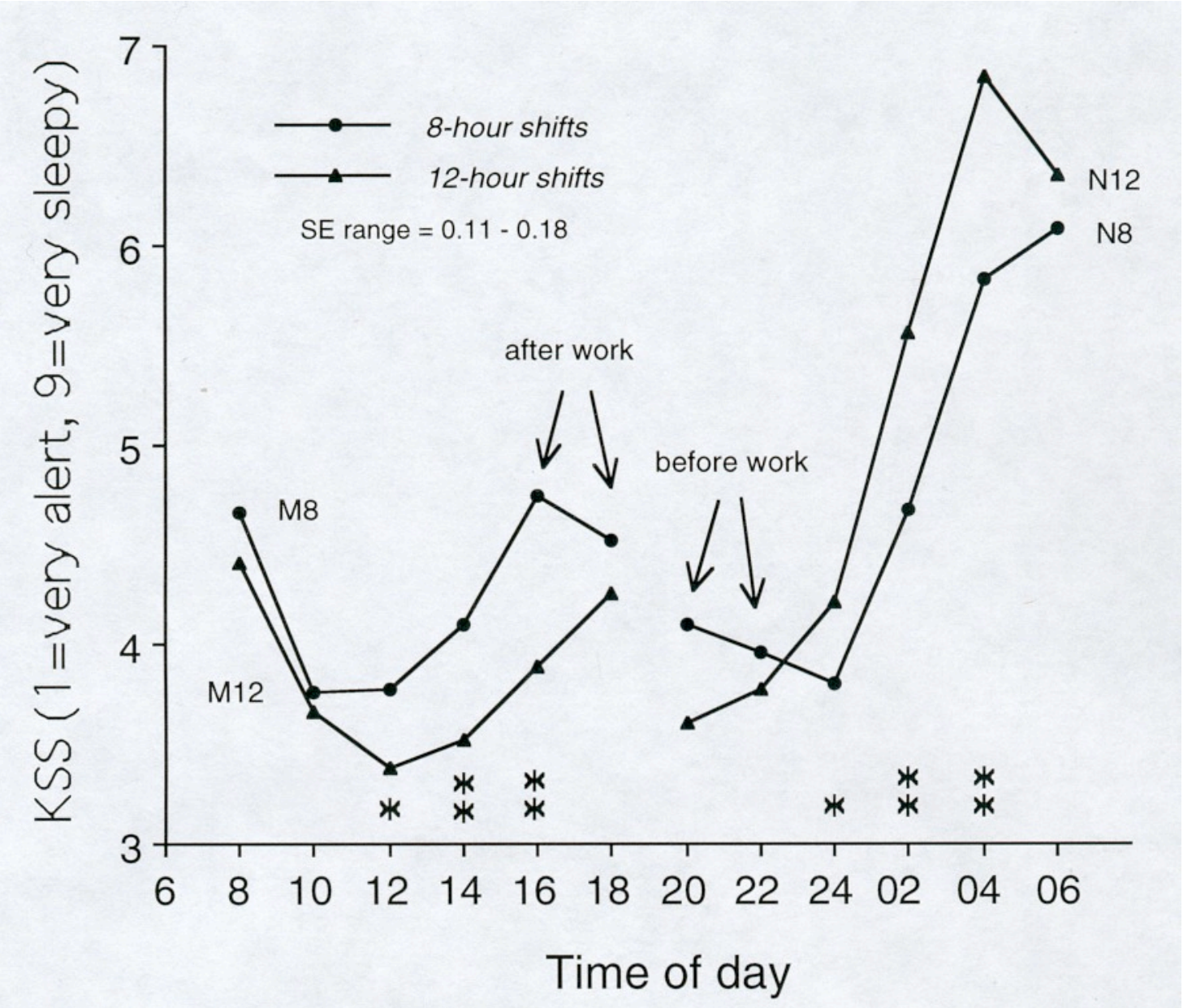

Figure 2. Mean ratings of sleepiness (KSS) every $2^{\text {nd }}$ hour on $8 \mathrm{~h}-\mathrm{M}$-shifts (M8), $12 \mathrm{~h}$ M-shifts (M12), 8h-N-shifts $(8 \mathrm{~N})$, and $12 \mathrm{~h} \mathrm{~N}$-shifts $(12 \mathrm{~N})$. Two ratings after M8 and before $\mathrm{N} 8$ are also plotted. Asterisks indicate significant $\left({ }^{*} \mathrm{p}<.05,{ }^{* *} \mathrm{p}<.01\right)$ pairwise differences between 8 - and $12 \mathrm{~h}$ shifts. 
The apparent negative covariation between sleepiness and physical load was tested with a least square dummy variable regression model. The correlation coefficient for the entire data set was -.34 $(\mathrm{p}=.0001)$.

The only main effect for any performance measure showed that reaction times were slower at the end of shifts compared to the beginning $(p<.05)$. An interaction between "shift type" and "time on shift" showed that performance (both mean reaction times and the $10 \%$ slowest reaction times) declined at the end of $\mathrm{N}$-shifts, while there were almost no difference between the start and the end on M-shifts.

Sleepiness (all ratings from rise time to bed time) was higher during workdays (4.8 \pm .1$)$ than daysoff (4.4 \pm .1$)$, the impact of the entire shift schedule being $4.6 \pm .1$.

\section{Study III - Tolerance to shift work - how does it relate to sleep and wakefulness?}

This study was carried out to evaluate whether satisfaction with ones work hours was related to alterations of the daily patter of sleep, sleepiness and performance. We followed two groups of workers that were either highly satisfied or dissatisfied with their shift schedule, across their entire shift schedule. Thirty-six males and 20 female shift workers were selected according to their satisfaction with their shift schedule. This shift cycle included seven work periods (see below). Each work period consisted of a "triad" of shifts; a N-shift, an A-shift and a M-shift, with only 8-9 hours off (quick returns) between shifts, but followed by a day off. Included days/shifts in the analysis are underlined.

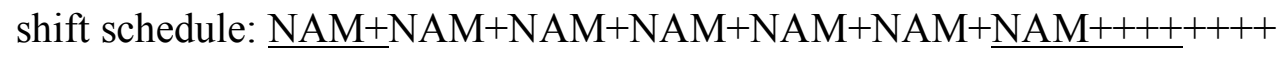

$\mathrm{N}=$ Night shift, $\mathrm{A}=\mathrm{Afternoon}$ shift, $\mathrm{M}=$ Morning shift, $+=$ Day off, underlined=measured days, shift changes were $06: 00 \mathrm{~h}, 14: 00 \mathrm{~h}, 21: 00 \mathrm{~h}$

Sleep length was radically reduced before A-shifts and M-shifts (4.8h and 5.4h, respectively, $\mathrm{p}<.01)$. Sleepiness was increased during all shifts, particularly on $\mathrm{N}$-shifts $(\mathrm{p}<.01)$ compared to days off. Sleepiness did not increase across triads, but was higher the first day off (interaction between work period and day, $\mathrm{p}<.01$ ). There were few significant gender differences.

Dissatisfied shift workers reached much higher levels of sleepiness (see Figure 3, $\mathrm{p}<.01$ ) and reported less sufficient sleep $(\mathrm{p}<.01)$, but not objectively poorer or shorter sleep. Amongst dissatisfied workers, this resulted in an increase of sleepiness problems across shifts within the triad of shifts $(\mathrm{p}<, 01)$.

The mean sleepiness (from rise time to bed time) showed more sleepiness during workdays than

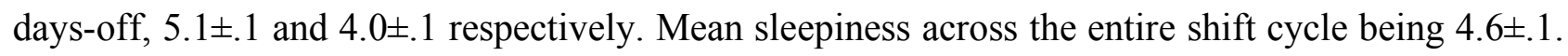
Satisfied shift workers were less sleepy during workdays than dissatisfied shift workers (4.8 \pm .1 vs.

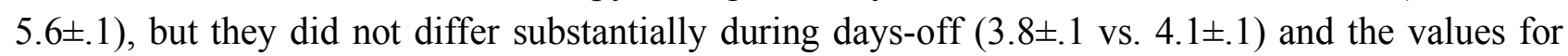


the entire shift periods was $4.3 \pm .1$ vs. $4.9 \pm .1$ for these groups. There were no significant gender differences during workdays (5.3 \pm .1 vs $5.1 \pm .2$ ), days off (both $4.0 \pm .1$ ), or across the entire shift cycle ( $4.7 \pm .1$ vs. $4.5 \pm .1$ for women and men respectively).

\section{Sleepiness}

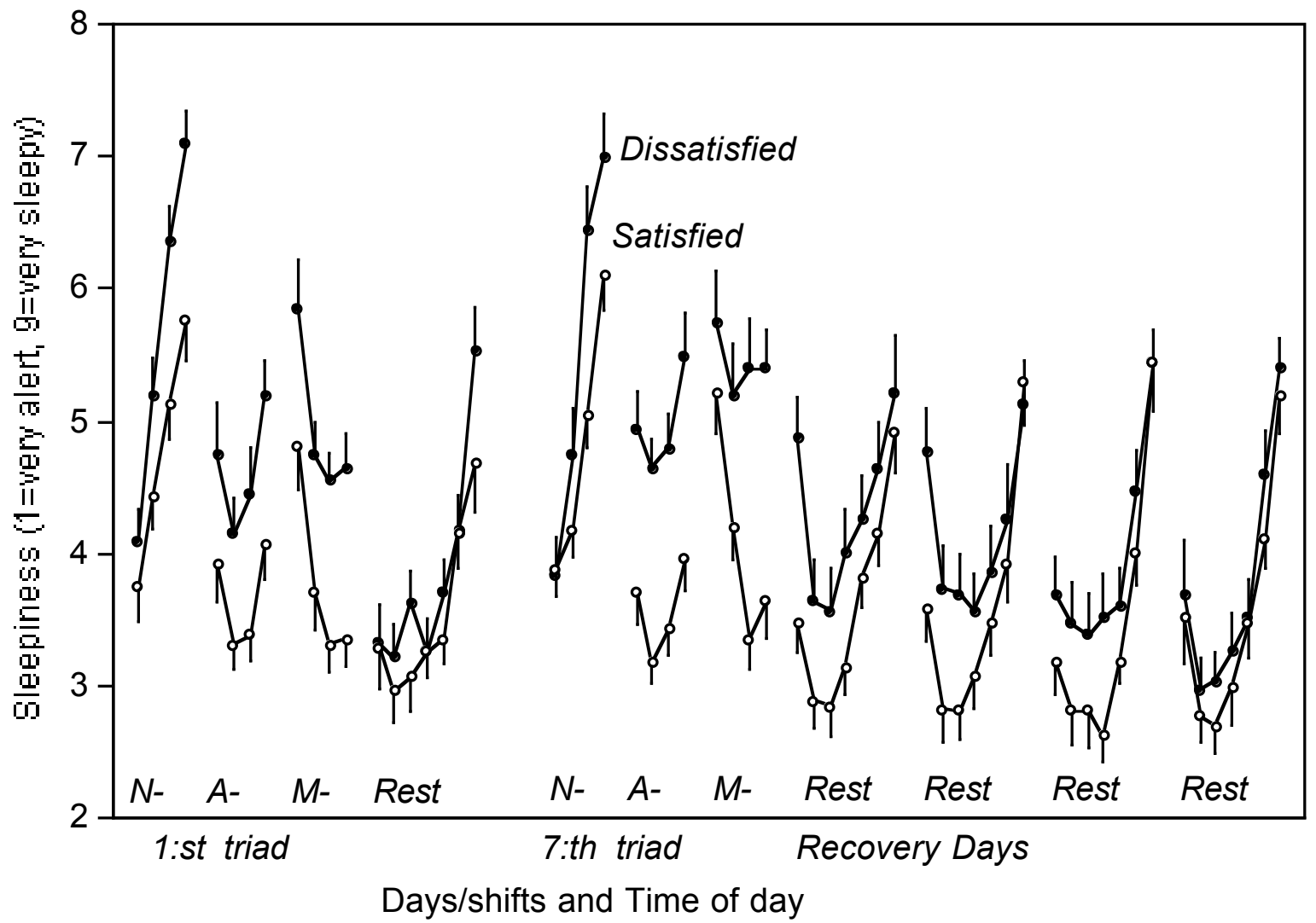

Figure 3. Mean \pm SE of sleepiness for N-, A- and M-shifts and days off during the first and seventh triads (work periods). The first days of the week off are also presented. Satisfied (open circles) and dissatisfied (closed circles) shift workers. The analysis comparing "days off" with work included ratings at 12:00h, 14:00h, 16:00h and 18:00h during days off. The ratings at 10:00h, 20:00h nd 22:00h are also included when only comparing days off are analysed.

\section{Study IV - Hormonal changes in satisfied and dissatisfied shift workers across a shift cycle}

The main purposes of this study were to evaluate whether satisfied and dissatisfied shift workers differ with respect to catabolic and anabolic parameters; whether working an entire shift cycle would be related to these parameters; and whether satisfied and dissatisfied shift workers differed in their responses to working a shift cycle.

Twenty-two satisfied and 20 dissatisfied male shift workers participated in two health examinations. The groups were chosen (from a larger population of 318 full time shift workers who had finished a 
questionnaire) to maximize the difference in satisfaction (with their work hours) between the two groups. Morning blood samples were drawn between 07:00h and 09:00h during the first and the last M-shift of the shift cycle (see below)

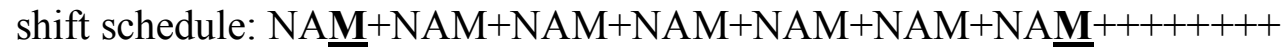

$\mathrm{N}=$ Night shift, $\mathrm{A}=\mathrm{Afternoon}$ shift, $\mathrm{M}=$ Morning shift, +=Day off, underlined= blood samples

Dissatisfied shift workers had lower morning testosterone than satisfied ones $(p<.01)$, but did not significantly differ with respect to cortisol or prolactin. Low testosterone levels were, in addition, associated with a greater sleep need $(p<.01)$, disturbed sleep/wakefulness $(p<.01)$ and an increased need for recovery after the work period $(\mathrm{p}<.001)$, the latter being the best predictor of testosterone levels (see Fig. 5).

The only change across the shift cycle concerned a significant decrease of morning cortisol at the end of the shift cycle $(\mathrm{p}<.05)$. High morning cortisol, itself, was related to having a morning personality $(\mathrm{p}<.01)$ and less sleep problems before the M-shift $(\mathrm{p}<.01)$.

Table 4. Hormone levels for satisfied and dissatisfied shift workers during their first and their last (7th) work period in the shift schedule. Means, standard errors (SE) and results from the analysis of variance (ANOVA).

\begin{tabular}{|c|c|c|c|c|c|c|c|c|}
\hline & \multicolumn{4}{|c|}{ Mean \pm SE } & \multicolumn{4}{|c|}{ F-values } \\
\hline & \multicolumn{2}{|c|}{ satisfied } & \multicolumn{2}{|c|}{ dissatisfied } & \multirow{2}{*}{\multicolumn{2}{|c|}{ Satisfaction }} & \multirow{2}{*}{$\begin{array}{l}\text { Work- } \\
\text { period }\end{array}$} & \multirow{2}{*}{$\mathbf{S} \times \mathbf{W}$} \\
\hline & 1 st & 7 th & 1 st & 7th & & & & \\
\hline \multicolumn{9}{|l|}{ Hormones } \\
\hline Cortisol (nmol/1) & $402 \pm 23$ & $381 \pm 24$ & $389 \pm 23$ & $334 \pm 25$ & 1.0 & & $6.0 *$ & 1.2 \\
\hline Testosterone (nmol/1) & $14 \pm 1$ & $13 \pm 1$ & $10 \pm 1$ & $10 \pm 1$ & 6.9 & $* *$ & 1.0 & 0.0 \\
\hline Prolactine $(\mu \mathrm{g} / \mathrm{l})$ & $5.5 \pm .7$ & $5.2 \pm .6$ & $7.5 \pm .8$ & $6.9 \pm .7$ & 3.7 & $\dagger$ & 1.9 & 0.2 \\
\hline
\end{tabular}

$\mathrm{S} \times \mathrm{W}=$ the interaction between satisfaction and work period. Df ranges between 1/40-41. Significance levels are $*=p<.05, * *=p<.01$. Trends are set as $\dagger=p<.10$. 
testosterone

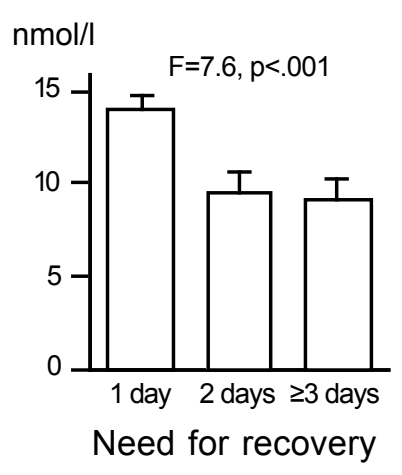

testosterone

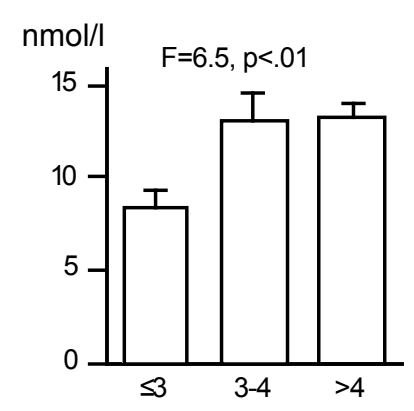

Sleepiness problems cortisol

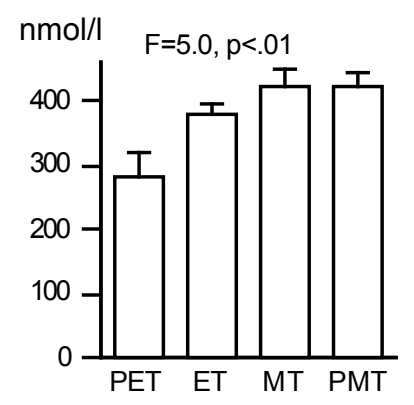

Diurnal type

Figure 4. Left - Morning testosterone levels $(m e a n \pm S E)$ plotted against need for recovery after a work period. Middle - Morning testosterone levels (mean \pm SE) plotted against sleepiness problems (index, scale $1=$ always problems, $5=$ never). Right - Morning cortisol levels (mean \pm SE) plotted against diurnal type (PET=pronounced evening type, ET=evening type, MT=morning type, $\mathrm{PMT}=$ pronounced morning type).

In summary, dissatisfaction with the shift system seems related to lower testosterone levels, which in turn are related to disturbed sleep/wakefulness and increased need for sleep and recovery. Morning cortisol was reduced across a shift cycle. It was suggested that the reduction of cortisol, at the end of the shift cycle, was a result of the increased strain of working an entire shift cycle and/or the possibility that the (shift workers) circadian rhythm were slightly altered. It was also hypothesized that reduced testosterone levels may be part of a mechanism of shift work maladjustment.

\section{Study $V$ - The effects of a short daytime nap after restricted night sleep}

The first aim of this study was to investigate the effects of curtailed sleep on alertness. The second aim was to evaluate whether a short daytime nap could counteract any potential alertness problems caused by curtailed sleep. The restriction of sleep was used to "simulate" the effects of a quick return in a controlled laboratory environment. The experiment involved a cross-over repeated measurements design with three conditions: baseline (BL, habitual night sleep $\approx 7-7.5$ hours), curtailed sleep (CS, 4hours of night sleep) and nap (NAP, 4 hours of night sleep + a daytime nap).

All sleep took place in the subjects own homes (BL approximately between 23-07, CS and NAP conditions approximately 24-04). The following day was spent in the sleep laboratory between 0816 with the same protocol for all conditions, with the exception of the nap (scheduled between $10: 45 \mathrm{~h}-11: 15 \mathrm{~h})$ in the NAP condition.

The eight participants were male students or employees at our institute and were instructed to avoid caffeine after rising. They were also instructed to spend their wake time reading or in other sedentary activities after awakening and before travelling to the laboratory. 
The subjects arrived at 08:00h for instructions and application of electrodes. The experiment started at 09:00h with a 10 minute standardized objective sleepiness test - the Karolinska Drowsiness Test (KDT). A test battery of 45 minutes (including a 10-min reaction time test and a 28 -min vigilance task) were performed at 09:45h, 11:45h and 15:00h during each condition. Sleepiness ratings (KSS) were obtained every hour and before and after each test from awakening until the test session ended at $16: 00 \mathrm{~h}$.

The restrictions of sleep increased subjective and objective (EEG/EOG) sleepiness during tests. Also vigilance performance deteriorated with shorter sleep compared to normal sleep. All subjects fell asleep during the scheduled nap (mean sleep length $=19.8 \pm 2.4 \mathrm{~min}$ ), which restored performance back to baseline levels. The nap reduced subjective sleepiness in the laboratory, but neither a nap nor curtailed sleep affected sleepiness outside the laboratory.

Mean sleepiness $(07.00 \mathrm{~h}$ to bed time) differed between conditions, baseline $(6.7 \pm .2 \mathrm{~h}$ sleep $)=$ $4.7 \pm .1$; short sleep $(3.7 \pm .1 \mathrm{~h}$ sleep $)=5.6 \pm .2$; and for short sleep and a nap $(3.7 \pm .1 \mathrm{~h}$ in bed $+\mathrm{a}$ $20 \pm 2 \mathrm{~min}$ sleep during the nap) $=5.1 \pm .2$ (the subjects were in the laboratory from $08.00 \mathrm{~h}$ to $16.00 \mathrm{~h}$, no sleepiness ratings preceded by performance tests were included).

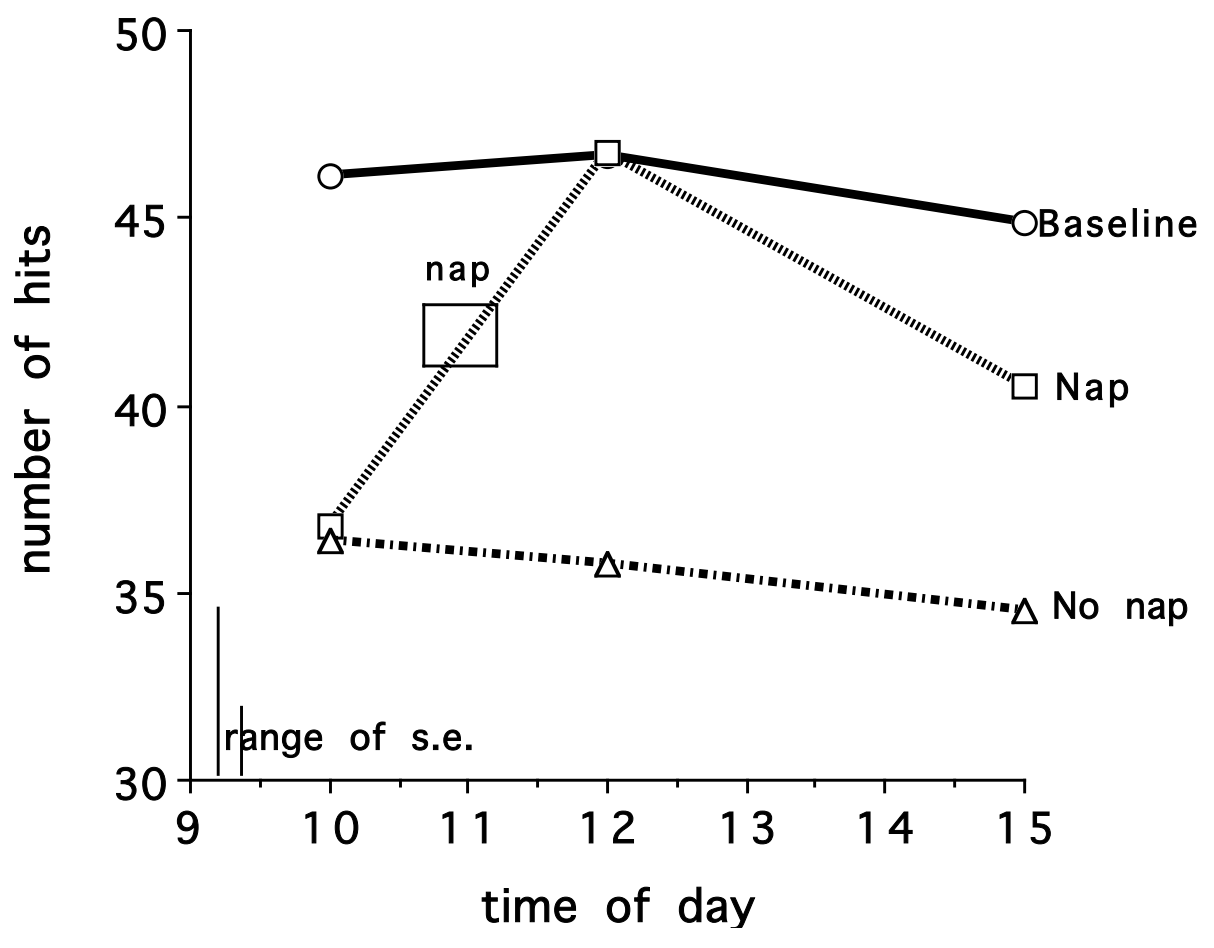

Figure 5. The number of hits (mean $\pm \mathrm{SE}$ ) on the vigilance task (mean of 8 subjects). The range of the SE (the largest and the smallest SE) is shown to the left. 


\section{DISCUSSION}

"If you can't convince them, confuse them"

Harry S Truman

The discussion will firstly summarize our main findings of shift work on the whole, of long shifts, short recovery periods, individual differences in tolerance and whether the total burden of different schedules are reflected in sleepiness ratings. Each issue will also be subjected to a more thorough discussion in the light of earlier research. This is followed by a more detailed discussion of the limitations of the present thesis, a concluding discussion of our findings and the conclusions.

\section{Night- and morning shifts}

Our data (study I-III) confirm the literature that $\mathrm{N}$ - and M-shifts disturb sleep and increase sleepiness (Kecklund and Åkerstedt, 1995; Tilley et al., 1982; Åkerstedt, 1988, 1998). Sleepiness was worst during N-shifts, while sleep seemed equally curtailed by $\mathrm{N}$ - and M-shifts. However, neither N-shifts nor M-shifts reduced the quality of sleep, even though these shifts affected sufficiency of sleep and easiness to rise after sleep. Our findings also support the notion that no shift type is characterised by poor performance in general. Instead, performance was generally good at the beginning of shifts (with the exception of M-shifts) and deteriorated across N-shifts. This is in line with several studies showing a deteriorating performance at the end of the night (Monk and Folkard, 1985).

\section{Long shifts}

This chapter will go through the relation of long M- and N-shifts (12h) with sleep, sleepiness and performance and relate our findings to earlier research. This is followed by a discussion of why $12 \mathrm{~h}$ shifts fail to induce substantially more problems in our studies.

To start, none of our studies could support that extended shifts cause problems with sleep, sleepiness or performance (see figure 6-8). In general, this is in line with the majority of the literature (Peacock et al., 1983; Smith et al., 1998a; Tucker et al., 1996; Williamson et al., 1994). On the contrary, but still in concordance with some findings, both of our studies showed workers to be more alert during 12h M-shifts compared to 8h M-shifts, (Tucker et al., 1996; Tucker et al., 1998a; Williamson et al., 1994) (See figure 6). In study II, this improvement was probably due to longer and better sleep, particularly before the third, and last, 12h M-shift, which started one hour later (Sunday morning). Here, the difference in sleepiness between $12 \mathrm{~h}$ and $8 \mathrm{~h} \mathrm{M}$-shifts disappeared when comparing subjects with similar sleep duration.

In addition, subjects sleeping longer before $12 \mathrm{~h}$ M-shifts were also more alert. The sleepiness problems with $8 \mathrm{~h} \mathrm{M}$-shifts in study I were most likely due to the fact that the sequence of $8 \mathrm{~h} \mathrm{M}$ - 
shifts were preceded by two A-shifts and a quick return (short rest) while the $12 \mathrm{~h} \mathrm{M}$-shift sequence was preceded by 4 days off. This suggests that sleep length and being fully recuperated before starting a sequence of M-shifts are important factors. Both variables seemed more important for shift sleepiness than the length of shifts.

Our results also add to the bulk of data showing that sleepiness on M-shifts is largely dependent on its starting time (Folkard and Barton, 1993), supporting the opinion that M-shifts should not start before $07.00 \mathrm{~h}$.

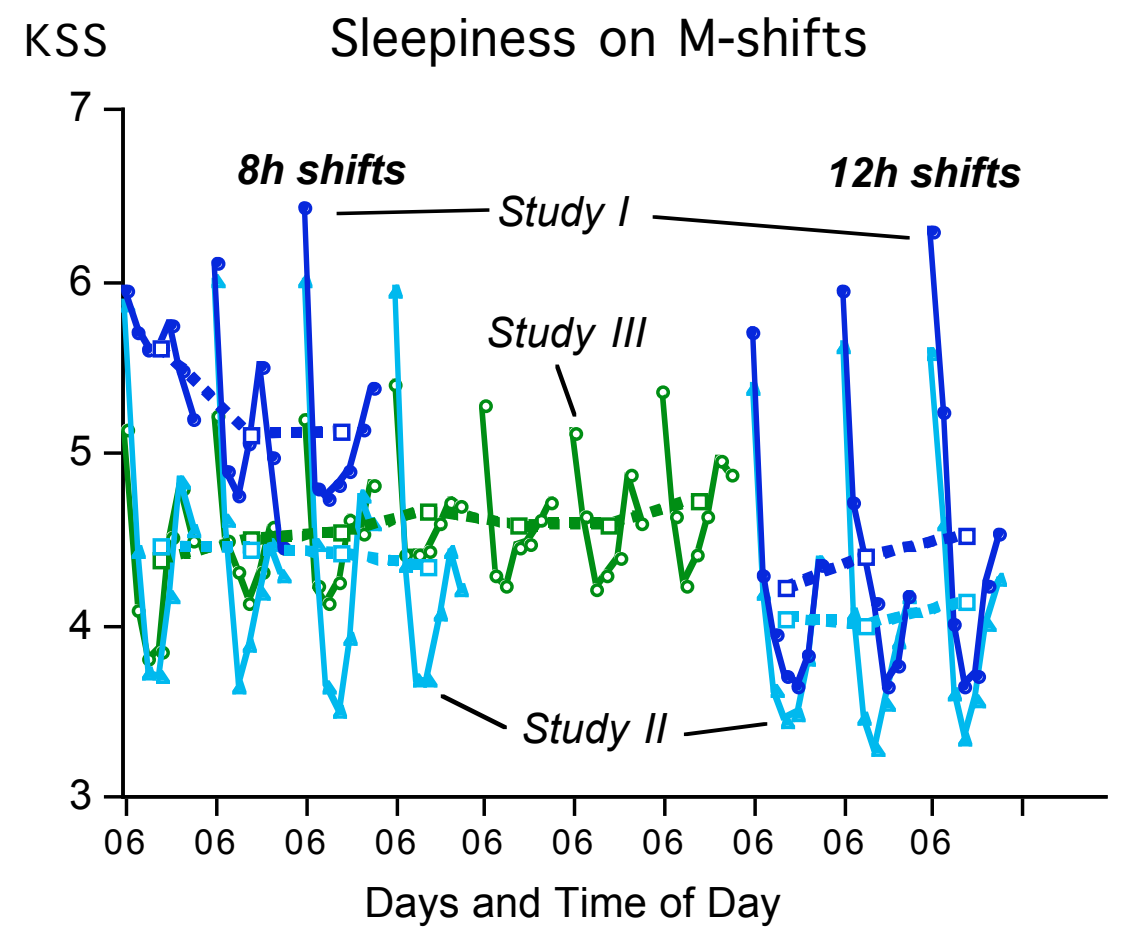

Figure 6. Mean sleepiness on M-shifts on the 3 different schedules (ratings on the KSS, 1=very alert, 9=very sleepy, $08.00 \mathrm{~h}$ to $18.00 \mathrm{~h}$ ); dark blue (black) lines with filled circles = study I; light blue (grey) lines with triangles = Study II; green (grey) lines with open circles = study III (only $8 \mathrm{~h}$ shifts). The Dotted lines with open squares shows the mean level across the sequences of shifts (with exception of study III, which shows all non sequential 7 shifts across the shift cycle).

The only negative effect for extended shifts concerned more sleepiness during $12 \mathrm{~h} \mathrm{~N}$-shifts in study II (see figure 7). However, this effect was moderate and probably related to less physical effort during the weekend when $12 \mathrm{~h} \mathrm{~N}$-shifts were carried out (the workers reported lower work demands/pace during the weekend - $12 \mathrm{~h}$ shifts were carried out Fri-Sun, $8 \mathrm{~h}$ shifts Mon-Thu). Dichotomising the group with respect to physical effort showed that low effort was related to more sleepiness during N-shifts. This supports the notion that control room work is sedentary and that such tasks ideally are carried out with a moderate work demand/pace (to maintain alertness). Our findings are in line with experimental studies showing that highly sedentary tasks (monitoring screens) are very demanding and are more affected by time on task than by time of day (Colquhoun et al., 1975). Against our expectations, workers were more alert during $12 \mathrm{~h} \mathrm{~N}$-shifts compared to $8 \mathrm{~h}$ $\mathrm{N}$-shifts in study I. It was difficult to explain why, but may be due to the fact that the workers had 
better sleep quality in connection with $12 \mathrm{~h} \mathrm{~N}$-shifts. Another explanation may be more recovery days in the $12 \mathrm{~h}$ shift system.

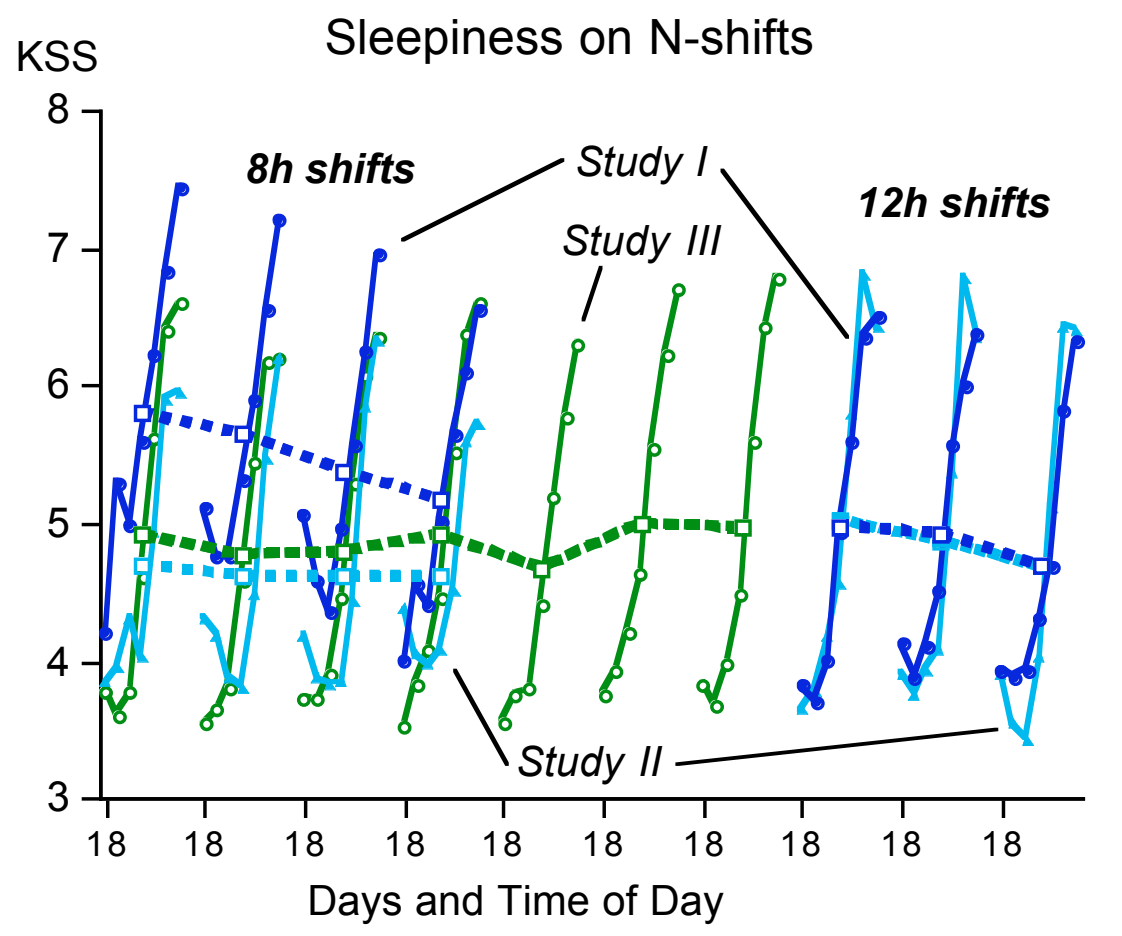

Figure 7. Mean sleepiness on N-shifts on the 3 different schedules (ratings on the KSS, 1=very alert, $9=$ very sleepy, $18.00 \mathrm{~h}$ to $06.00 \mathrm{~h}$ ); dark blue (black) lines with filled circles = study I; light blue (grey) lines with triangles = Study II; green (grey) lines with open circles $=$ study III (only $8 \mathrm{~h}$ shifts). Dotted lines with open squares show the mean level across the sequences of shifts (with exception of study III, which shows all non sequential 7 shifts across the shift cycle).

As most sleepiness problems occur during the latter part of the $\mathrm{N}$-shift, and therefore may be particularly vulnerable to extended hours (Hamelin, 1987; Hänecke et al., 1998), an additional figure comparing the last $4 \mathrm{~h}$ of the $\mathrm{N}$-shifts (ratings from $02.00 \mathrm{~h}$ to $06.00 \mathrm{~h}$ ) from all shift sequences were made (see figure 8). This figure is not a formal statistical analysis, but merely a crude illustration of the development of sleepiness in relation to timing and length of shifts. It was, again, signs of sleepiness to be worst on $8 \mathrm{~h} \mathrm{~N}$-shifts in study I, while least sleepiness seemed to occur during $8 \mathrm{~h} \mathrm{~N}$-shifts in study II, and the two $12 \mathrm{~h} \mathrm{~N}$-shifts were somewhere in between. It should be noted that sleepiness, on group levels, were below 7 on the KSS and no shift sequence, perhaps with the exception of $8 \mathrm{~h} \mathrm{~N}$-shifts in study I, induced severe sleepiness with direct practical consequences (i.e. for accident risk). Taken together, it appears that $12 \mathrm{~h}$ shifts are not inducing substantially more sleepiness at the end of shifts compared to $8 \mathrm{~h}$ shifts. This contrasts to some findings (Ellingstad and Heimstra, 1970; Grandjean et al., 1971; Hamelin, 1987; Hänecke et al., 1998; Kecklund and Åkerstedt, 1993; Volle et al., 1979), but supports others (Fields and Loveridge, 1988; Gillespie and Curzio, 1996; Peacock et al., 1983; Tucker et al., 1996; Tucker et al., 1998b; Washburn, 1991). It is suggested that a main difference between studies may depend on the nature of the work tasks. 


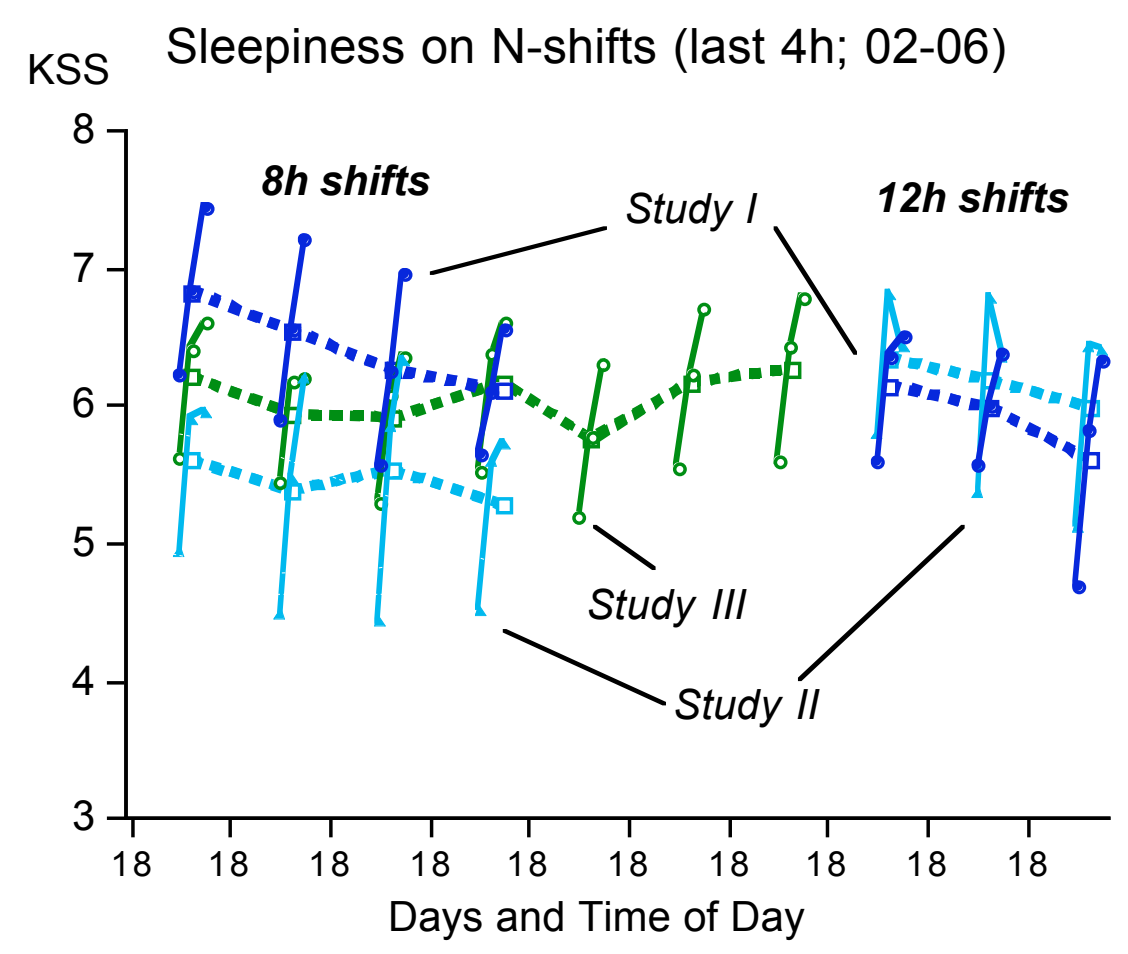

Figure 8. Mean sleepiness on the last $4 \mathrm{~h}$ of N-shifts on the 3 different schedules (ratings on the KSS, $1=$ very alert, 9=very sleepy, 02.00 to $06.00 \mathrm{~h}$ ); dark blue (black) lines with filled circles $=$ study I; light blue (grey) lines with triangles = Study II; green (grey) lines with open circles $=$ study III (only 8h shifts). Dotted lines with open squares shows the mean level across the sequences of shifts (with exception of study III, which shows all non sequential 7 shifts across the shift cycle).

The attempt to integrate all ratings of sleepiness across the entire shift cycle supported that there were small differences between $8 \mathrm{~h}$ and $12 \mathrm{~h}$ shifts systems on the whole (see the section "comparing different shift schedules").

The measurement of performance tests at the work site is rather rare in the literature. In study I-III, well-established and validated reaction time and vigilance tasks were performed at the beginning and at the end of shifts. The lack of performance differences between $8 \mathrm{~h}$ and $12 \mathrm{~h}$ shifts supports some findings (Peacock et al., 1983), but not others (Macdonald and Bendak, 2000; Rosa and Bonnet, 1993; Todd et al., 1989; Volle et al., 1979). Our negative findings have three possible explanations: a lack of effect of extended shifts, insufficient sensitivity of the designs to find such differences or "confounding". It is possible that the tests were performed at "incorrect" times (the beginning and the end of shifts), or the amount of testing may have been too infrequent (twice per shift). Another problem, as in all field studies, is the lack of control over contextual factors that may help the worker to counteract possible sleepiness (Kjellberg, 1977b). However, even if we could not control for lack of compliance, the workers were carefully instructed to sit down in a calm environment when carrying out the tests. Reaction time tests are very sensitive to sleep loss and circadian effects in experimental settings as well as in field studies (Blake, 1967; Dinges and Kribbs, 1991; Kjellberg, 1977d). We also found the expected slowing at the end of N-shifts supporting earlier research (Monk and Folkard, 1985) - suggesting an adequate sensitivity. Still, the tests may have been too short (a duration of 10 minutes) to find more subtle effects, but this is less likely as other studies have found effects from shorter reaction time tests (i.e. 3-5min) (Lamond and 
Dawson, 1999), however testing during the beginning and the end of a shift may be misleading, particularly as the timing of the tests are not the same in $8 \mathrm{~h}$ and $12 \mathrm{~h}$ shifts. On the other hand, the decision to test only at these times was intentional, as more frequent testing would have interfered too much with work tasks and increased the amount of missing data. Taken together, we found no support for $12 \mathrm{~h}$ shifts affecting performance.

To some degree our data contradict studies suggesting that the problems with extended working hours are related to shortened or disturbed sleep (Sasaki et al., 1999; van der Hulst, 2003) (both being related to overtime), but support studies showing improved sleep in $12 \mathrm{~h}$ shift systems (Peacock et al., 1983; Tucker et al., 1996; Williamson et al., 1994). There were few signs of any accumulations of problems across the sequence of extended shifts, which contrasts to some earlier studies (Colquhoun et al., 1969; Volle et al., 1979), but confirms that daily recovery was, on the whole, sufficient in the present studies (study I and II). A possible explanation for the difference between our data and earlier studies might be that our workers carried out tests during work hours, while other participants were tested before and after work (Volle et al., 1979) or in experimental settings (Colquhoun et al., 1969), and it is possible that their study protocols, themselves, induce fatigue.

Our results suggest that the main reasons for possible problems with $12 \mathrm{~h}$ shifts (besides the well known circadian influences on all odd working hours) are related to the amount of sleep and time on task effects. Longer sleep seems to increase subsequent on-shift alertness and the degree of physical activity should not be too low, at least when tasks are sedentary as in the case of some power plant workers (the participants were control room operators, shift engineers, machinists and shift supervisors). It has earlier been shown that "work load" is a mediating factor for developing problems with fatigue, sleepiness and performance. Macdonald (Macdonald and Bendak, 2000) found no differences between 8 - and $12 \mathrm{~h}$ - shifts with low work load, but $12 \mathrm{~h}$ shifts became noticeably problematic with increasing work load, while $8 \mathrm{~h}$ shifts were largely unaffected. Knauth also recommended that $12 \mathrm{~h}$ shifts should only be used for tasks with light work load (Knauth, 1993). However, work tasks that contain strong time on task effects - whether through being sedentary, monotonous, or physically heavy - are obviously more problematic to carry out during 12 consecutive hours than 8 consecutive hours, and it has earlier been recommended to avoid extended shifts if work tasks are physically heavy or highly monotonous (Knauth, 1993; Tepas, 1985). These recommendations are mainly based on risks related to the transport sector and findings of sedentary tasks in experimental findings. Our data support that lower physical effort is related to increased sleepiness in relation to extended shifts in other occupational settings. Moreover, other adverse work environment factors such as noise, exposure to toxic substances etc. may have exaggerated effects if exposure is increased to $12 \mathrm{~h}$ rather than $8 \mathrm{~h}$ at a time.

Perhaps the main question concerns why $12 \mathrm{~h}$ shifts failed to induce substantially more problems with sleep and sleepiness. With respect to sleep and time awake, our data suggest that the workers do not need to change their sleep/wake patterns significantly when working extended shifts. The few existing differences were in favour of $12 \mathrm{~h}$ shifts. The findings of increased sleep duration may have been a result of a greater need for sleep and/or changed priorities in relation to working extended shifts (it may be easier to motivate longer sleep when working fewer shifts). The finding 
that workers slept longer prior to and during the sequence with $12 \mathrm{~h}$ shifts (in study II) suggests changed priorities in favour of extended shifts. Another explanation for better recovery in relation to weekend sleeps (when the $12 \mathrm{~h}$ shifts were carried out) may be less environmental (noise, etc) and psychosocial (stress, mood, etc) disturbances, shorter commuting times (no rush hour) and/or an additional day off (4 days instead of 3). In addition, it has been suggested that a major drawback with extending shifts is the decreased possibility to carry out naps. We could confirm that the number of naps decreased, but, still, $25 \%$ and $46 \%$ managed to nap before or on $12 \mathrm{~h} \mathrm{~N}$-shifts, in study I and II respectively; and it has even been reported that the frequency of naps increase in relation to $12 \mathrm{~h} \mathrm{~N}$-shifts (53\% vs. 15\% during $8 \mathrm{~h} \mathrm{~N}$-shifts) (Rosa and Bonnet, 1993). Taken together, $12 \mathrm{~h}$ shifts did not affect sleep negatively, the only support was for the opposite.

A summary of our data suggest that extended shifts, at least in the form of scheduled $12 \mathrm{~h}$ shifts, do not need to compromise sleep and sleepiness as long as other working conditions are acceptable. An important finding is that it is possible to sleep at least equally long in relation to extended shifts. This may, or may not, counteract the increased demand for recovery acutely, but is likely to be sufficient for most workers when combined with the extra days-off,

\section{Short recovery periods}

The discussion will firstly go through the effects of different recovery times $(8 \mathrm{~h}, 9 \mathrm{~h}, 12 \mathrm{~h}, 16 \mathrm{~h}$ and in some cases $+24 \mathrm{~h}$ ), sleep and sleepiness with respect to shift type. This is followed by an illustration of the relationship between recovery time and sleep - on a general level - and how the priority for sleep changes when recovery time is limited. The discussion on short recovery periods is mainly focused on the effects of quick returns, even though longer recovery times of $12 \mathrm{~h}, 16 \mathrm{~h}$ and, in some cases, also $+24 \mathrm{~h}$ of recovery between shifts are included.

As mentioned in the previous section, there were no signs of worse or shorter sleep when free time (time off/recovery times) was shortened from $16 \mathrm{~h}$ to $12 \mathrm{~h}$ (see fig 9). However, quick returns (only $8 \mathrm{~h}$ of free time) curtailed sleep by approximately $1 \mathrm{~h}$ (to between $4-5 \mathrm{~h}$ of sleep), with the exception of the quick return with $9 \mathrm{~h}$ of recovery time (between A- and M-shifts in study III). The latter resulted in a little more than $5 \mathrm{~h}$ of sleep, which is equal to sleep obtained before other M-shifts (preceded by longer periods of free time). It could, hence, be argued that $9 \mathrm{~h}$ of free time is sufficient before M-shifts. However, it could also be expected that it was the workers sleep debt, from the previous quick return (before the A-shift), that made workers prioritising more sleep on the $9 \mathrm{~h}$ quick return than otherwise. That this sleep was still insufficient to give full recovery was also supported by the fact that sleepiness on the subsequent M-shift was worse than on M-shifts preceded by longer recovery periods (see figure 10 and the following section).

Sleepiness related to the amount of preceding recovery time is presented in fig 10 . The figure illustrates that three M-shifts was particularly affected by sleepiness, both M-shifts preceded by a quick return, but also M-shifts preceded by $16 \mathrm{~h}$ of recovery time in study I. The quick return in study III was not as affected as the quick return in study I, but that was probably due to the fact that these subjects managed $1 \mathrm{~h}$ longer sleep (the quick return was $9 \mathrm{~h}$ instead of $8 \mathrm{~h}$ ). However, sleepiness was not close to becoming as severe as during N-shifts - and it could be debatable 
whether performance or wellbeing are affected. On the other hand, the finding that a quick return preceding a sequence of M-shifts still had effects on the third (and last) M-shift confirms that quick returns have substantial effects. In addition, it also indicates that it is difficult to recover when working M-shifts. On the whole, quick returns resulted in augmented M-shift sleepiness, while longer recovery times - whether in the form of $12 \mathrm{~h}, 16 \mathrm{~h}$ or longer free time - seemed to have less impact. It is therefore recommended to avoid quick returns before M-shifts, particularly if they precede a sequence of M-shifts.

TST and TIB according to time off before:

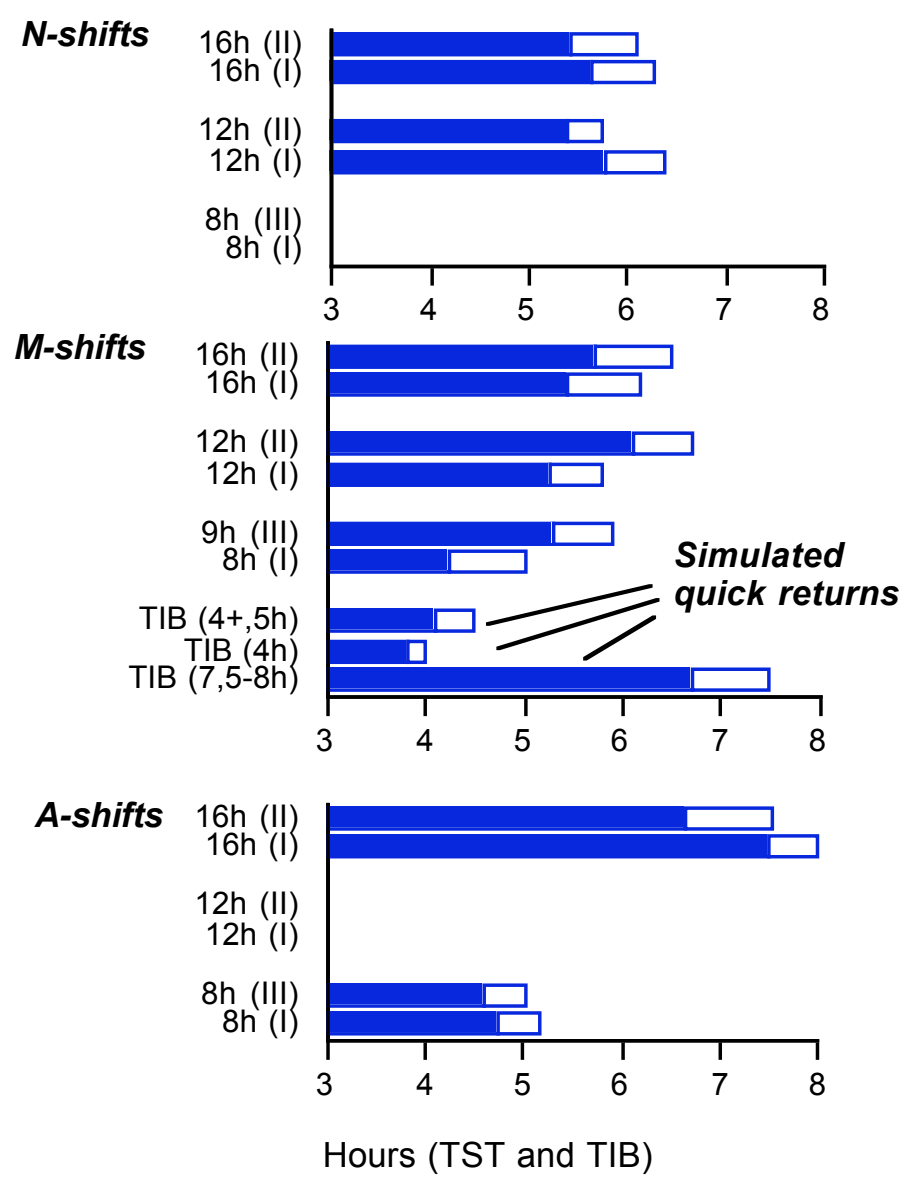

Figure 9 illustrates the relation between sleep duration and previous free time before the different shifts. Filled bar = Total sleep time (TIB - sleep latency and time awake during the sleep period); open bar = sleep latency and time awake during sleep. Study I and III used actigraphy data, while study II and V are based on sleep diaries. This was possible since the deviation of sleep timing between actigraphy and diaries was less than 15 minutes in study I and III, and similar deviations were approximated for study II and V. A ratio between sleep diary ratings of latency + time awake and actigraphy sleep efficiency was calculated for study I and III (no significant difference between them) and applied for study II and V.

With respect to quick returns before A-shifts, our data support the notion that sleep is curtailed to just about 5h of sleep, which confirms earlier studies (Saito and Kogi, 1978; Totterdell and Folkard, 1990; Tucker et al., 2000). As in the case with M-shifts, quick returns resulted in a similar increase 
of A-shift sleepiness, even though it was less pronounced. Notably, the quick return had more effect on sleepiness in study I than study III. The literature has also shown inconsistent findings. Saitos preliminary data (Saito and Kogi, 1978) found strong effects while other two found no or minute effects on subsequent sleepiness/fatigue (Totterdell and Folkard, 1990; Tucker et al., 2000). This seems surprising as sleep length was similarly affected most studies. A potential mechanism may be the amount of preceding shifts and sleep debt. The A-shift in study I was preceded by $4 \mathrm{~N}$-shifts, while (the less affected) A-shift in study II was preceded by one N-shift. Another possible explanation is that sleepiness is worse, but still reasonable compared to N-shift sleepiness, and therefore differently interpreted by shift workers as well as researchers. A third explanation may be the nature of the studies; the studies with no or minute effects are survey studies.

\section{Sleepiness with respect to preceeding recovery time KSS}

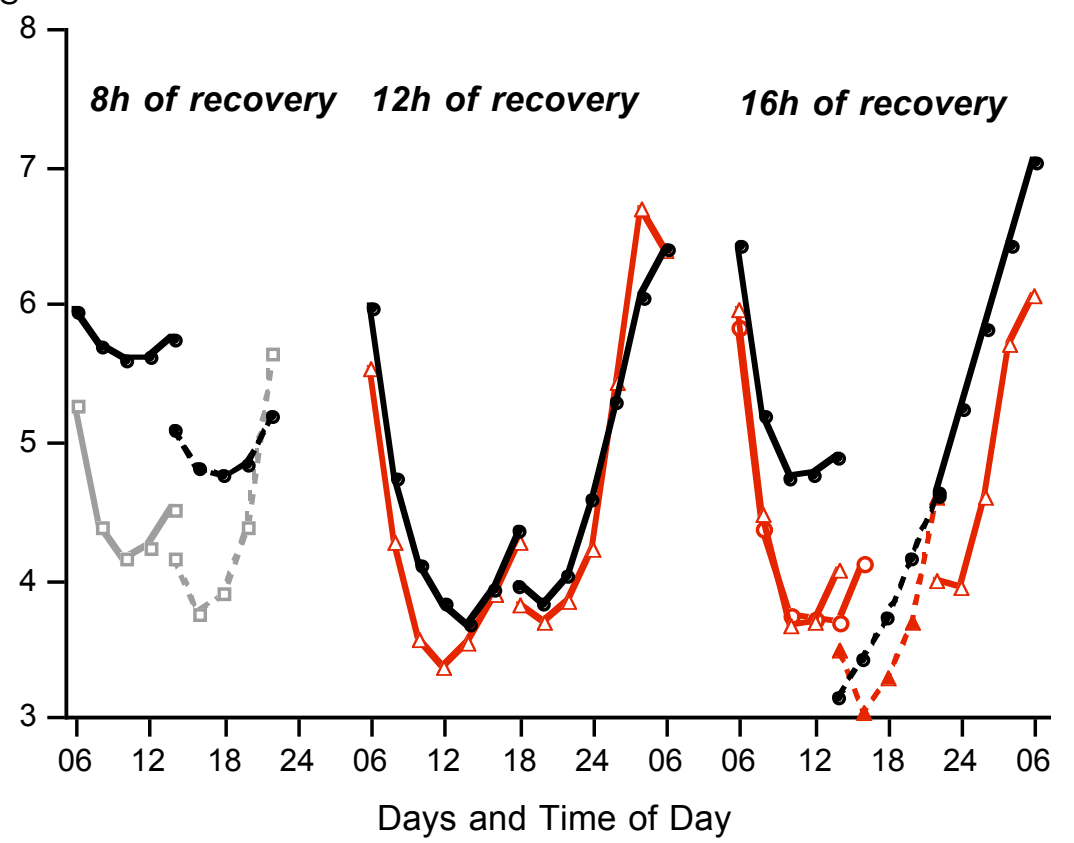

Figure 10. Mean sleepiness (KSS, $1=$ very alert, 9=very sleepy) on shifts with respect to prior recovery times $(8 \mathrm{~h}, 12 \mathrm{~h}$ and $16 \mathrm{~h})$. Black lines and filled circles $=$ study 1 ; red (grey) lines with open triangles/circles $=$ study 2 ; light grey lines with open squares $=$ study 3 (only to the far left in the figure); dotted lines $=$ A-shifts. The figure illustrates that preceding recovery time becomes more important when recovery times are below $12 \mathrm{~h}$ of recovery.

No N-shifts were preceded by quick returns, but the section of extended shifts (earlier) showed that whether the N-shift was preceded by $12 \mathrm{~h}$ or more was of little importance for sleep or shift alertness. The literature suggests that having a quick return during the day (between $\mathrm{M}-$ and Nshifts) results in severe shortenings of sleep (Knauth et al., 1983; Kurumatani et al., 1994) to between 2-4h. However, that sleep between $\mathrm{M}$ - and $\mathrm{N}$-shifts are drastically shortened should be seen with respect to a minimal need for sleep at this time (they have slept prior the M-shift). Instead, the major problem are those who do not manage a profylactic nap before the subsequent Nshift (Knauth and Rutenfranz, 1982), and, thus, increasing time without sleep to the near extreme. The workers are then continuously awake for more than 24 hours, of which $16 \mathrm{~h}$ is work. There is a clear need to evaluate the consequences of not having a nap in between these shifts. 
Our findings are partly contradicted by a recent study on railway workers (Härmä et al., 2002; Sallinen et al., 2003). This study focused on how irregular systems affect sleep/wake rhythms and on factors associated with the risk for severe sleepiness on subsequent shifts. This study found similar relationships between recovery time and sleep duration (Sallinen et al., 2003), even though sleep curtailments only had limited effects on subsequent sleepiness (Härmä et al., 2002). Having less than $8 \mathrm{~h}$ of free time only tended to be associated with increased risk for severe sleepiness when compared with the longest analysed free time before the shift ( $\geq 16 \mathrm{~h}$ of free time). Yet, sleep length was clearly associated with the risk for subsequent severe sleepiness, each hour decreased the risk with 15\% (Härmä et al., 2002). Hence, they found similar links as our studies (between, recovery time, time of day, sleep duration and sleepiness), even though their data supported that severe sleepiness was mainly a result of the start time of the rest period, not to the amount of recovery time (Härmä et al., 2002), which is somewhat contradictory as sleep duration was related to subsequent sleepiness.

The different findings may be explained by several factors. For instance, the studies were made on different occupational groups and with different quick returns - their studies included recovery times before $\mathrm{M}$ - and $\mathrm{N}$-shifts in an irregular shift system, while our studies included short recovery times before M- and A-shifts in a regular shift system. Short recovery periods before N-shifts are special in the sense that they include both the sleep prior to the M-shift and a daytime nap between the M- and N-shift. It is likely that having a nap or not, before the N-shift, is far more important than small differences in sleep duration on the prior sleep or the nap itself. Moreover, our studies evaluated the mean sleepiness across shifts and days and not the occurrence of severe sleepiness, although all studies used the KSS to measure sleepiness. In addition, the Finnish study included more subjects in their analyses even though they only included one quick return. That short recovery periods shorten sleep has been shown in other recent studies (Cruz et al., 2003; Roach et al., 2003), the latter supporting that the relationship between recovery time and sleep duration is affected by time of day. Unfortunately, no sleepiness ratings were reported in these studies.

Several studies have shown a clear relationship between recovery time and sleep duration (Kurumatani et al., 1994; Sallinen et al., 2003), the relationship being particularly strong in one study $(r=.95)$ (Kurumatani et al., 1994). Our data support a strong relation too, even if the relation was weaker ( (logarithmic regression $\mathrm{r}=.71, \mathrm{r} 2=.51, \mathrm{t}=3.5, \mathrm{p}<.005$; see fig $11 \mathrm{a})$, the main reasons for the differences are that time of day has a strong influence on sleep times (sleep during the day is severely curtailed) and the fact that Kurumatani included more than one sleep episode when recovery time exceeded $24 \mathrm{~h}$. The main purpose of fig $11 \mathrm{a}$ is to illustrate that sleep duration is most effected by free times shorter than $12 \mathrm{~h}$, and that sleep duration is not prolonged despite lengthening free time from 12 to $16 \mathrm{~h}$ between continuous $\mathrm{N}$-and M-shifts (sleep is here more dependent on time of day). Hence, it doesn't seem to matter whether recovery time is $12 \mathrm{~h}$ or $16 \mathrm{~h}$ before N- and Mshifts. On the other hand, short recovery periods seem to have similar strong limitations on sleep duration independently of time of day, while longer free times only results in longer sleep before Ashifts. It is only between continuous A-shifts that sleep duration exceed 5.5-7h in bed. Taken together, recovery time is a strong terminator of sleep duration, particularly for recovery periods shorter than $12 \mathrm{~h}$. 
Two additional regressions were carried out to illustrate how recovery time is related to the $\%$ of free time spent in bed and asleep, for TIB $(\mathrm{R}=.88, \mathrm{R} 2=.78, \mathrm{t}=-6.5, \mathrm{p}<.0001)$ and TST $(\mathrm{R}=.90$, $\mathrm{R} 2=.80, \mathrm{t}=-7.0, \mathrm{p}<, 0001$ ), see fig $11 \mathrm{~b}$. The main information from this figure is that it is, on the whole, difficult to obtain more than $60 \%$ sleep out of any period of free time. The "actual sleep/free time-ratio" is $60 \%$ when having $8 \mathrm{~h}$ of recovery time, this is lowered to about $50 \%$ and $40 \%$ when recovery time is $12 \mathrm{~h}$ and $16 \mathrm{~h}$, respectively. The implication being that the shorter the free time, the more sleep is prioritised. However, while sleep duration is relatively more enhanced with shorter recovery time, the time for other social tasks/responsibilities is similarly reduced. This will inevitably lead to conflicts for those with significant social responsibilities. For instance, having young children reduces time for sleep even more (Kurumatani et al., 1994). Another important message is that, an extra hour of free time does not equal $1 \mathrm{~h}$ longer sleep.

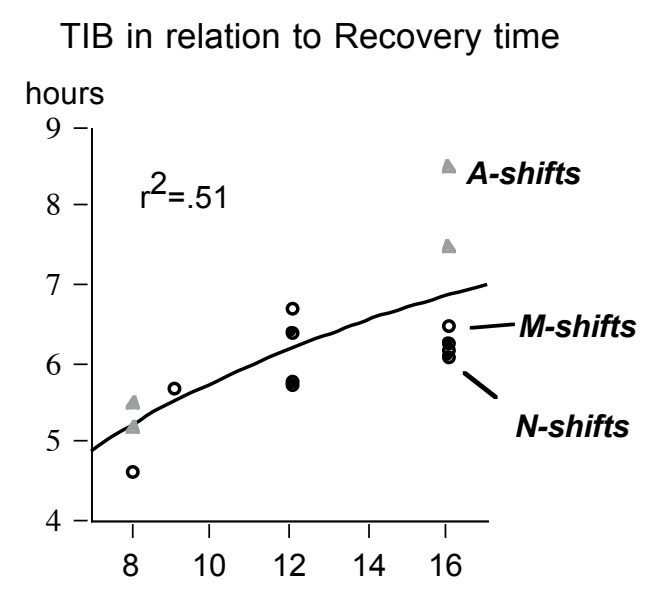

Recovery time between shifts

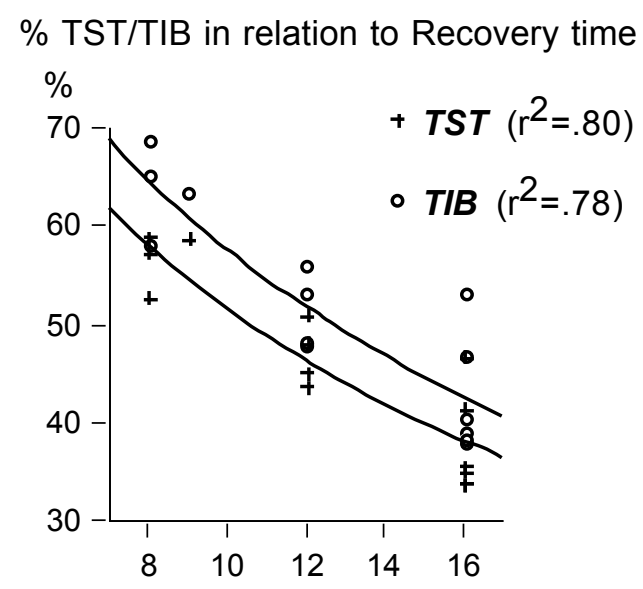

Recovery time between shifts

Figure 11a and $b$. Left - The relationship between recovery time and time in bed (TIB). Right - The figure illustrates how recovery time affects the relationship between actual sleep time (TST) and other activities during recovery time. Crosses $=$ TST in $\%$ of recovery time; open circles $=$ TIB in $\%$ of recovery time.

The laboratory study (V) confirmed that curtailing sleep to $4 \mathrm{~h}$ increases subsequent sleepiness in a similar manner as a quick return before a M-shift. Even though the experimental shortening to $4 \mathrm{~h}$ of sleep resulted in slightly shorter sleep than the quick returns in study I-III, it showed that a short nap managed to improve performance temporarily.

Our studies show that quick returns shorten sleep and increase subsequent sleepiness. The sleep curtailment is about $1 \mathrm{~h}$ before M-shifts, and longer before A-shifts. One could question whether this sleep debt is significant or not as sleepiness levels are still lower than during N-shifts. However, these effects should be seen as an extra strain on sleep and sleepiness in addition to the already deleterious effects of shift work. Nevertheless, sleep duration seem to be most affected by recovery times shorter than $12 \mathrm{~h}$, while longer free times seemed to be of less importance for sleep duration. 


\section{Individual differences}

The discussion of why some tolerate shift work while others do not first focuses on both individual factors as well as shift related aspects. This is followed by a discussion of the few differences found between men and women and possible mechanisms that may be important for resiliency to shift work.

Both men and women that were dissatisfied with the shift schedule had more subjective problems with sleep and sleepiness even though it was not manifested in worse performance (see figure 12). The major difference concerned sleepiness - to some extent during N-shifts, but in particular during A- and M-shifts. Yet, there was no significant difference in the amount, or objective quality, of sleep preceding these shifts. However, the dissatisfied workers rated the sleep periods as considerably more insufficient and, in addition, reported a longer sleep need than satisfied workers. Interestingly, sleepiness levels gradually returned to normal during days off, when normal night sleep was taken. These observations suggest that the dissatisfied group is more sensitive to curtailed sleep. Moreover, dissatisfied workers rated themselves as having lower sleep flexibility than satisfied workers, which supports earlier research (Folkard et al., 1979). However, again, no objective sleep measures supported this difference, and other individual sleep-related factors like age, diurnal type, how much they worried about their sleep, or problems in overcoming sleepiness did not differ between groups.

The results from study III demonstrate that dissatisfied shift workers have few problems during days off and when starting a work period (when coming down to the N-shift). From then on, however, dissatisfied shift workers increase their sleepiness across the work period. This accumulation of problems is probably a result of insufficient recovery between shifts, and, obviously, several consecutive quick returns contain insufficient possibilities to recover (sleep) fully. The problems with sleep and sleepiness seem to be acute as the differences between groups disappear on days off. There was no indication of an accumulation of problems across the shift cycle, not even amongst dissatisfied shift workers, which suggests that $55 \mathrm{~h}$ of free time between work periods was sufficient for most of these workers. Consequently, besides the obvious problems with $\mathrm{N}$-shifts and day sleep, the main problems amongst dissatisfied shift workers are related to the acute effects of quick returns. Nevertheless, the long-term effects of repeated disturbances of recovery are still poorly understood.

The virtual absence of differences between men and women supports earlier findings (Beermann, 1995; Beermann et al., 1990; Estryn-Behar et al., 1990), but also contrasts with studies showing more problems amongst women (Dirkx, 1991; Oginska et al., 1993). It is possible that the lack of agreement derives from work related issues or social responsibilities (Beermann, 1995). It should also be noted that stress research in general describes women as more likely to experience and report more problems in response to stressors (Heinisch and Jex, 1997). The lack of differences reported in our study could also be related to the fact that the gender groups were not randomly chosen; the groups were chosen to maximize differences in satisfaction towards the shift schedule and, hence, left out the "intermediates". Consequently, it is possible that we have underestimated gender differences in the population. 
Difference in sleepiness between Satisfied and Dissatisfied shift workers $\triangle \mathrm{KSS}$

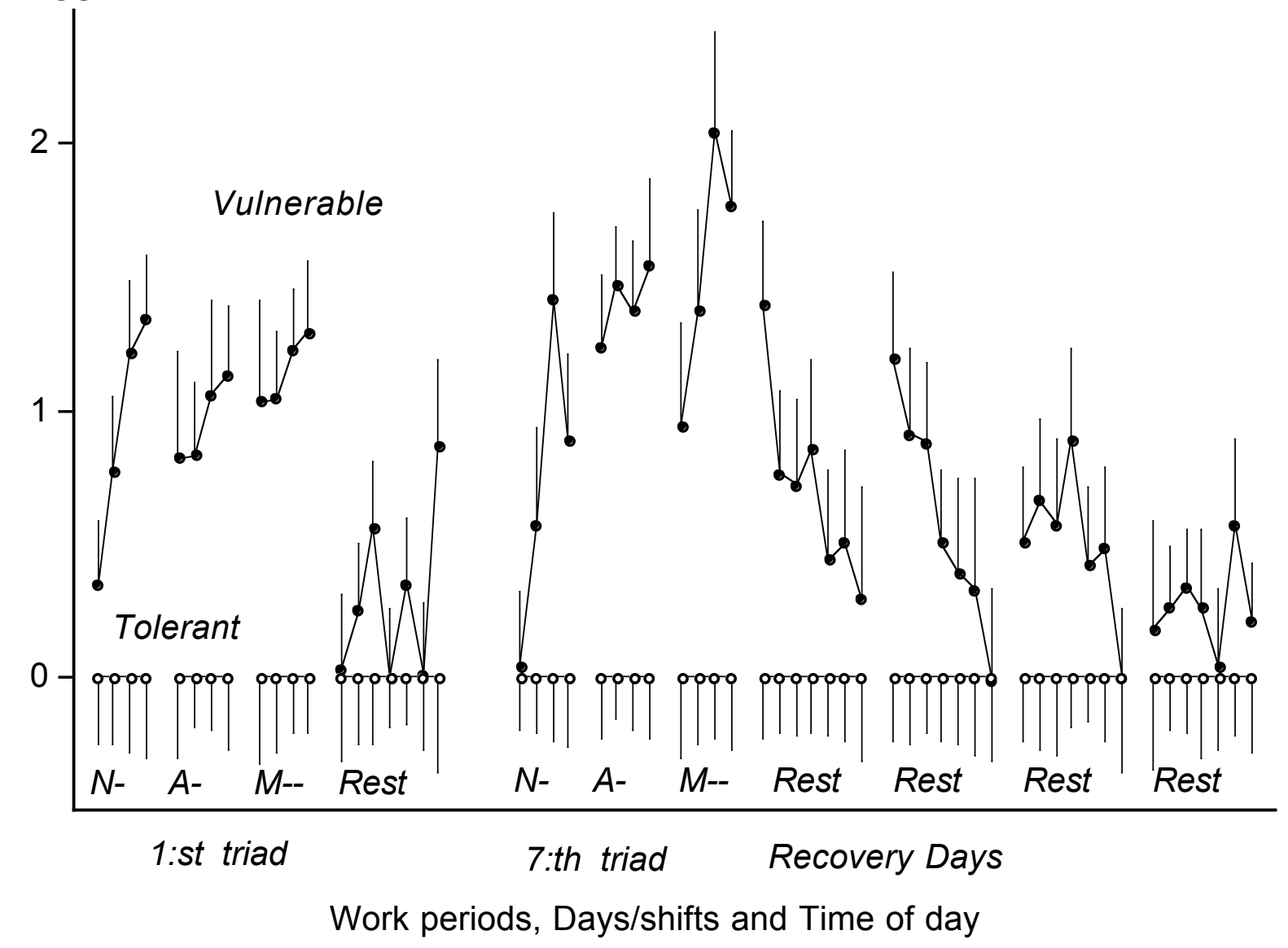

Figure 12. The difference in sleepiness $(\Delta \mathrm{KSS})$, between satisfied and dissatisfied shift workers during workdays and days-off. $\mathrm{N}=\mathrm{N}$-shift, $\mathrm{A}=\mathrm{A}$-shift, $\mathrm{M}=\mathrm{M}$-shift, Rest=Days off. The scale used = scale steps on the KSS, $>0=$ more sleepiness.

In study IV we followed tolerant and intolerant male shift workers across a shift cycle and measured major anabolic and catabolic processes to evaluate whether any of these biological mechanisms were connected to shift work tolerance. The main results were that dissatisfied shift workers had lower morning testosterone than satisfied ones, but the two groups did not differ significantly with respect to levels of cortisol or prolactin (although there was a trend for higher prolactin in the dissatisfied group). Low testosterone levels were, furthermore, associated with a greater sleep need, disturbed sleep and sleepiness problems. The results seem to link an important endocrine variable to the main problems in shift workers, disturbed sleep/alertness - problems that accumulated across the work period when recovery time was limited.

The lower testosterone in dissatisfied shift workers may be interpreted in four different perspectives - sleep loss, stress, depression and lack of control (see study V in the appendix for a more extensive review). The connection between low testosterone and disturbed night sleep is supported by the observations that night work and being on-call at night suppresses morning testosterone (Chatterton and Dooley, 1999; Touitou et al., 1990), and that more severe sleep disturbances (long term sleep deprivation, sleep fragmentation and sleep apnea) in the laboratory suppress or disrupt testosterone regulation, as well as increase sleepiness (Luboshitzky et al., 2002; Luboshitzky et al., 
2000; Åkerstedt et al., 1980). The degree of testosterone suppression is related to the degree of sleep disruption (Schiavi et al., 1992). In addition, short sleep (3hrs) is less disruptive for testosterone than no sleep at all (Opstad and Aakvaag, 1983). Moreover, low testosterone levels are associated with fatigue (Morley, 2001) and exogenous testosterone has been shown to improve alertness and well-being in hypogonadal patients (Christiansen, 2001; Morley, 2001).

In the light of our testosterone results, even though our data cannot yield causal relationships, it seems reasonable to hypothesize that the low levels of testosterone may be due to disturbed sleep and/or a high sleep need, which, in turn, may result in more sleepiness and a greater need for recovery after a work period and, as a consequence of these problems, dissatisfaction with the shift schedule.

Another explanatory possibility concerns the consequences of control. Both primate and human studies have shown that being unsuccessful (being dominated, loosing a competition, social defeat) reduces testosterone (Bjorkqvist, 2001; Booth et al., 1989; Kraus et al., 1999; Mazur and Booth, 1998). In contrast, winning a competition increases testosterone, the increase being even greater if the winner is in a positive mood or if he evaluates his own performance highly (Booth et al., 1989; Mazur and Booth, 1998). Thus, it is possible that dissatisfied shift workers may experience their situation as hopeless, resulting in a suppression of testosterone. Indeed, it has been demonstrated that the testosterone response works as a feedback regulator, reinforcing or weakening the hormonal pattern that stimulated the behaviour in the first place (Christiansen, 2001; Zitzmann and Nieschlag, 2001). It could be debated whether it is the stressor itself or if it is how one experiences the outcome that suppresses testosterone. As a consequence, testosterone levels may instead reflect how well someone is coping. However, such an adaptive response mechanism, which also would reflect "fitness" and social status (Mazur and Booth, 1998), would not explain the fact that low testosterone levels are related to disturbed sleep. Without stating the exact causal relationships, the results clearly suggest that dissatisfaction with the shift system is related to lower testosterone levels, and that the latter are related to disturbed sleep/wakefulness and increased need for sleep and recovery.

A key issue concerns why some develop problems while others do not. In a schedule with quick returns, resilient shift workers had a shorter sleep need and high levels of morning testosterone (the latter amongst men), reflecting a sufficient sleep as a support against periods with hard work and little time for recovery. The opposite was true for vulnerable shift workers. The importance of these findings for tolerance to other types of shift schedules are uncertain, but some generalisations may be relevant, as shift work often include short sleep periods. Another interesting finding - those with higher adrenalin levels are more resilient to the effects of short sleep (Gillberg, 1986) - may link a mechanism to shift work intolerance (such persons may be better at counteracting sleepiness). However, further studies are needed to evaluate why some have higher levels of adrenalin and whether this is linked to disturbed sleep in the first place.

To summarize, tolerance to shift work was dependent on characteristics of the shift schedule as well as on individual characteristics - mainly an inability to recover during short sleep, but most likely an increased sensitivity to working N-shifts as well. Even though it is likely that a weakened recovery 
mechanism would be problematic in most shift systems, one should be careful to generalise the effects of individual traits. Some traits may be harmful/suitable in some shift systems, but not in others. This may explain some of the inconsistent results of this issue.

\section{Comparing shift schedules}

A myriad of different shift schedules exist, and it is still a controversy of which aspects of shift work that should be preferred to others. Different schedules contain different advantages and disadvantages and a problem is the lack of a good indicator for deciding whether a particular schedule is particularly bad or not. In an attempt to obtain a measure of the total burden of working an entire shift schedule - and, therefore, avoiding the problems of only comparing more or less incompatible periods between different schedules - we used all sleepiness ratings across the entire shift cycle. All sleepiness data (from rise time to bed-time) across workdays as well as days-off were used to obtain the total strain induced by the different shift systems (see Fig. 12a-c).

The comparison of the different shift schedules, revealed smaller sleepiness differences than expected (see Fig 12a-c). The $8 \mathrm{~h}$ shift in study I inflicted most sleepiness, while there was small difference between the other shift systems. The few differences, and that most problems were related to a $8 \mathrm{~h}$ shift system, are in opposition to our initial hypothesis of increased problems in schedules with compressed working hours. An interesting aspect was that study III was characterised by slightly more sleepiness during workdays, but with higher alertness during days off. The workers seemed to be almost fully restored after only one recovery sleep. The fast recovery was probably a result of the undisturbed recovery and of the fact that there was no need for circadian readjustment - since any tendencies to delay after the $\mathrm{N}$-shift would have been counteracted by the final M-shift. It is likely that this effect was popular amongst the workers, as alertness is probably higher valued during free time than during work (reasoning based on how shift workers value their time) (Baker et al., 2004). This may explain why so many workers were satisfied with this schedule, more than $70 \%$ of the workers were satisfied (satisfied or very satisfied) with the shift system and reported relatively minor problems with poor sleep and sleepiness.

Similar data were calculated for 3 different day-working populations and shift workers working the D-shift for one week (study II), see Fig 12b. The day working populations included the comparison group from study I and two construction working populations, working either 5 consecutive $8 \mathrm{~h}$ shifts or 7 consecutive 12h shifts (personal correspondence with G Kecklund, 2004, unpublished data). It became clear that day workers at the chemical plant were the most alert group studied (study I). Even though shift workers, working D-shifts, or the two construction working populations showed slightly less sleepiness than shift workers, the differences were small. This is surprising as they never worked N-shifts, but is probably due to the hard labour (construction workers). The shift workers in study II had one week with day work, but they did not seem to be substantially more alert compared to when working shifts or to the two groups of construction workers. Participants in the laboratory study (study $\mathrm{V}$; in the lab from $08.00 \mathrm{~h}$ to $16.00 \mathrm{~h}$ ) were most sleepy after a $4 \mathrm{~h}$ sleep, a short nap seemed to counteract some sleepiness even though it did not take them down to the same levels as when having 7,5h of sleep. Being in the lab with $7,5 \mathrm{~h}$ of prior sleep was still related to more sleepiness than day work in the field. 
Sleepiness for work days, days-off and the total shift schedule

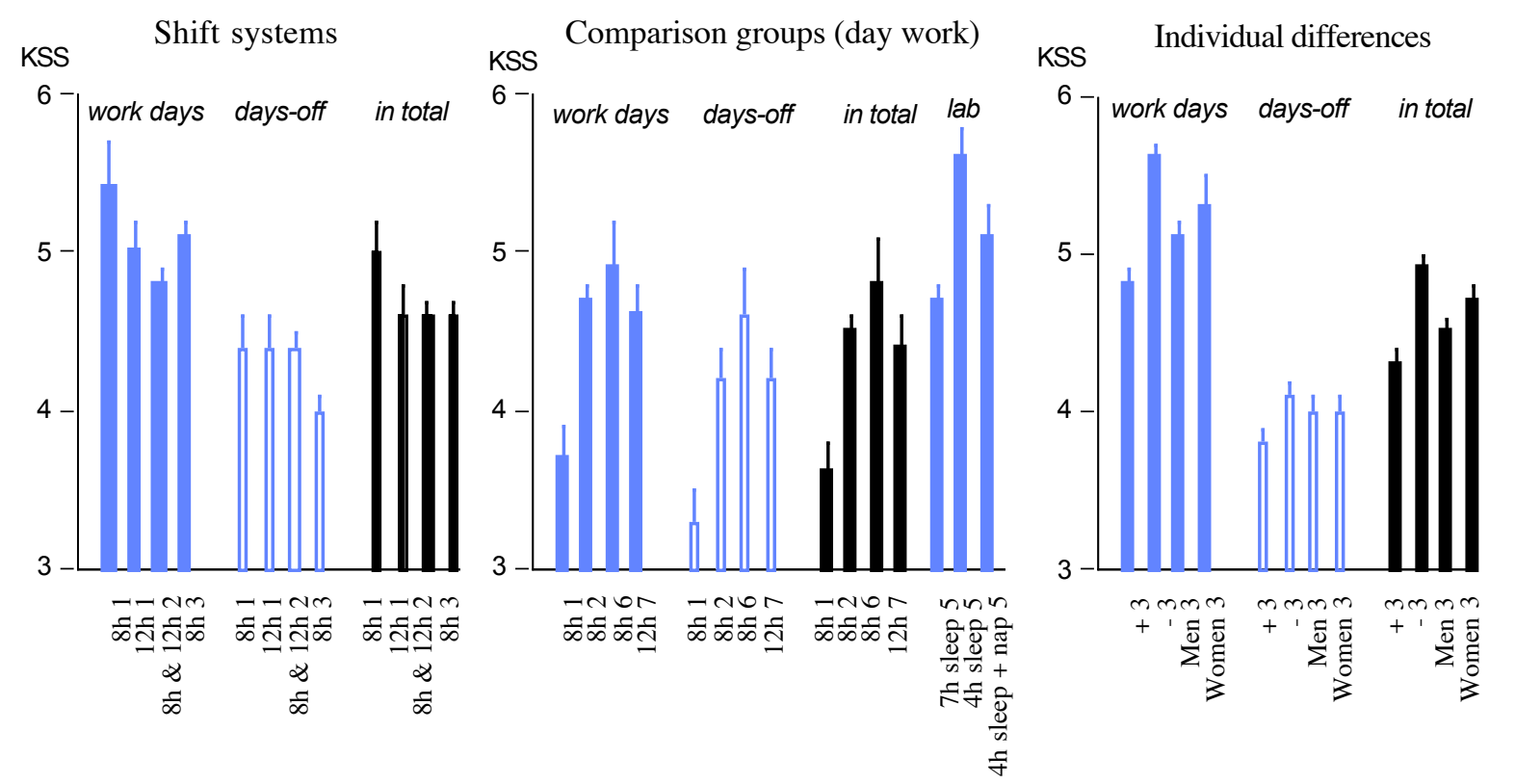

Figure 12a-c. The mean for all sleepiness ratings (from rise time to bed time) for all workdays (light blue/grey), days-off (unfilled bars), and the total shift cycle (black bars). The left part (12a) shows sleepiness for the 4 shift systems included in the present thesis. The middle part (12b) shows sleepiness in relation to day work. The right part (12c) illustrates how sleepiness differs between different groups of workers in the same shift schedule. The sleepiness scale (KSS; 1=very alert, 9= very sleepy), $8 \mathrm{~h}=8 \mathrm{~h}$ shifts, $12 \mathrm{~h}=12 \mathrm{~h}$ shifts; $+=$ satisfied shift workers; $-=$ dissatisfied shift workers, 1=study I; $2=$ study II; $3=$ study III: $5=$ study V (a laboratory study); $6=$ construction workers with a $40 \mathrm{~h}$ working week; $7=$ construction workers with 7 consecutive $12 \mathrm{~h}$ shifts (the latter two are comparison data from personal correspondence with G Kecklund).

With respect to individual differences (Fig 12c), dissatisfied shift workers were sleepier than satisfied shift workers during work, while there were no or few differences during free time. No gender difference was found.

Measuring the total burden in different groups showed that dissatisfied shift workers were substantially more sleepy during workdays, but less so on days-off. Men and women were very similar in their sleepiness levels during both workdays and days-off.

Taken together, the measure of total sleepiness gave some indications of the general burden of the different schedules. The $8 \mathrm{~h}$ shift system inflicted most sleepiness during workdays, which was probably due to the long lasting effects of the quick returns. There were few differences during days off. Best alertness levels during days off were reported in study III, where recovery days were never preceded by an A- or a N-shift. There were no signs that $12 \mathrm{~h}$ shift systems were worse off than $8 \mathrm{~h}$ shift systems. The only major sign of quick returns to be problematic were related to study I, but this was not confirmed in study III, which had more frequent quick returns and earlier possibilities to recover. Further studies are needed to evaluate whether this method should be accepted for a wider use. 


\section{Limitations}

The present thesis includes four field studies of three occupational groups and one experiment. Obviously, the designs and characteristics of the studies have strong effects on the interpretations and generalisations of our findings. This chapter will first consider the designs and the statistical procedures and how this affects the interpretation of the data. This is followed by a discussion of the pros and cons of each of the main issues of the present thesis. Lastly, there is a discussion of the possibilities and problems of generalising the data to other occupational settings and circumstances.

Firstly, four out of five studies are field studies, and numerous factors may confound our data in these real life settings. These variables results in a noise, or error variance, that will make it harder to find the relationships under study. Examples of such variables are, different work tasks, age, sex, marital status, having (young) children, commuting time, body composition, social commitments, smoking etc. Many of these variables vary considerably between individuals and may confound the results significantly. To eliminate error variance from factors related to differences between individuals, all studies evaluated changes within individuals, the exceptions being study III and IV which also included comparisons between groups. Here, the groups (satisfied vs. dissatisfied and women vs. men) did not differ on most background variables like age, marital status, proportion with young children, diurnal type or body mass index (BMI), with the exception of women having slightly lower BMI than men.

There are also problems related to changes across time. This means that all features that differ between the time points (for each study respectively), and that are not related to condition (e.g. shift length) may have confounded our data. For example, it is not only the change of the schedule from the old $8 \mathrm{~h}$ shift system to the new $12 \mathrm{~h}$ shift system that occurred between the two measures in study I. Other changes occurred at or outside the work place. To control for, or at least get a grasp of, their impact, study I included a comparison group and the impact from other variables were measured. For instance, both groups improved sleepiness even though work tasks during both trials and working times were the same in the comparison group. Obviously, factors that change differently in the comparison group and the experimental group are difficult to consider. For instance, it is possible that an initial negative attitude towards the $8 \mathrm{~h}$ shift schedule may have confounded the data in this study. In study II, it is possible that changes between weekdays and weekends may have influenced our findings (the participants worked $8 \mathrm{~h}$ shifts Mon-Thu and $12 \mathrm{~h}$ shifts Fri-Sun). For example, sleep environment (noise), commuting times and amount of managers often differ between weekdays and weekends. Study III, IV and V, were partly balanced to control for changes across time. Study III and IV were balanced with respect to work period (half of the subjects started the study protocol at the first work period of the shift cycle and the other half started with the last), but not for shift or time of day. Study V was counterbalanced with respect to condition. An additional problem relating to changes across time is the "healthy worker effect", with unhealthy workers leaving and healthy ones remaining. This "selection/condensation" of workers will inevitably decrease the possibility to generalise the findings to other populations. The degree of this process is unknown in these studies. 
With respect to statistical procedures all studies used a significance level, or rejection level, of .05 (i.e. the chance for this effect to be random is less than 5\%). However, also a stricter p-level was used to minimise the risk of "mass significance" (type I-errors) in study III and IV. These studies included many statistical tests, and the procedure aimed to avoid reporting effects that were due to random rather than a true effect. The problem with a stricter p-level is the loss of power and an elevated risk of making type II-errors (i.e. rejecting existing effects). From this aspect, it is important to find a compromise between the power, the p-level, the amount of tests and the possibility to make generalisations from the data. Another statistical problem is the lack of possibility to assign shift workers randomly. This violates the statistical assumption of all subjects having equal chance of being assigned. However, this is a main issue in most research areas and perhaps even more so in field studies, when the burden of participating is extensive and practical considerations are often in conflict with research. One consequence is the decreased possibilities to generalise the findings from the study population to the general population.

The issue of long shifts was evaluated in two different occupational groups with different shift schedules. Despite these differences, the results on long shifts were, on the whole in agreement. The exception being the great difficulties with the $8 \mathrm{~h}$ shift system in study I.

The effects of short recovery time (study I-III) are influenced by several confounding variables. The most prominent are perhaps change-over times, commuting times and whether the workers can sleep at, or close to, the working place. For example, study I and III took place in smaller communities and had relatively moderate commuting times (20 and 16 minutes, respectively). Commuting times was substantially longer in Study II, in Stockholm (40 minutes). Shorter recovery periods are more problematic to carry out in larger cities with longer commuting times. In addition, it was only the employer in study III that could offer sleeping facilities close to the work place. Moreover, the amount of social responsibilities (like child care) are obviously of importance for sleep duration and quality (Kurumatani et al., 1994).

The interpretations of the findings of individual differences are affected by several factors. The few differences between men and women, plus the larger differences amongst men than women could be due to the fact that the groups (dissatisfied and satisfied) were chosen to maximize variation and that there were more men (269) than women (48) at this work site. Therefore, it is possible that the male "dissatisfied" and "satisfied" groups were more "extreme" than the female ones, even if their satisfaction scores were rather similar.

With respect to the biological differences and tolerance to shift work amongst men, many factors besides satisfaction may affect testosterone, for example, age, time of day, general health, BMI, sexual/physical activity, genetic factors, smoking, alcohol use and intake of other drugs (Booth et al., 1999; Dai et al., 1981; Vermeulen, 1983). In the present sample there were no differences between satisfied and dissatisfied shift workers with respect to age, BMI, smoking, physical activity or intake of medicines, and none of these variables were significantly correlated to testosterone. No control for alcohol was made due to the problems of obtaining accurate information and the conflicting results of a link between alcohol and testosterone (Dai et al., 1981; Heller et al., 1981; Zitzmann and Nieschlag, 2001). Secondly, one needs to consider circadian changes. To control for 
such effects, all blood samples were taken between 07:00 and 09:00 in the morning. At this time testosterone is released in a stable manner and representative of an individual's testosterone levels (Dai et al., 1981; Vermeulen and Verdonck, 1992; Zitzmann and Nieschlag, 2001). Each individual was, in addition, sampled twice, with a high intra-individual correlation between the first and the last work period, for all measured hormones. This suggests that a single morning sample reflects well the individual levels at that time of day. A further consideration concerns the fact that we may not have obtained an optimal baseline measure of the hormones, a common problem in many field studies. As a consequence, we cannot determine whether the difference in testosterone represents an acute suppression or a whether there is a more chronic down-regulation of the hypothalamus pituarity - gonadal (HPG) system. Since all M-shifts were preceded by a N- and an A-shift, it was not feasible to get morning samples that were preceded by days off. In addition, it was not possible, for practical reasons, to sample blood outside the work place. However, the fact that the individual testosterone levels were highly stable across the seven work periods $(\mathrm{r}=.79)$ suggests a more chronic suppression.

The present thesis also aimed to measure the total burden of the entire shift schedule by integrating all ratings of sleepiness across workdays and days-off. The main purpose was to obtain a measure that would reflect the total burden of a particular schedule. Remarkably, very few differences in sleepiness were seen between shift schedules. This is surprising as the schedules differed considerably and that sleepiness is affected by contextual factors, for example physical effort was related to more alertness (study I). The latter may vary between different occupations. Alternatively, it may be that the total impact between shift systems was small, supporting studies finding few differences when comparing shift systems (Tucker et al., 2000). In addition, the method still showed that the $8 \mathrm{~h}$ shift schedule in study I induced most sleepiness and that the schedule in study III induced least sleepiness during days-off, which may explain its unexpected popularity. Further studies are needed before a wider use can be proposed.

The main weakness with the laboratory study - evaluating the effects of curtailed sleep and whether a short day time nap could counteract sleepiness and performance deteriorations - was that prior sleep was not polysomnographically recorded, but assessed by sleep diaries. It is, therefore, difficult to know the exact sleep duration and sleep architecture. On the other hand, there is a fair agreement between subjective and polysomnographically recorded sleep (Åkerstedt et al., 1994b). Another problem may be that long vigilance tasks, although very sensitive to sleepiness and extensively used in sleep research, may have low ecological validity.

A main purpose of research is to generalise the findings in other settings than the one studied. However, one has to be careful as many of the findings may be specific to the study population. It is a strength that the thesis includes results from three different work places and occupations (a chemical plant, a power plant and a paper and pulp factory), although not completely different work tasks (to a large part control room operators, but also shift supervisors). On the other hand, all studies are carried out in Sweden and cross-cultural differences are likely to occur. Two studies were carried out in smaller towns (less than 100.000 inhabitants) and one was carried out in Stockholm, the capital of Sweden. In addition, most workers have college education, and the data may not be applicable in other occupations were work tasks and education levels differ. In addition, 
there are many other cultural confounders and a particular weakness of studies of compressed working hours is the lack of studies outside North America, Western Europe and Australia (Hung, 1996). Moreover, there are probably different selection processes according to occupation and shift system. This means that results from a certain shift working population may not be fully applicable to other groups of shift workers. Taken together, one should be careful with generalisations in other occupations and cultures and understand what processes are important in certain settings.

All in all, the main weaknesses of the present thesis are probably confounders that are related to order/time; that all studies are carried out in a relatively homogeneous culture (shift workers in Sweden); and that different selection processes exist in different shift systems and work places. Another weak point was the problems to fulfil the statistical demand of random assignment of subjects. Perhaps the main strength is that all studies included evaluations of changes within individuals. An additional strong point is that the generalisations are built upon findings in different shift systems in different occupations, which increases the possibility that these findings are universal. Moreover, our findings are not controversial and seem to stand on firm ground.

\section{Concluding discussion}

The main aim of the present study was to evaluate the effects of compressed working hours. Undeniably, there is a limit how much recovery time can be shortened between shifts, and for how many hours in a row that we can work, before performance is impaired - or even more importantly before the risk of developing health problems occur. On the other hand, compressing working hours to the work period and free time to days off (the number of shifts during a shift cycle is reduced by 1/3) may not only increase strain during the work period, but also allow for better recovery in between work periods - at least when the worker gives priority to recovery during days off. It is probable that workers with $12 \mathrm{~h}$ schedules are better recuperated at the start of a new work period.

Our data suggest that extending work hours (to $12 \mathrm{~h}$ ) is less invasive than shortening recovery periods, at least acutely. Extending working hours will also limit the possibility to recover, but the shortening from $16 \mathrm{~h}$ to $12 \mathrm{~h}$ of recovery seemed to have no or minute effects on sleep and sleepiness, at least when comparing with the deleterious effect of quick returns. It is likely that workers with high social demands (e.g. having small children) will have more problems with extended shifts than other groups of workers. Moreover, most workers are satisfied with extended hours and choice and control over working hours are important mediating factors. For instance, it is possible that the popularity amongst workers (caused by the extra $50 \%$ of free days, particularly free weekends) may lead to higher motivation and may stimulate greater effort to reduce fatigue.

An additional argument for extending working hours is that it is more cost effective. In other words, each $12 \mathrm{~h}$ shift results in $12 \mathrm{~h}$ extra free time (i.e. two $12 \mathrm{~h}$ shifts $=$ three days with $8 \mathrm{~h}$ shifts), while each quick return only result in $8 \mathrm{~h}$ of extra free time. It would hence be necessary to have 3 quick returns to get one extra day off. To summarise, it seems as if extension of working hours is less invasive and have greater benefits (creates more free time) than shortening free time between shifts. On the whole, there is a trade-off between having free time within a work period or between work 
periods, and common sense says that there are clear limits to how much we can compress working hours before the effects become harmful.

It is clear that both timing of shifts (shift type and start/end times of shifts) and recovery time between shifts affects sleep duration. It seems that $12 \mathrm{~h}$, or close to it, of recovery time is necessary for sufficient recovery. Perhaps the main question of this thesis is: what factors determine sleep duration?

Another central message from the present thesis concerns sleepiness levels among shift workers in different occupational settings. The dissertation suggests that timing of shifts and recovery time between shifts are two crucial shift characteristics. N-shifts are worst off according to timing and quick returns producing a sleep debt that increases subsequent sleepiness. In addition, contextual factors are also important. The present dissertation showed that low physical activity/effort is related to sleepiness. The aim to assess the total burden of a shift schedule was partially successful, the worst shift system was identified as well as the particular consequences of the shift system in study III (workers were more alert during free time than other shift workers). However, the few differences between other systems suggest that further validations are needed.

There was some evidence for accumulation of problems across the shift cycle. In study III, the workers were slightly more sleepy after the last work period compared to the first worker period, and sleepiness was gradually reduced during the first 4 days of their week off. In addition, morning cortisol levels were reduced on the last M-shift in the cycle compared to the first. This could either reflect some form of down-regulation of the HPA-axis (hypothalamus - pituarity - adrenal) due to long-term stress (Yehuda et al., 1993) or, alternatively, an alteration of the circadian rhythm at the end of the shift period. A change of the circadian rhythm is difficult to control for as our data are based on a single morning sample, but no or small alterations of the rhythm could be expected in this extremely rapidly rotating shift schedule (Härmä, 1993). On the whole, though, there were no signs of intolerant workers accumulating more problems across the shift cycle than tolerant workers. The differences between tolerant and intolerant workers were only seen with respect to the accumulations of problems across each work period.

\section{Practical implications}

The findings of the present studies have several practical implications. The most important is perhaps that the acute effects of compressed working hours are less harmful than expected. It is suggested that $12 \mathrm{~h}$ shifts may be used to cover shorter or longer periods of the shift cycle if other circumstances are not too demanding. For example, the nature of the work tasks is important and should ideally be moderately demanding. Long working hours should not include tasks that are sedentary/monotonous, physically hard or solitary work. The major concerns are related to $12 \mathrm{~h} \mathrm{~N}$ shifts, as there is little support for problems with $12 \mathrm{~h}$ M-shifts. Still, however, M-shifts should not start too early, at least when working extended shifts (the literature suggest no earlier than $07.00 \mathrm{~h}$ ).

The effects of quick returns were more dubious. All quick returns impaired sleep and sleepiness, but more so in one study than the other. However, it seemed that quick returns were manageable when 
the sequence of shifts was short - so that the recovery could take place shortly after. On the other hand, workers with less effective sleep, for one reason or another, seem vulnerable for quick returns. In consequence, we cannot recommend the use of short recovery periods, particularly if they are interjected in longer sequences of shifts. Nevertheless, if a shift system still includes quick returns, it is recommended to minimise the strain by maintaining sleep facilities at, or close to, the work place, particularly if travel times are extensive.

An important issue concerns finding vulnerable workers as early as possible, preferably before they develop health problems. In an extremely rapidly rotating shift schedule with quick returns, it was evident that dissatisfaction with the shift schedule was related to major problems with sleep and sleepiness during workdays, but not during days-off. The main problem amongst vulnerable shift workers concerned the recuperative value of sleep that failed to counteract intensive work periods. Possible screening tools to find vulnerable shift workers would involve daily diaries across the most problematic work period in a shift sequence, to evaluate whether they attain sufficient recovery. The questionnaire should contain questions of sleep need and how many recovery days are needed after a work period and dissatisfaction with working hours. The diary should involve questions of sufficient sleep and sleepiness (preferably several measures a day). This should, if possible, be combined with a health examination, including measures of testosterone in males.

\section{Further research}

Although the present thesis failed to find substantial problems with long working hours, it is only concerned with the acute effects on sleep and sleepiness. It is still possible that other subtle effects occurred acutely, and that they may be harmful in the long run. In consequence, there is a need for longitudinal studies of compressed working hours on health, including both long shifts and quick returns.

A better understanding of what aspects of shift work that are harmful for intolerant shift workers may lead to better interventions. Our studies suggest that intolerance to shift work may be related to disturbed recovery and low testosterone levels amongst men. Comparable studies should be conducted amongst female shift workers. However, there is still a lack of studies evaluating the mechanisms involved in intolerance to shift work. To acquire a better understanding of why some individuals are more resilient to shift work than others, future research will need more ambitious sampling procedures of biological parameters. An obvious study would be to evaluate tolerant and intolerant shift workers in experimental settings, preferably using polysomnographic recordings in combination with endocrinological and immunological parameters. In addition, the development and usage of new statistical tools will hopefully help in understanding the mechanisms related to tolerance on an individual level. Another important research question concerns accidents - both the causes and how they may be prevented. It is here a desperate need for better longitudinal studies of how the type of shift system and individual factors relate to accident risk. There is a need for more longitudinal studies connecting particular aspects of shift schedules and individuals to future morbidity. 


\section{Conclusions}

"No matter where you go, there you are"

Buckaro Banzai

Apart from the obvious effects of night work on sleep and sleepiness, the present thesis has demonstrated that long shifts do not seem to impair sleep or alertness. Short recovery periods (around 8h), however, impairs sleep and alertness acutely, even though this was partly counteracted by better alertness levels during days-off. Most of the problems with short recovery periods were related to short sleep, and there is, clearly, a subgroup of workers that suffer more from this than others. Satisfaction with the shift schedule seems to reflect how well the shift workers were coping with the schedule. It is argued that low testosterone levels and disturbed sleep might be key factors for developing shift intolerance, mainly by reducing the capacity to recover from shift work. The implications of the findings seem obvious. Compressed work hours should not be achieved through quick returns. 


\section{REFERENCES}

Aanonsen, A., 1959, Medical Problems of Shift-Work: Industrial Medicine and Surgery, p. 422-427.

Aanonsen, A., 1964, Shift work and health: Oslo, Universitetsforlaget.

Aaronson, L. S., C. S. Teel, V. Cassmeyer, G. B. Neuberger, L. Pallikkathayil, J. Pierce, A. N. Press, P. D. Williams, and A. Wingate, 1999, Defining and Measuring Fatigue: Journal of Nursing Scholarship, v. 31, p. $45-50$.

Adam, K., and I. Oswald, 1977, Sleep is for tissue restoration: $J$ R Coll Physicians Lond, v. 11, p. 376-88.

Adam, K., and I. Oswald, 1984, Sleep helps healing: British Medical Journal, v. 289, p. 1400-14001.

Ader, R., N. Cohen, and D. Felten, 1995, Psychoneuroimmunology: interactions between the nervous system and the immune system: The Lancet, v. 345, p. 99-102.

Ader, R., D. Felten, and N. Cohen, 1990, Interactions between the brain and the immune system: Annu Rev Pharmacol Toxicol, v. 30, p. 561-602.

Agnew, H. W., W. B. Webb, and R. L. Williams, 1966, The first night effect: an EEG study of sleep: Psychophysiology, v. 2, p. 263-266.

Ahlborg, G., Jr., G. Axelsson, and L. Bodin, 1996, Shift work, nitrous oxide exposure and subfertility among Swedish midwives: Int J Epidemiol, v. 25, p. 783-90.

Andlauer, P., 1960, The effect of shift working on the workers' health. European Productivity Agency, TU Information Bulletin, 29.

Angersbach, D., P. Knauth, H. Loskant, M. J. Karvonen, K. Undeutsch, and J. Rutenfranz, 1980, A retrospective cohort study comparing complaints and disease in day and shift workers: Int Arch Occup Environ Health, v. 45, p. 127-140.

Anisman, H., M. G. Baines, I. Berczi, C. N. Bernstein, M. G. Blennerhassett, R. M. Gorczynski, A. H. Greenberg, F. T. Kisil, R. D. Mathison, E. Nagy, D. M. Nance, M. H. Perdue, D. K. Pomerantz, E. R. Sabbadini, A. Stanisz, and R. J. Warrington, 1996, Neuroimmune mechanisms in health and disease: 1. Health: Cmaj, v. 155, p. 867-74.

Aschoff, J., 1964, Survival value of diurnal rhythms: Symp. zool. soc. London, p. 79-98.

Aschoff, J., 1965, Response curves in circadian periodicity, in J. Aschoff, ed., Circadian clocks: Amsterdam, North Holland Publishing Co., p. 95-111.

Aschoff, J., 1967, Human circadian rhythms in activity, body temperature and othr functions, Life Sciences and Space Research: Erling-Andechs, Germany, p. 159-173.

Aschoff, J., 1978, Features of circadian rhythm relevant for the design of shift schedules: Ergonomics, v. 21, p. 739-754.

Aschoff, J., 1979, Circadian Rhythms: Influences of internal and external factors on the period measured in constant conditions: Z. Tierpsychol, v. 49, p. 225-249.

Aschoff, J., U. Gerecke, and R. Wever, 1967, Desynchronization of human circadian rhyhms.: Japanese Journal of Physiology, v. 17, p. 450-457.

Axelsson, G., C. Lutz, and R. Rylander, 1984, Exposure to solvents and outcome of pregnancy in university laboratory employees: Br J Ind Med, v. 41, p. 305-312.

Axelsson, G., and R. Rylander, 1989, Outcome of pregnancy in relation to irregular and inconvenient work schedules: Br J Ind Med, v. 46, p. 306-312.

Babkoff, H., T. Caspy, and M. Mikulincer, 1991, Subjective sleepiness ratings: The effects of sleep deprivation, circadian rhythmicity and cognitive performance: Sleep, v. 14, p. 534-539.

Baker, A., G. Roach, S. Ferguson, and D. Dawson, 2004, Shiftwork experience and the value of time: Ergonomics, v. 47, p. 307-17.

Balsalobre, A., S. A. Brown, L. Marcacci, F. Tronche, C. Kellendonk, H. M. Reichardt, G. Schutz, and U. Schibler, 2000, Resetting of circadian time in peripheral tissues by glucocorticoid signaling: Science, v. 289, p. 2344-7.

Barton, J., and S. Folkard, 1993, Advancing versus delaying shift systems: Ergonomics, v. 36, p. 59-64.

Barton, J., S. Folkard, L. Smith, and C. J. M. Poole, 1994, Effects on health of a change from a delaying to an advancing shift system: Occupational and Environmental Medicine, v. 51, p. 749-755.

Barton, J., E. Spelten, P. Totterdell, L. Smith, and S. Folkard, 1995, Is there an optimum number of shifts? Relationship between sleep, health and well-being.: Work and Stress, v. 9, p. 109-123. 
Beermann, B., 1995, Working shifts - different effects for women and men?: Work and Stress, v. 9, p. 289297.

Beermann, B., J. Rutenfranz, and F. Nachreiner, 1990, Gender related effects of shiftwork? An analysis of some confounding variables, in G. G. G. Costa, K. Kogi, A. Wedderburn, ed., Studies in Industrial and Organizational Psychology, v. 10, p. 45-51.

Benington, J. H., and H. C. Heller, 1995, Restoration of brain energy metabolism as the function of sleep.: Progress in Neurobiology, v. 45, p. 347-360.

Berger, R. J., and I. Oswald, 1962, Effects of sleep deprivation on behavior, subsequent sleep, and dreaming: $J$ Mental Sci, v. 108, p. 457-465.

Besedovsky, H. O., and A. del Rey, 1999, The immune - neuroendocrine network, in U. T. Manfred Schedlowski, ed., Psychoneuroimmunology: New York, Kluwer Academic/Plenum Publishers, p. 223234.

Bixler, E., A. Kales, C. Soldatos, J. Kales, and S. Healey, 1976, Prevalence of sleep disorders in the Los Angeles Metropolitan area: Am J Psychiatry, v. 136, p. 1257-1262.

Bjorkqvist, K., 2001, Social defeat as a stressor in humans: Physiol Behav, v. 73, p. 435-42.

Blake, M. J. F., 1967, Time of day effects on performance in a range of tasks: Psychon Sci, v. 9, p. 349-350.

Bliwise, D. L., 1993, Sleep in Normal Aging and Dementia: Sleep, v. 16, p. 40-81.

Bliwise, D. L., 2000, Normal aging, in M. H. Kryger, T. Roth, and W. C. Dement, eds., Principles and practice of sleep medicine: Philadelphia, W.B. Saunders Company, p. 26-42.

Bloch, K. E., 1997, Polysomnography: a systematic review: Technology and Health Care, v. 5, p. 285-305.

Bohle, P., and A. J. Tilley, 1989, The impact of night work on psychological well-being: Ergonomics, v. 32, p. 1089-1099.

Boisard, P., D. Cartron, M. Gollac, and A. Valeyre, 2002, Time and work: duration of work, Dublin, European Foundation for the Improvement of Living and Working Conditions, p. 61.

Bonnet, M. H., and D. L. Arand, 1995, We are chronically sleep deprived: Sleep, v. 18, p. 908-911.

Bonnet, M. H., and D. L. Arand, 1997, Hyperarousal and insomnia: Sleep Medicine Reviews, v. 1, p. 97-108.

Bonnet, M. H., and R. R. Rosa, 1987, Sleep and performance in young adults and older normals and insomniacs during acute sleep loss: Biol Psychol, v. 25, p. 153-172.

Booth, A., D. R. Johnson, and D. A. Granger, 1999, Testosterone and Men's Health: Journal of Behavioral Medicine, v. 22, p. 1-19.

Booth, A., G. Shelley, A. Mazur, G. Tharp, and R. Kittok, 1989, Testosterone, and Winning and Losing in Human Competition: Hormones and Behavior, v. 23, p. 556-571.

Borbély, A. A., 1982, A two-process model of sleep regulation: Hum Neurobiol, v. 1, p. 195-204.

Borbély, A. A., 1998, Processes Underlying Sleep Regulation: Hormone Research, v. 49, p. 114-117.

Borbély, A. A., F. Baumann, D. Brandeis, I. Strauch, and D. Lehmann, 1981, Sleep deprivation: effects on sleep stages and EEG power density in man: Electroencephalogr Clin Neurophysiol, v. 51, p. 483-493.

Borg, G., 1990, Psychophysical scaling with applications in physical work and the perception of exertion: Scandinavian Journal of Work Environment and Health, v. 16 (suppl 1), p. 55-58.

Bramham, C. R., C. Maho, and S. Laroche, 1994, Suppression of long-term potentiation induction during alert wakefulness but not during 'enhanced' REM sleep after avoidance learning: Neuroscience, v. 59, p. 501-9.

Broughton, R., 1975, Biorhythmic variations in consciouness and psychological functions: Canad. Psychol Rev, v. 16, p. 217-239.

Broughton, R., 1982, Performance and Evoked Potential Measures of Various States of Daytime Sleepiness: Sleep, v. 5, p. S135-S146.

Bruusgaard, A., 1969, Shift work is an occupational health problem, On Night and Shift Work: Stockholm, Nat. Inst. of Occ. Health.

Burke, R. J., 1970, Occupational and life strains, satisfaction, and mental health: Journal of Business Administration, v. 1, p. 35-41.

Bøggild, H., and A. Knutsson, 1999, Shift work, risk factors and cardiovascular disease: Scandinavian Journal of Work Environment and Health, v. 25, p. 85-99.

Cabon, P., R. Mollard, and A. Coblentz, 1991, Sleep deprivations and irregular work schedules: Human Factors society 35th Annual Meeting, p. 1154-1158.

Campbell, S. S., and D. Dawson, 1990, Enhancement of nighttime alertness and performance with bright ambient light: Physiology and Behavior, v. 48, p. 317-320. 
Carskadon, M., and W. Dement, 1982a, The multiple sleep latency test: What does it measure?: Sleep, v. 5, p. 67-72.

Carskadon, M. A., 1990, Patterns of sleep and sleepiness in adolescents: Pediatrician, v. 17, p. 5-12.

Carskadon, M. A., and W. C. Dement, 1979, Effects of total sleep loss on sleep tendency: Perceptual and Motor Skills, v. 48, p. 495-506.

Carskadon, M. A., and W. C. Dement, 1981, Cumulative effects of sleep restriction on daytime sleepiness: Psychophysiology, v. 18, p. 107-113.

Carskadon, M. A., and W. C. Dement, 1982b, Nocturnal determinants of daytime sleepiness: Sleep, v. 5(suppl), p. S67-72.

Carskadon, M. A., and W. C. Dement, 1989, Normal human sleep: an overview, in M. H. Kryger, T. Roth, and W. C. Dement, eds., Principles and practices of sleep medicine: Philadelphia, W.B. Saunders Company, p. 3-13.

Carskadon, M. A., W. C. Dement, M. M. Mitler, C. Guilleminault, V. P. Zarcone, and R. Spiegel, 1976, Selfreports versus sleep laboratory findings in 122 drug-free subjects with complaints of chronic insomnia: American Journal of Psychiatry, v. 133, p. 1382-1388.

Carskadon, M. A., and T. Roth, 1991, Sleep restriction, in M. TH., ed., Sleep, sleepiness and performance: New York, John Wiley \& Sons, p. 155-167.

Chatterton, R. T., and S. L. Dooley, 1999, Reversal of Diurnal Cortisol Rhythm and Suppression of Plasma Testosterone in Obstetric Residents on Call: Journal of Society for Gynecologic Investigation, v. 6, p. 50-54.

Christiansen, K., 2001, Hormones and sport. Behavioural effects of androgen in men and women: Journal of Endocrinology, v. 170, p. 39-48.

Cluydts, R., E. De Valck, E. Verstraeten, and P. Theys, 2002, Daytime sleepiness and its evaluation: Sleep Med Rev, v. 6, p. 83-96.

Cole, R. J., D. F. Kripke, W. Gruen, D. J. Mullaney, and J. C. Gillin, 1992, Automatic sleep/wake identification from wrist activity: Sleep, v. 15, p. 461-469.

Colquhoun, W. P., M. J. F. Blake, and R. S. Edwards, 1968a, Experimental studies of shift work. I: A comparison of "rotating" and "stabilzed" 4-hour systems: Ergonomics, v. 11, p. 437-453.

Colquhoun, W. P., M. J. F. Blake, and R. S. Edwards, 1968b, Experimental studies of shift work. II: Stabilized 8-hour shift system: Ergonomics, v. 11, p. 527-546.

Colquhoun, W. P., M. J. F. Blake, and R. S. Edwards, 1969, Experimental studies of shift work. III: Stabilized 12-hour shift system: Ergonomics, v. 12, p. 865-882.

Colquhoun, W. P., P. Hamilton, and R. S. Edwards, 1975, Effects of circadian rhythm, sleep deprivation and fatigue on performance during the night hours, in P. Colquhoun, S. Folkard, P. Knauth, and J. Rutenfranz, eds., Experimental Studies of Shiftwork (Forschungsberichte des Landes NordrheinWestfalen Report no 2513): Opladen, Westdeutscher Verlag, p. 20-28.

Costa, G., F. Lievore, G. Casaletti, and E. Gaffuri, 1989, Circadian characteristics influencing interindividual differences in tolerance and adjustment to shift work: Ergonomics, v. 32, p. 373-385.

Craig, A., and R. E. Cooper, 1992, Symptoms of acute and chronic fatigue, in A. P. Smith, and D. M. Jones, eds., Handbook of human performance, v. 3: London, Harcourt Brace Jovanovich, p. 289-339.

Cruz, C., C. Detwiler, T. Nesthus, and A. Boquet, 2003, Clockwise and counterclockwise rotating shifts: effects on sleep duration, timing, and quality: Aviat Space Environ Med, v. 74, p. 597-605.

Cruz, C., P. D. Rocco, and C. Hackworth, 2000, Effects of Quick Rotatin Shift Schedules on the Health and Adjustment of Air Traffic Controllers: Aviation Space and Environmental Medicine, v. 71, p. 400-407.

Czeisler, C. A., J. F. Duffy, T. L. Shanahan, E. N. Brown, J. F. Mitchell, D. W. Rimmer, J. M. Ronda, E. J. Silva, J. S. Allan, J. S. Emens, D.-J. Dijk, and R. E. Kronauer, 1999, Stability, Precision, and Near-24Hour Period of the Human Circadian Pacemaker: Science, v. 284, p. 2177-2181.

Czeisler, C. A., M. C. Moore-Ede, and R. M. Coleman, 1982, Rotating shift work schedules that disrupt sleep are improved by applying circadian principles: Science, v. 217, p. 460-463.

Czeisler, C. A., E. D. Weitzman, M. C. Moore-Ede, J. C. Zimmerman, and R. S. Knauer, 1980, Human sleep: its duration and organization depend on its circadian phase: Science, v. 210, p. 1264-1267.

Daan, S., and J. Aschoff, 2001, The entrainment of circadian systems, in F. W. T. J.S. Takahashi, R.Y. Moore, ed., Handbook of Behavioral Neurobiology, v. 12: New York, Kluwer Academic/Plenum Publishers, p. 7-43.

Daan, S., D. G. M. Beersma, and A. A. Borbély, 1984, Timing of human sleep: recovery process gated by a circadian pacemaker: Am J Physiol, v. 246, p. R161-178. 
Dai, W., L. H. Kuller, R. E. LaPorte, J. P. Gutai, L. Falvo-Gerard, and A. Gaggiula, 1981, The epidemiology of plasma testosterone levels in middle-aged men: American Journal of Epidemiology, v. 114, p. 804816.

Daniel, J., and A. Potasova, 1989, Oral temperature and performance in $8 \mathrm{~h}$ and $12 \mathrm{~h}$ shifts.: Ergonomics, v. 32, p. 689-696.

Davis, S., D. K. Mirick, and R. G. Stevens, 2001, Night Shift Work, Light at Night, and Risk of Breast Cancer: Journal of the National Cancer Institute, v. 92, p. 1557-1562.

Dawson, D., and S. S. Campbell, 1991, Timed exposure to bright light improves sleep and alerness during simulated night shifts: Sleep, v. 14, p. 511-516.

Dement, W., and N. Kleitman, 1957, Cyclic variations in EEG during sleep and their relation to eye movements, body motility, and dreaming: Electroencephalogr Clin Neurophysiol, v. 9, p. 673-690.

Dement, W. C., and M. A. Carskadon, 1982, Current perspectives on daytime sleepiness: the issues: Sleep, v. 5 , p. 56-66.

Dijk, D.-J., J. F. Duffy, and C. A. Czeisler, 2000, Contribution of circadian physiology and sleep homeostasis to age-related changes in human sleep: Chronobiology International, v. 17, p. 285-311.

Dijk, D.-J., J. F. Duffy, T. L. Shanahan, and C. A. Czeisler, 1999, Ageing and the circadian and homeostatic regulation of human sleep during forced desynchrony of rest, melatonin and temperature rhythms: Journal of Physiology, v. 516, p. 611-627.

Dijk, D. J., D. P. Brunner, D. G. M. Beersma, and A. A. Borbély, 1990, Electroencephalogram power density and slow wave sleep as a function of prior waking and circadian phase: Sleep, v. 13, p. 430-440.

Dijk, D. J., and C. A. Czeisler, 1994, Paradoxical timing of the circadian rhythm of sleep propensity serves to consolidate sleep and wakefulness in humans: Neuroscience Letters, v. 166, p. 63-68.

Dijk, D. J., J. F. Duffy, and C. A. Czeisler, 1992, Circadian and sleep-wake dependent aspects of subjective alertness and cognitive performance: J Sleep Res, v. 1, p. 112-117.

Dinges, D., and N. Kribbs, 1991, Performing while sleepy: effects of experimentally induced sleepiness., in T. Monk, ed., Sleep, sleepiness and performance: Chichester, John Wiley \& Sons Ltd, p. 97-128.

Dinges, D. F., 1992, Probing the limits of functional capability: the effects of sleep loss on short-duration tasks., in R. J. Broughton, and R. D. Ogilvie, eds., Sleep, Arousal, and Performance.: Boston, Birkhauser, p. 176-188.

Dinges, D. F., 1995, An overview of sleepiness and accidents: Journal of Sleep Research, v. 4 (suppl 2), p. 4-14.

Dinges, D. F., F. Pack, K. Williams, K. A. Gillen, J. W. Powell, G. E. Ott, C. Aptowicz, and A. I. Pack, 1997, Cumulative sleepiness, mood disturbance, and psychomotor vigilance performance decrements during a week of sleep restricted to 4-5 hours per night: Sleep, v. 20, p. 267-277.

Dirkx, J., 1987, A comparison of experienced shiftworkers with and without health complaints, in A. Oginski, J. Pokorski, and J. Rutenfranz, eds., Shiftwork research '87. Contemporary advances in shiftwork research: Krakow, Medical Academy, p. 313-322.

Dirkx, J., 1991, Recent research on night work for women: a review, in W. Singleton, and J. Dirkx, eds., Ergonomics, Health and Safety. Perspectives for the Nineties: Leuven, Leuven University Press, p. 5975.

Douglass, A. B., R. Bornstein, G. Nino-Murcia, S. Keenan, L. Miles, V. P. Zarcone Jr, C. Guilleminault, and W. C. Dement, 1994, The sleep disorders questionnaire I: Creation and multivariate structure of SDQ: Sleep, v. 17, p. 160-167.

Driver, H. S., 1996, Sleep in women: Journal of Psychosomatic Research, v. 40, p. 227-230.

Duchon, J., and T. Smith, 1993, Extended workdays and safety: International Journal of Industrial Ergonomics, v. 11, p. 37-49.

Duchon, J. C., K. C. M, and T. Smith, 1994, Extended workdays in an underground mine: A work performance analysis: Hum Factors, v. 36, p. 258-268.

Eberhardt, J. L., L.-O. Stråle, and M. H. Berlin, 1987, The influence of continuous and intermittent traffic noise on sleep: Journal of Sound and Vibration, v. 116, p. 445-464.

Ellingstad, V., and N. Heimstra, 1970, Performance changes during the sustained operation of a complex psychomotor task.: Ergonomics, v. 13, p. 693-705.

Escribà-Agüir, V., 1992, Nurses'attitudes towards shiftwork and quality of life: Scand J Soc Med, v. 20, p. 115-118. 
Estryn-Behar, M., C. Gadbois, E. Peigne, A. Masson, and V. Le Gall, 1990, Impact of nightshift on male and female hospital staff.: 9th International Symposium on Night and Shift Work: Shiftwork; health, sleep and performance, p. 89-94.

Ferrara, M., and L. de Gennaro, 2001, How much sleep do we need?: Sleep Medicine Reviews, v. 5, p. 155179.

Fields, W. L., and C. Loveridge, 1988, Critical Thinking and Fatigue: How do Nurses on 8- \& 12-Hour Shifts Compare: Nursing Economics, v. 6, p. 189-191.

Folkard, S., J. Arendt, and M. Clark, 1989, Sleep and mood on a "weekly" rotating (7-7-7) shift system: some preliminary results, in G. C. G. C. K. K. A. Wedderburn, ed., Shiftwork: Health, Sleep and Performance, v. 10: Verona, Italy, Peter Lang, p. 484-489.

Folkard, S., and J. Barton, 1993, Does the "forbidden zone" for sleep onset influence morning shift sleep duration?: Ergonomics, v. 36, p. 85-91.

Folkard, S., K. I. Hume, D. S. Minors, J. M. Waterhouse, and F. L. Watson, 1985, Independence of the circadian rhythm in alertness from the sleep/wake cycle: Nature, v. 313, p. 678-679.

Folkard, S., and T. H. Monk, 1981, Individual differences in the circadian response to a weekly rotating shift system, in A. Reinberg, N. Vieux, and P. Andlauer, eds., Night and Shift Work: Biological and Social aspects: Oxford, Pergamon Press, p. 367-374.

Folkard, S., T. H. Monk, and M. C. Lobban, 1979, Towards a predictive test of adjustment to shift work: Ergonomics, v. 22, p. 79-91.

Folkard, S., and T. Åkerstedt, 1987, Towards a model for the prediction of alertness and/or fatigue on different sleep/wake schedules, in A. Oginski, J. Pokorski, and J. Rutenfranz, eds., Contemporary Advances in Shiftwork Research: Krakow, Medical Academy, p. 231-240.

Folkard, S., and T. Âkerstedt, 1991, A three process model of the regulation of alertness and sleepiness, in R. Ogilvie, and R. Broughton, eds., Sleep, Arousal and Performance: Problems and Promises: Boston, Birkhäuser, p. 11-26.

Folstein, M. F., and R. Luria, 1973, Reliability, validity and clinical application of the visual analogue mood scale: Psychol Med, v. 3, p. 479-486.

Foret, J., B. Bensimon, O. Benoit, and N. Vieux, 1981, Quality of sleep as a function of age and shift work, in A. Reinberg, N. Vieux, and P. Andlauer, eds., Night and shift work: biological and social aspects: Oxford, Pergamon Press, p. 149-154.

Foret, J., and G. Lantin, 1972, The sleep of train drivers: An example of the effects of irregular work schdules on sleep, in W. P. Colquhoun, ed., Aspects of Human Efficiency. Diurnal Rhythm and Loss of Sleep: London, The English Universities Press Ltd, p. 273-281.

Frank, M. G., N. P. Issa, and M. P. Stryker, 2001, Sleep enhances plasticity in the developing visual cortex: Neuron, v. 30, p. 275-87.

Freeman, M. E., B. Kanyicska, A. Lerant, and G. Nagy, 2000, Prolactin: Structure, Function, and Regulation of Secretion: Physiological Reviews, v. 80, p. 1523-1631.

Frese, M., and K. Okonek, 1984, Reasons to leave shiftwork and psychological and psychosomatic complaints of former shiftworkers: J Appl Psychol, v. 69, p. 509-514.

Frese, M., and N. Semmer, 1986, Shiftwork, stress, and psychosomatic complaints: a comparison between workers in different shiftwork schdules, non-shiftworkers, and former shiftworkers: Ergonomics, v. 29, p. 99-114.

Fruhstorfer, H., P. Langanke, K. Meinzer, J. H. Peter, and U. Pfaff, 1977, Neurophysiological vigilance indicators and operational analysis of a train vigilance monitoring device: a laboratory and field study, in R. R. Mackie, ed., Vigilance: New York, Plenum Press, p. 147-162.

Fröberg, J., C.-G. Karlsson, L. Levi, and L. Lidberg, 1972, Circadian Variations in Performance, Psychological Ratings, Catecholamine Excretion, and Diuresis During Prolonged Sleep Deprivation: International Journal of Psychobiology, v. 2, p. 23-36.

Fröberg, J. E., 1985, Sleep deprivation and prolonged working hours, in S. Folkard, and T. H. Monk, eds., Hours of Work: Chichester, John Wiley, p. 67-75.

Gadbois, C., 1981, Women on night shift: Interdependence of sleep and off-the-job activities, in A. Reinberg, N. Vieux, and P. Andlauer, eds., Night and Shift Work: Biological and Social aspects: Oxford, Pergamon Press, p. 223-227.

Gillberg, M., G. Kecklund, and T. Åkerstedt, 1994, Relations between performance and subjective ratings of sleepiness during a night awake: Sleep, v. 17, p. 236-241. 
Gillberg, M., and T. Åkerstedt, 1994, Sleep restriction and SWS-suppression: effects on daytime alertness and night-time recovery: $J$ Sleep Res, p. 144-151.

Gillberg, M. a. Å., T., 1986, Individual differences in susceptibility to sleep loss, in M. K. M. Haider, and R. Cervinka, ed., Night and shiftwork: long term effects and their prevention: Studies in Industrial and Organizational Psychology, v. 3: Frankfurt am Main, Verlag Peter Lang, p. 117-122.

Gillespie, A., and J. Curzio, 1996, A comparison of a 12-hour and eight-hour shift system: Nursing Times, v. 92, p. 36-39.

Grandjean, E., G. Wotzka, R. Schaed, and A. Gilgen, 1971, Fatigue and stress in air traffic controllers.: Ergonomics, v. 14, p. 159-165.

Greenhouse, S. W., and S. Geisser, 1959, On methods in the analysis of profile data: Psychometrika, v. 24, p. 95-112.

Guilleminault, C., S. Czeisler, R. Coleman, and L. Miles, 1982, Circadian rhythm disturbances and sleep disorders in shift workers (EEG Supl no. 36), in P. A. Buser, W. A. Cobb, and T. Okuma, eds., Kyoto Symposia: Amsterdam, Elsevier, p. 709-714.

Hamelin, P., 1987, Lorry driver's time habits in work and their involvement in traffic accidents: Ergonomics, v. 30, p. 1323-1333.

Hansen, J., 2001, Light at Night, Shiftwork, and Breast Cancer Risk: Journal of the National Cancer Institute, v. 93, p. 1513-1515.

Harrington, J. M., 1978, Shift work and health. A critical review of the literature: London, HMSO.

Harris, W., 1977, Fatigue, circadian rhythm and truck accidents, in R. R. Mackie, ed., Vigilance: New York, Plenum Press, p. 133-146.

Harrison, Y., and J. A. Horne, 1996, Long-term extension to sleep - Are we really chronically sleep deprived?: Psychophysiology, v. 33, p. 22-30.

Hastings, M. H., A. B. Reddy, and E. S. Maywood, 2003, A clockwork web: circadian timing in brain and periphery, in helath and disease: Nature Reviews Neuroscience, v. 4, p. 649-661.

Heinisch, D. A., and S. M. Jex, 1997, Negative affectivity and gender as moderators of the relationship between work-related stressors and depressed mood at work: Work and Stress, v. 11, p. 46-57.

Heller, R. F., N. E. Miller, B. Lewis, A. Vermeulen, A. Fairney, V. H. T. James, and A. V. Swan, 1981, Associations between sex hormones, thyroid hormones and lipoproteins: Clinical Science, v. 61, p. 649651.

Hobson, J. A., 1999, Sleep and dreaming, in Z. M. J. e. al, ed., Fundamental Neuroscience: San Diego, Academic Press, p. 1207-1227.

Hoch, C. C., C. F. Reynolds III, D. J. Kupfer, S. R. Berman, P. R. Houck, and J. A. Stack, 1987, Empirical note: self-report versus recorded sleep in healthy seniors: Psychophysiology, v. 24, p. 293-299.

Hoddes, E., V. Zarcone, H. Smythe, R. Phillips, and W. Dement, 1973, Quantification of sleepiness: a new approach: Psychophysiology, v. 10, p. 431-436.

Horne, J., 1988, Why we sleep - The functions of sleep in humans and other mammals: Oxford, University Press.

Horne, J., 2000, Images of lost sleep: Nature, v. 403, p. 605-606.

Horne, J. A., and A. N. Pettit, 1985, High incentive effects on vigilance performance during $72 \mathrm{~h}$ of total sleep deprivation: Acta Psychol, v. 58, p. 123-139.

Horne, J. A., and L. A. Reyner, 1995, Sleep related vehicle accidents: Br Med J, v. 310, p. 565-567.

Hung, R., 1996, An annotated bibliography of compressed workweeks: International Journal of Manpower, v. 17, p. $43-53$.

Huynh, H., and L. S. Feldt, 1976, Estimation at the box correction for degrees of freedom for sample data in randomised block and split-plot designs: Journal of Educational Statistics, v. 1, p. 69-82.

Hänecke, K., S. Tiedemann, F. Nachreiner, and H. Grzech-Sukalo, 1998, Accident risk as a function of hour at work and time of day as determined from accident data and exposure models for the German working population: Scandinavian Journal of Work Environment and Health, v. 24, suppl 3, p. 43-48.

Härmä, M., 1993, Individual differences in tolerance to shiftwork: a review: Ergonomics, v. 36, p. 101-109.

Härmä, M., M. Sallinen, R. Ranta, P. Mutanen, and K. Müller, 2002, The effect of an irregular shift system on sleepiness at work in train drivers and railway traffic controllers: Journal of Sleep Research, v. 11, p. 141-151.

Härmä, M., J. Waterhouse, D. Minors, and P. Knauth, 1994a, Effect of masking on circadian adjustment and interindividual differences on a rapidly rotating shift schedule: Scand JWork Environ Health, v. 20, p. $55-61$. 
Härmä, M. I., T. Hakola, T. Åkerstedt, and J. T. Laitinen, 1994b, Age and adjustment to night work: Occup Environ Med, v. 51, p. 568-573.

Härmä, M. I., J. Ilmarinen, and P. Knauth, 1988a, Physical fitness and other individual factors relating to the shiftwork tolerance of women: Chronobiol Int, v. 5, p. 417-424.

Härmä, M. I., J. Ilmarinen, P. Knauth, J. Rutenfranz, and O. Hänninen, 1988b, Physical training intervention in female shift workers: 1 . The effects of intervention on fitness, fatigue, sleep, and psychosomatiac symptoms: Ergonomics, v. 31, p. 39-50.

Ishida, N., M. Kaneko, and R. Allada, 1999, Biological clocks: Proceedings of the National Academy of Sciences, v. 99, p. 8819-8820.

Iskra-Golec, I., 1993, The relationship between circadian, personality, and temperament characteristics and attitude towards shiftwork: Ergonomics, v. 36, p. 149-153.

Iskra-Golec, I., S. Folkard, T. Marek, and C. Noworol, 1996, Health, well-being and burnout of ICU nurses on 12- and 8-h shifts: Work and Stress, v. 3, p. 251-256.

Johns, M. W., 1992, Reliability and factor analysis of the Epworth Sleepiness scale: Sleep, v. 15, p. 376-381.

Johnson, L. C., 1981, On varying work/sleep schedules: issues and perspectives as seen by a sleep researcher, in L. C. Johnson, W. P. Colquhoun, D. I. Tepas, and M. J. Colligan, eds., Biological rhythms, sleep and shift work: Lancaster, MTP Press Ltd, p. 335346.

Johnson, L. C., 1982, Sleep deprivation and performance, in W. B. Webb, ed., Biological Rhythms, Sleep and Performance: Chichester, Wiley, p. 111-141.

Karni, A., D. Tanne, B. S. Rubenstein, J. J. M. Askenasy, and D. Sagi, 1994, Dependence on REM sleep of overnight improvement of a perceptual skill: Science, v. 265, p. 679-682.

Kawachi, I., G. A. Colditz, M. J. Stampfer, W. C. Willett, J. E. Manson, F. R. Speizer, and C. H. Hennekens, 1995, Prospective study of shift work and risk of coronary heart desease in women: Circulation, v. 92, p. 3178-3182.

Kecklund, G., and T. Åkerstedt, 1992, The psychometric properties of the Karolinska Sleep Questionnaire: $J$ Sleep Res, v. 1, suppl 1, p. 113.

Kecklund, G., and T. Åkerstedt, 1993, Sleepiness in long distance truck driving: an ambulatory EEG study of night driving: Ergonomics, v. 36, p. 1007-1017.

Kecklund, G., and T. Åkerstedt, 1995, Effects of timing of shifts on sleepiness and sleep duration: Journal of Sleep Research, v. 4 (suppl 2), p. 47-50.

Kecklund, G., and T. Åkerstedt, 1996, Objective components of individual differences in subjective sleep quality: Journal of Sleep Research, v. 5, Supplement 1, p. 105.

Kecklund, G., and T. Åkerstedt, 1997, Objective components of individual differences in subjective sleep quality: Journal of Sleep Research, v. 6, p. 217-220.

Kecklund, G., T. Åkerstedt, J. Axelsson, and A. Lowden, 2000, Determinants of the attitude to work and subjective health, in K. Isaksson, C. Hogstedt, C. Eriksson, and T. Theorell, eds., Health Effects of the New Labour Market: New York, Kluwer Academic/Plenum Publishers, p. 215-229.

Kecklund, G., T. Åkerstedt, and A. Lowden, 1997, Morning work: Effects of early rising on sleep and alertness: Sleep, v. 20, p. 215-223.

Kjellberg, A., 1977a, Sleep deprivation and some aspects of performance, I. Problems of arousal changes: Waking and Sleeping, v. 1, p. 139-143.

Kjellberg, A., 1977b, Sleep deprivation and some aspects of performance, II. Lapses and other attentional effects: Waking and Sleeping, v. 1, p. 145-148.

Kjellberg, A., 1977c, Sleep deprivation and some aspects of performance, III. Motivation, comment and conclusions: Waking and Sleeping, v. 1, p. 149-153.

Kjellberg, A., 1977d, Sleep deprivation, arousal and performance, in R. R. Mackie, ed., Vigilance: New York, Plenum Press, p. 529-535.

Klein, D. C., R. Y. Morre, and S. M. Reppert, 1991, Suprachiasmatic nucleus: the mind's clock: New York, Oxford UP.

Knauth, P., 1993, The design of shift systems: Ergonomics, v. 36, p. 15-28.

Knauth, P., 1996, Design of shiftwork systems, in W. P. Colquhoun, G. Costa, S. Folkard, and P. Knauth, eds., Shiftwork. Problems and solutions.: Frankfurt am Main, Peter Lang GmbH, p. 155-173.

Knauth, P., J. Keller, G. Schindele, and P. Totterdell, 1995, A 14-h night-shift in the control room of a fire brigade.: Work and Stress, v. 9, p. 176-186.

Knauth, P., and E. Kiesswetter, 1987, A change from weekly to quicker shift rotations: a field study of discontionuous three-shift workers: Ergonomics, v. 30, p. 1311-1321. 
Knauth, P., E. Kiesswetter, W. Ottman, M. J. Karvonen, and J. Rutenfranz, 1983, Time-budget studies of policemen in weekly or swiftly rotating shift systems: Appl Ergonomics, v. 14, p. 247-252.

Knauth, P., K. Landau, C. Dröge, M. Schwitteck, M. Widynski, and J. Rutenfranz, 1980, Duration of sleep depending on the type of shift work: Int Arch Occup Environ Health, v. 46, p. 167-177.

Knauth, P., and J. Rutenfranz, 1981, Duration of sleep related to the type of shift work, in A. Reinberg, N. Vieux, and P. Andlauer, eds., Night and Shift Work: Biological and Social Aspects: Oxford, Pergamon Press.

Knauth, P., and J. Rutenfranz, 1982, Development of criteria for the design of shiftwork systems. Proceedings of the 6th International Symposium on Night and Shift Work: J Hum Ergol, v. 11, suppl.

Knutsson, A., and T. Åkerstedt, 1992, The healthy-worker effect: self-selection among Swedish shift workers: Work and Stress, v. 6, p. 163-167.

Knutsson, A., T. Åkerstedt, B. G. Jonsson, and K. Orth-Gomér, 1986, Increased risk of ischemic heart disease in shift workers: Lancet, v. 12;2, p. 89-92.

Kogi, K., 1982, Sleep problems in night and shift work: J. Human Ergol., v. 11, p. 217-231.

Kogi, K., 1985, Introduction to the problems of shiftwork, in S. Folkard, and T. H. Monk, eds., Hours of Work: Chichester, John Wiley \& Sons, p. 165-184.

Kogi, K., 1995, Increasing flexibility in shiftwork arrangements.: Work and Stress, v. 9, p. 211-218.

Koller, M., 1983, Health risks related to shift work: Int Arch Occup Environ Health, v. 53, p. 59-75.

Koller, M., M. Härmä, J. T. Laitinen, M. P. Kundi, B., and M. Haider, 1994, Different patterns of light exposure in relation to melatonin and cortisol rhythms and sleep of night workers: J Pineal Res, v. 16, p. 127-135.

Koller, M., M. Kundi, and R. Cervinka, 1978, Field studies of shift work at an Austrian oil refinery. I. Health and psychosocial wellbeing of workers who drop out of shift work: Ergonomics, v. 21, p. 835-847.

Konz, S., 1998, Work/rest: Part II - The scientific basis (knowledge base) for the guide: International Journal of Industrial Ergonomics, v. 22, p. 73-99.

Kraus, C., M. Heistermann, and P. M. Kappeler, 1999, Physiological Suppression of Sexual Function of Subordinate Males: A Subtle Form of Intrasexual Competition Among Male Sifakas: Physiology and Behavior, v. 5, p. 855-861.

Krueger, J. M., and J. A. Majde, 1995, Cytokines and sleep: International Archives of Allergy and Immunology, v. 106, p. 97-100.

Krueger, J. M., F. J. Obal, J. Fang, T. Kubota, and P. Taishi, 2001, The role of cytokines in physiological sleep regulation: Ann N Y Acad Sci, v. 933, p. 211-21.

Kryger, M. H., T. Roth, and M. Carscadon, 1994, Circadian rhythms in humans: An overview, in K. M., R. T., and D. W., eds., Principles and practice of sleep medicine: Philadelphia, W.B. Saunders Company, p. 301-308.

Kryger, M. H., D. Steltjes, Z. Pouliot, H. Neufeld, and T. Odynski, 1991, Subjective versus objective evaluation of hypnotic efficacy: experience with Zolpidem: Sleep, v. 14, p. 399-407.

Kundi, M., M. Koller, R. Cervinka, and M. Haider, 1980, Job satisfaction in shift workers and its relation to family situation and health, in N. V. A. Reinberg, P. Andlauer, ed., Night and shift work: Oxford, Pergamon Press, p. 237-243.

Kurumatani, N., S. Koda, S. Nakagiri, A. Hisashige, K. Sakai, Y. Saito, H. Aoyama, M. Dejima, and T. Moriyama, 1994, The effects of frequently rotating shiftwork on sleep and the family life of hospital nurses: Ergonomics, v. 37, p. 995-1007.

Lamond, N., and D. Dawson, 1999, Quantifying the performance impairment associated with fatigue: Journal of Sleep Research, v. 8, p. 255-262.

Langlois, P. H., M. H. Smolensky, B. P. Hsi, and F. W. Weir, 1985, Temporal patterns of reported singlevehicle car and truck accidents in Texas, USA during 1980-1983: Chronobiol Int, v. 2, p. 131-146.

Lavie, P., N. Chillag, R. Epstein, O. Tzischinsky, R. Givon, S. Fuchs, and B. Shahal, 1989, Sleep disturbances in shift workers: a marker for maladaptation syndrome: Work \& Stress, v. 3, p. 33-40.

Lees, R. E., and B. R. Laundry, 1989, Comparison of reported workplace morbidity in 8-hour and 12-hour shifts in one plant.: Journal of Occupational Medicine, v. 39, p. 81-84.

Levine, B., T. Roehrs, F. Zorick, and T. Roth, 1988, Daytime sleepiness in young adults: Sleep, v. 11, p. 3946.

Lewy, A., R. Sack, and C. Singer, 1985, Immediate and delayed effects of bright light on human melatonin production: shifting 'dawn' and 'dusk' shifts the dim light melatonin onset (DLMO). Annals of the New York Academy of Science, v. 453, p. 253-259. 
Lewy, A. J., R. L. Sack, and R. H. Frederickson, 1983, The use of bright light in the treatment of chronobiologic sleep and mood disorders: The phase-response curve: Psychopharmacol Bull, v. 19, p. 523-525.

Lindberg, E., C. Janson, T. Gislason, E. Björnsson, J. Hetta, and G. Boman, 1997, Sleep disturbances in a young adult population: Can gender differences be explained by differences in psychological status?: Sleep, v. 20, p. 381-387.

Lisper, H. O., and A. Kjellberg, 1972, Effects of 24-hour sleep deprivations on rate of decrement in a 10minute auditory reaction time task: $J$ Exp Psychol, v. 96, p. 287-290.

Locke, E. A., 1976, The nature and causes of job satisfaction, in M. D. Dunnette, ed., Handbook of industrial and organizational psychology: Chicago, Rand McNally, p. 1297-1349.

Lockley, S. W., D. J. Skene, and J. Arendt, 1999, Comparison between subjective and actigraphic measurement of sleep and sleep rhythms: Journal of Sleep Research, v. 8, p. 175-183.

Luboshitzky, R., A. Aviv, A. Hefetz, P. Herer, Z. Shen-Orr, L. Lavie, and P. Lavie, 2002, Decreased Pituitary-Gonadal Secretion in Men with Obstructive Sleep Apnea: Journal of Clinical Endocrinology and Metabolism, v. 87, p. 3394-3398.

Luboshitzky, R., Z. Zabari, Z. Shen-Orr, P. Herer, and P. Lavie, 2000, Disruption of the Nocturnal Testosterone Rhythm by Sleep Fragmentation in Normal Men: Journal of Clinical Endocrinology and Metabolism, v. 86, p. 1134-1139.

MacDonald, I., L. Smith, S. L. Lowe, and S. Folkard, 1997, Effects on accidents of time into shift and of short breaks between shifts: International Journal of Occupational and Environmental Health, v. 3, p. 2:S40-S45.

Macdonald, W., and S. Bendak, 2000, Effects of workload level and 8-versus 12-h workday duration on test battery performance: International Journal of Industrial Ergonomics, v. 26, p. 399-416.

Maquet, P., 2000, Sleep on it!: Nature, v. 3, p. 1235-1236.

Mason, J. W., 1959, Hormones and metabolism. Psychological influences on the pituitary-adrenal cortical system: Recent Prog Horm Res, v. 15, p. 345-389.

Mazur, A., and A. Booth, 1998, Testosterone and dominance in men: Behavioral and Brain Sciences, v. 21, p. 353-397.

McEwen, B. S., 1998, Protective and demaging effects of stress mediators: The New England Journal of Medicine, v. 338, p. 171-179.

McGinty, D., and R. Szymusiak, 1990, Keeping cool: a hypothesis about the mechanisms and functions of slow wave sleep.: Trends Neurosci, v. 13, p. 480-487.

McNamee, R., K. Binks, S. Jones, D. Faulkner, A. Slovak, and N. M. Cherry, 1996, Shiftwork and mortality from ischaemic heart disease: Occupational and Environmental Medicine, v. 53, p. 367-373.

Meijer, J., and W. Rietveld, 1989, Neurophysiology of the suprachiasmatic circadian pacemaker in rodents: Physiological Reviews, v. 69, p. 671-707.

Mills, M. E., B. Arnold, and C. Mooney Wood, 1983, Core-12: a controlled study of the impact of 12-hour scheduling: Nurs Res, v. 32, p. 356-361.

Minors, D. S., and J. M. Waterhouse, 1981, Circadian rhythms and the human: Bristol, John Wright and Sons.

Mital, A., 1984, Comprehensive maximum acceptable weight of lift database for regular 8-hour work shifts. Ergonomics, v. 27, p. 1127-1138.

Mitchell, R. J., and A. M. Williamson, 2000, Evaluation of an 8 hour versus a 12 hour shift roster on employees at a power station: Applied Ergonomics, v. 31, p. 83-93.

Mitler, M., K. Gujavarty, and C. Broman, 1982, Maintenance of Wakefulness Test: a polysomnographic technique for evaluating treatment efficacy in patients with excessive somnolence: Electroencephalogr Clin Neurophysiol, v. 1982, p. 658-661.

Mitler, M. M., M. A. Carskadon, C. A. Czeisler, W. C. Dement, D. F. Dinges, and R. C. Graeber, 1988, Catastrophes, sleep and public policy: concensus report: Sleep, v. 11, p. 100-109.

Monk, T. H., 1988, Shiftwork: Determinants of coping ability and areas of application, in W. T. J. M. Hekkens, G. A. Kerkhof, and W. J. Rietveld, eds., Trends in chronobiology: Advances in the biosciences, v. 73: Oxford, Pergamon Press, p. 195-207.

Monk, T. H., and S. Folkard, 1985, Shiftwork and performance, in T. H. Monk, and S. Folkard, eds., Hours of work: Chichester, John Wiley, p. 239-252.

Moore, R. Y., 1995, Organization of the mammalian circadian system, in D. J. Chadwick, and K. Ackrill, eds., Circadian clocks and their adjustment: Chichester, John Wiley \& Sons, p. 88-99. 
Moore-Ede, M. C., F. M. Sulzman, and C. A. Fuller, 1982, The clocks that time us: Cambridge, MA: Harvard Universisty Press.

Morley, J. E., 2001, Androgens and aging: Maturitas, v. 38, p. 61-73.

Mott, P. E., F. C. Mann, Q. McLoughlin, and D. P. Warwick, 1965, Shift work - the social, psychological and physical consequences, Ann Arbor: University of Michigan Press.

Mullaney, D. J., D. F. Kripke, and S. Messin, 1980, Wrist actigraphic estimation of sleep time: Sleep, v. 3, p. 83-92.

Nachreiner, F., 1975, Role perceptions, job satisfaction, and attitudes towards shiftwork of workers in different shift systems as related to situational and personal factors, in P. Colquhoun, S. Folkard, P. Knauth, and J. Rutenfranz, eds., Experimental Studies of Shiftwork, Westdeutscher Verlag, p. 232-243.

Nachreiner, F., 1998, Individual and social determinants of shiftwork tolerance: Scandinavian Journal of Work Environment and Health, v. 24, p. 34-42.

Nakanishi, H., Y. Sun, R. K. Nakamura, K. Mori, M. Ito, S. Suda, H. Namba, F. I. Storch, T. P. Dang, W. Mendelson, M. Mishkin, C. Kennedy, J. C. Gillin, C. B. Smith, and L. Sokoloff, 1997, Positive correlations between cerebral protein synthesis rates and deep sleep in Macaca mulatta: Eur J Neurosci, v. 9, p. 271-9.

Noel, G. L., H. K. Suh, G. Stone, and A. G. Frantz, 1972, Human Prolactin and Growth Hormone Release during Surgery and other Conditions of Stress: Journal of Clinical Endocrinology and Metabolism, v. 35 , p. 840-851.

Nurminen, T., 1998, Shift work and reproductive health: Scandinavian Journal of Work Environment and Health, v. 24 (suppl 3), p. 28-34.

Oginska, H., J. Pokorski, and A. Oginski, 1993, Gender, ageing, and shiftwork intolerance: Ergonomics, v. 36 , p. 161-168.

Opp, M. R., 1995, Corticotropin-releasing hormone involvement in stressor-induced alterations in sleep and in the regulation of waking: Advances in Neuroimmunology, v. 5, p. 123-143.

Opstad, P. K., and A. Aakvaag, 1983, The effect of sleep deprivation on the plasma levels of hormones during prolonged physical strain and calorie deficiency: Eur J Appl Physiol, v. 51, p. 97-107.

Osborne, E. E., 1919, The output of women workers in relation to hours of work in shell making. Industrial fatigue research board, HMSO.

Panda, S., J. B. Hogenesch, and S. A. Kay, 2002, Circadian rhythms from flies to human: Nature, v. 417, p. 329-35.

Parkes, K. R., 1994, Sleep patterns, shiftwork, and individual differences: a comparison of onshore and offshore control-room operators: Ergonomics, v. 37, p. 827-844.

Parkes, K. R., 1999, Shiftwork, job type, and work environment as joint predictors of health-related outcomes: Journal of Occupational Health Psychology, v. 4, p. 256-68.

Patkai, P., and K. Dahlgren, 1981, Satisfaction with different types of rapidly rotating shift systems., in A. Reinberg, N. Vieux, and P. Andlauer, eds., Night and shiftwork: Biological and social aspects., v. 30: Oxford, Pergamon Press, p. 245-250.

Patkai, P., T. Åkerstedt, and K. Pettersson, 1977, Field studies of shift work: I Temporal patterns in psychophysical activation in permanent night workers: Ergonomics, v. 20, p. 611-619.

Peacock, B., R. Glube, M. Miller, and P. Clune, 1983, Police officers' responses to 8 and 12 hour shift schedules: Ergonomics, v. 325, p. 479-493.

Petty, M. M., G. W. McGee, and J. W. Cavender, 1984, A meta-analysis of the relationships between individual job satisfaction and individual performance: Academy of Management Review, v. 9, p. 712721.

Porkka-Heiskanen, T., R. E. Strecker, M. Thakkar, A. A. Bjorkum, R. W. Greene, and R. W. McCarley, 1997, Adenosine: A mediator of the sleep-inducing effects of prolonged wakefulness: Science, v. 276, p. 1265-1268.

Ramm, P., and C. T. Smith, 1990, Rates of cerebral protein synthesis are linked to slow wave sleep in the rat: Physiol Behav, v. 48, p. 749-53.

Rechtschaffen, A., and A. Kales, 1968, A manual of standardized terminology, techniques and scoring system for sleep stages of human subjects: Bethesda, US Department of Health, Education and Welfare, Public Health Service.

Rechtschaffen, A., and P. Verdone, 1964, Amount of dreaming; Effect of incentive, adaptation to laboratory, and individual differences: Perceptual and Motor Skills, v. 19, p. 947-958. 
Reid, K., and D. Dawson, 1999, Correlation between wrist activity monitor and electrophysiological measures of sleep in a simulated shiftwork environment for younger and older subjects: Sleep, v. 22, p. $378-385$.

Reid, N., G. Robinson, and C. Todd, 1993, The quantity of nursing care on wards working 8- and 12-hour shifts.: International Journal of Nursing Studies, v. 30, p. 403-413.

Reinberg, A., P. Andlauer, P. Guillet, A. Nicolai, N. Vieux, and A. Laporte, 1980, Oral temperature, circadian rhythm amplitude, aging and tolerance to shiftwork: Ergonomics, v. 23, p. 55-64.

Reyner, A., and J. A. Horne, 1995, Gender- and age-related differences in sleep determined by homerecorded sleep logs and actmetry from 400 adults: Sleep, v. 18, p. 127-134.

Roach, G. D., K. J. Reid, and D. Dawson, 2003, The amount of sleep obtained by locomotive engineers: effect of break duration and time of break onset: Occupational and Environmental Medicine, v. 60, p. 60(12)e17.

Rosa, R., 1993, Napping at home and alertness on the job in rotating shift workers: Sleep, v. 16, p. 727-735.

Rosa, R., 1995, Extended workshifts and excessive fatigue: Journal of Sleep Research, v. 4 (suppl 2), p. 5156.

Rosa, R. R., 1991, Performance, alertness, and sleep after 3.5 years of 12-hour shifts: A follow-up study.: Work and Stress, v. 5, p. 107-116.

Rosa, R. R., and M. H. Bonnet, 1993, Performance and alertness on $8 \mathrm{~h}$ and $12 \mathrm{~h}$ rotating shifts at a natural gas utility: Ergonomics, v. 36, p. 1177-1193.

Rosa, R. R., and M. J. Colligan, 1989, Extended workdays: effects of 8-hour and 12-hour rotating shift schedules on performance, subjective alertness, sleep patterns, and psychosocial variables: Work and Stress, v. 3, p. 21-32.

Rosa, R. R., D. D. Wheeler, J. S. Warm, and M. J. Colligan, 1985, Extended workdays: Effects on performance and ratings of fatigue and alertness: Beh Res Meth Inst Comp, v. 17, p. 6-15.

Rusak, B., and I. Zucker, 1979, Neural Regulation of Circadian Rhythms: Physiological Reviews, v. 59, p. 449-526.

Rutenfranz, J., W. P. Colquhoun, P. Knauth, and J. N. Ghata, 1977, Biomedical and psychological aspects of shift work: Scand J Work Environ Health, v. 3, p. 165-182.

Sadeh, A., J. Alster, D. Urbach, and P. Lavie, 1989, Actigraphically based automatic bedtime sleep-wake scoring: Validity and clinical applications: J Ambulatory Monitoring, v. 2, p. 209-216.

Sadeh, A., P. J. Hauri, D. F. Kripke, and P. Lavie, 1995, The role of actigraphy in the evaluation of sleep disorders: Sleep, v. 18, p. 288-302.

Saito, Y., and K. Kogi, 1978, Psychological conditions of working night and subsequent day shifts with short sleep hours between them.: Ergonomics, v. 21, p. 871.

Sallinen, M., M. Harma, P. Mutanen, R. Ranta, J. Virkkala, and K. Muller, 2003, Sleep-wake rhythm in an irregular shift system: J Sleep Res, v. 12, p. 103-12.

Sasaki, T., K. Iwasaki, T. Oka, N. Hisanaga, T. Ueda, Y. Takada, and Y. Fujiki, 1999, Effect of working hours on cardiovascular-autonomic nervous functins in engineers in an electronics manufacturing company: Industrial Health, v. 37, p. 55-61.

Schernhammer, E. S., F. Laden, F. E. Speizer, W. C. Willett, D. J. Hunter, I. Kawachi, and G. A. Colditz, 2001, Rotating Night Shifts and Risk of Breast Cancer in Women Participating in the Nurses' Health Study: Journal of the National Cancer Institute, v. 93, p. 1563-1568.

Schiavi, R. C., D. White, and J. Mandeli, 1992, Pituitary-gonadal function during sleep in healthy aging men: Psychoneuroendocrinology, v. 17, p. 599-609.

Schultz, T. F., and S. A. Kay, 2003, Circadian clocks in daily and seasonal control of development: Science, v. 301, p. 326-8.

Scott, A. J., T. H. Monk, and L. L. Brink, 1997, Shiftwork as a risk factor for depression: A pilot study: International Journal of Occupational and Environmental Health, v. 3, p. 2-9.

Smith, L., S. Folkard, P. Tucker, and I. Macdonlad, 1998a, Work shift duration: a review comparing eight hour and 12 hour shift systems: Occupational and Environmental Medicine, v. 55, p. 217-229.

Smith, L., T. Hammond, I. Macdonald, and S. Folkard, 1998b, 12-h shifts are popular but are they a solution?: International Journal of Industrial Ergonomics, v. 21, p. 323-331.

Smith, P. A., B. M. Wright, R. W. Mackey, H. W. Milsop, and S. C. Yates, 1998c, Change from slowly rotating 8-hour shifts to rapidly rotating 8-hour and 12-hour shifts using participative shift roster design: Scandinavian Journal of Work Environment and Health, v. 24, p. 55-61. 
Spiegel, K., L. Weibel, C. Gronfier, G. Brandenberger, and M. Follenius, 1996, Twenty-four-hour prolacatin profiles in night workers: Chronobiology International, v. 13, p. 283-293.

Spiegel, R., 1981, Subjective sleep assessment and polygraphic criteria, in E. D. Weitzman, ed., Sleep and sleeplessness in advanced age: New York, Spectrum, p. 169-188.

Spielman, A. J., C.-M. Yang, and P. B. Glovinsky, 2000, Assessment techniques for insomnia, in M. H. Kryger, T. Roth, and W. C. Dement, eds., Principles and practice of sleep medicine: Philadelphia, W.B. Saunders Company, p. 1239-1250.

Spurgeon, A., J. M. Harrington, and C. L. Cooper, 1997, Health and safety problems associated with long working hours: a review of the current position: Occupational and Environmental Medicine, v. 54, p. $367-75$.

Stevens, J., J. Brown, and C. Lee, 2004, The Second Work-Life Balance stuy: Results from the Employees'Survey, London, MORI Social Research Institute, p. 115.

Stickgold, R., L. James, and J. A. Hobson, 2000, Visual discrimination learning requires sleep after training: Nature, v. 3, p. 1237-1238.

Stokkan, K. A., S. Yamazaki, H. Tei, Y. Sakaki, and M. Menaker, 2001, Entrainment of the circadian clock in the liver by feeding: Science, v. 291, p. 490-3.

Takahashi, J. S., 1993, Biological rhythms: From gene expression to behavior, in L. Wetterberg, ed., Light and biological rhythms in man: Stockholm, Pergamon Press, p. 3-22.

Taylor, P. J., and S. J. Pocock, 1972, Mortality of shift and day workers 1956-68: Br J Ind Med, v. 29, p. 201-207.

Tenkanen, L., T. Sjöblom, and M. Härmä, 1998, Joint effect of shift work and adverse life-style factors on the risk of coronary heart disease: Scandinavian Journal of Work Environment and Health, v. 24, p. 351-357.

Tepas, D. I., 1982, Shiftworker sleep strategies: J. Hum Ergol, v. 11, p. 325-336.

Tepas, D. I., 1985, Flexitime, compressed workweeks and other alternative work schedules, in S. Folkard, and T. H. Monk, eds., Hours of Work: Chichester, John Wiley \& Sons, p. 147-164.

Tepas, D. I., J. K. Walsh, and D. R. Armstrong, 1981, Comprehensive study of the sleep of shift workers, in L. C. Johnson, D. I. Tepas, W. P. Colquhoun, and M. J. Colligan, eds., Biological rhythms, sleep and shift work: Advances in sleep research, v. 7: New York, SP Medical \& Scientific Books, p. 347-356.

Thiis-Evensen, E., 1958, Shift work and health: Ind Med Surg, v. 27, p. 493-497.

Tilley, A. J., R. T. Wilkinson, P. S. G. Warren, W. B. Watson, and M. Drud, 1982, The sleep and performance of shift workers: Hum Factors, v. 24, p. 624-641.

Tobler, I., 2000, Phylogeny of sleep regulation, in M. H. Kryger, T. Roth, and W. C. Dement, eds., Principles and practice of sleep medicine: Philadelphia, W.B. Saunders Company, p. 72-81.

Todd, C., N. Reid, and G. Robinson, 1989, The quality of nursing care on wards working eight and twelve hour shifts: a repeated measures study using the MONITOR index of quality care: International Journal of Nursing Studies, v. 26, p. 359-368.

Todd, C., G. Robinson, and N. Reid, 1993, 12-hour shifts: job satisfaction of nurses: Journal of Nursing Management, v. 1, p. 215-220.

Torsvall, L., and T. Åkerstedt, 1980, A diurnal type scale: Scand J Work Environ Health, v. 6, p. 283-290.

Torsvall, L., and T. Åkerstedt, 1983, Sleepiness during day and night work: A field study of train drivers: Sleep Res, v. 12, p. 376.

Torsvall, L., T. Åkerstedt, K. Gillander, A. Borbély, I. Tobler, and A. Knutsson, 1987, Activity monitoring in shift work, in A. Oginsky, J. Pokorski, and J. Rutenfranz, eds., Contemporary advances in shiftwork research: Krakow, Medical Academy, p. 341-345.

Torsvall, L., T. Åkerstedt, K. Gillander, and A. Knutsson, 1986, $24 \mathrm{~h}$ recordings of sleep/wakefulness in shift work, in M. Haider, M. Koller, and R. Cervinka, eds., Night and Shift Work: Longterm Effects and Their Prevention: Frankfurt am Main, Verlag Peter Lang, p. 37-41.

Torsvall, L., T. Åkerstedt, and M. Gillberg, 1981, Age, sleep and irregular work hours: A field study with EEG recording, catecholamine excretion, and self-ratings: Scand J Work Environ Health, v. 7, p. 196203.

Totterdell, P., and S. Folkard, 1990, The effects of changing from a weekly rotating to a rapidly rotating shift schedule, in G. Costa, G. Cesena, K. Kogi, and A. Wedderburn, eds., Shiftwork: health, sleep and performance: Frankfurt am Main, Verlag Peter Lang, p. 646-650.

Totterdell, P., S. Reynolds, B. Parkinson, and R. B. Briner, 1994, Associations of sleep with everyday mood, minor symptoms and social interaction experience: Sleep, v. 17, p. 466-475. 
Touitou, Y., Y. Motohashi, A. Reinberg, C. Touitou, P. Bourdeleau, A. Bogdan, and A. Auzeby, 1990, Effect of shift work on the night-time secretory patterns of melatonin, prolactin, cortisol and testosterone: European Journal of Applied Physiology, v. 60, p. 288-292.

Tuchsen, F., H. Jeppesen, and E. Bach, 1994, Employment status, non-daytime work and gastric ulcer in men.: International Journal of Epidemiology, v. 23, p. 365-370.

Tucker, P., J. Barton, and S. Folkard, 1996, Comparison of eight and 12 hour shifts: impacts on health, wellbeing, and alertness during the shift: Occupational and Environmental Medicine, v. 53, p. 767-772.

Tucker, P., L. Smith, I. Macdonald, and S. Folkard, 1998a, The impact of early and late shift changeovers on sleep, health, and well-being in 8- and 12-hour shift systems: Journal of Occupational Health Psychology, v. 3, p. 265-275.

Tucker, P., L. Smith, I. Macdonald, and S. Folkard, 1998b, Shift length as a determinant of retrospective onshift alertness: Scandinavian Journal of Work Environment and Health, v. 24, p. 49-54.

Tucker, P., L. Smith, I. Macdonald, and S. Folkard, 1999, Distribution of rest days in 12 hour shift systems: impact on health, wellbeing, and on shift alertness: Occupational and Environmental Medicine, v. 56, p. 206-214.

Tucker, P., L. Smith, I. Macdonald, and S. Folkard, 2000, Effects of direction of rotation in continuous and discontinuous 8 hour shift systems: Occupational and Environmental Medicine, v. 57, p. 678-84.

Turek, F. W., 1986, Circadian principles and design of rotating shift work schedules: Am J Physiol, v. 251, p. R636-R638.

Ugrovics, A., and J. Wright, 1990, 12-Hour Shifts: Does Fatigue Undermine ICU Nursing Judgments?: Nursing Management, v. 21, p. 64a-64g.

Van Cauter, E., R. Leproult, and L. Plat, 2000, Age-related changes in slow wawe sleep and REM sleep and relationship with growth hormone and cortisol levels in healthy men: JAMA, v. 284, p. 861-868.

Van de Kar, L. D., and M. L. Blair, 1999, Forebrain Pathways Mediating Stress-Induced Hormone Secretion: Frontiers in Neuroendocrinology, v. 20, p. 1-48.

van der Hulst, M., 2003, Long workhours and health: Scandinavian Journal of Work Environment and Health, v. 29, p. 171-188.

Verhaegen, P., J. Dirkx, and A. Maasen, 1986, The evolution of shift workers' sleep four years and twelve years after starting shift work, in A. Oginski, J. Pokorski, and J. Rutenfranz, eds., Shiftwork research '87. Contemporary advances in shiftwork research: Krakow, Medical Academy, p. 269-276.

Verhaegen, P., A. Maasen, and A. Meers, 1981, Health problems in shift workers, in L. C. Johnson, D. J. Tepas, W. P. Colquhoun, and M. J. Colligan, eds., Biological rhythms and shift work: New York, Spectrum, p. 271-282.

Vermeulen, A., 1983, Androgen Secretion after Age 50 in Both Sexes: Hormone Research, v. 18, p. 37-42.

Vermeulen, A., and G. Verdonck, 1992, Representativeness of a Single Point Plasma Testosterone Level for the Long Term Hormonal Milieu in Men: Journal of Clinical Endocrinology and Metabolism, v. 74, p. 939-942.

Vernon, H. M., 1920, Industrial efficiency and fatigue., in E. L. Collis, ed., The Industrial Clinic: London, John Bale and Sons, p. 51-74.

Vik, A. G., and R. C. MacKay, 1982, How Does the 12-Hour Shift Affect Patient Care?: The Journal of Nursing Administration, v. January, p. 11-14.

Virtanen, A., and V. Notkola, 2002, Socioeconomic inequalities in cardiovascular mortality and the role of work: a register study of Finnish men: International Journal of Epidemiology, v. 31, p. 614-621.

Volle, M., G. R. Brisson, N. Perusse, M. Tanaka, and Y. Doyon, 1979, Compressed work-week: psychophysiological and physiological repercussions.: Ergonomics, v. 22, p. 1001-1010.

Wallace, M., and K. Greenwood, 1995, Twelve-hour shift: Work and Stress, v. 9, p. 105-108.

Washburn, M. S., 1991, Fatigue and Critical Thinking on Eight-and Twelve-Hour Shifts: Nursing Management, v. 22, p. 80-85.

Webb, W. B., and H. W. Agnew, 1974, The effects of a chronic limitation of sleep length: Psychophysiology, v. 11, p. $265-274$.

Webb, W. B., and H. W. Agnew, 1975, Are we chronically sleep deprived?: Bull Psychon Soc, v. 6, p. 47-48.

Webb, W. B., and J. Agnew, H.W., 1971, Stage 4 sleep: influence of time course variables: Science, v. 174, p. 1354-1356.

Wedderburn, A. A. I., 1967, Social Factors in Satisfaction with Swiftly Rotating Shifts: Occupational Psychology, v. 41, p. 85-107. 
Wedderburn, A. A. I., 1981, How important are social effects of shift work?, in L. C. Johnson, D. I. Tepas, W. P. Colquhoun, and M. J. Colligan, eds., Advances in sleep research: Advances in sleep research, v. 7: New York, Spectrum, p. 257-270.

Wegmann, H. M., S. Hasenclever, C. Michel, and S. Trumbach, 1985, Models to predict operational loads of flight scedules: Aviat Space Environ Med, v. 56, p. 27-32.

Weibel, L., and G. Brandenberger, 1998, Disturbances in Hormonal Profiles of Night Workers during Their Usual Sleep and Work Times: Journal of Biological Rhythms, v. 13, p. 202-208.

Wever, R., 1979, The circadian system of man: Results of experiments under temporal isolation: New York, Springer-Verlag.

Wilkinson, R., S. Allison, M. Feeney, and Z. Kaminska, 1989, Alerness of night nurses: two shift systems compared: Ergonomics, v. 32, p. 281-292.

Wilkinson, R. T., 1961, Interaction of lack of sleep with knowledge of results, repeated testing and individual differences: $J$ Exp Psychol, v. 62, p. 263-271.

Wilkinson, R. T., and D. Houghton, 1982, Field test of arousal: a portable reaction timer with data storage: Hum Factors, v. 24, p. 487-493.

Williamson, A. M., C. G. I. Gower, and B. C. Clarke, 1994, Changing the hours of shiftwork: a comparison of 8- and12-hour shift rosters in a group of computer operators: Ergonomics, v. 37, p. 287-298.

Winer, B. J., 1971, Statistical principles in experimental design: New York, McGraw-Hill.

Wu, H. C., and M. J. Wang, 2002, Relationship between maximum acceptable work time and physical workload: Ergonomics, v. 45, p. 280-9.

Wyatt, S., and R. Mariott, 1953, Night work and shift changes: Br J Ind Med, v. 10, p. 164-177.

Yehuda, R., H. Resnick, B. Kahana, and E. Giller, 1993, Long-lasting hormonal alterations to extreme stress in humans: normative or maladaptive?: Psychosomatic Medicine, v. 55, p. 287-297.

Zepelin, H., and A. Rechtschaffen, 1974, Mammalian Sleep, Longevity, and Energy Metabolism, in A. J. raimondi, ed., Child's Brain, S. Karger, p. 425-470.

Zitzmann, M., and E. Nieschlag, 2001, Testosterone levels in healthy men and the relation to behavioural and physical characteristics: facts and constructs: European Journal of Endocrinology, v. 144, p. 183197.

Zulley, J., and S. S. Campbell, 1985, Napping behavior during "spontaneous internal desynchronization": sleep remains in synchrony with body temperature: Hum Neurobiol, v. 4, p. 123-126.

Åhsberg, E., G. Kecklund, T. Åkerstedt, and F. Gamberale, 2000, Shiftwork and different dimensions of fatigue. Int J Ind Ergonomics, v. 26, p. 457-465.

Åkerstedt, T., 1987, Sleep and stress, in J. H. Peter, T. Podszus, and P. von Wichert, eds., Sleep related disorders and internal diseases: Heidelberg, Springer Verlag, p. 183-191.

Åkerstedt, T., 1988, Sleepiness as a consequence of shift work: Sleep, v. 11, p. 17-34.

Åkerstedt, T., 1991, Sleepiness at work: effects of irregular work hours, in T. Monk, ed., Sleep, Sleepiness and Perfomance: New York, Wiley.

Åkerstedt, T., 1995, Work hours and sleepiness: Neurophysiologie Clinique, v. 25, p. 367-375.

Åkerstedt, T., 1998, Shift work and disturbed sleep/wakefulness: Sleep Medicine Reviews, v. 2, p. 117-128.

Åkerstedt, T., 1999, Individual differences in reactions to irregular work hours, Venice, Italy, Scuola Navale Militare "Francesco Morosini", p. K2-1-7.

Åkerstedt, T., 2000, Consensus statement: fatigue and accidents in transport operations: Journal of Sleep Research, v. 9, p. 395-395.

Åkerstedt, T., C. A. Czeisler, D. F. Dinges, and J. A. Horne, 1994a, Accidents and sleepiness; a consensus statement from the International Conference on Work Hours, Sleepiness and Accidents, Stockholm, 810 September 1994.: J Sleep Res, p. 195.

Åkerstedt, T., and S. Folkard, 1995, Validation of the S and C components of the Three-process model of alertness regulation: Sleep, v. 18, p. 1-6.

Åkerstedt, T., and J. E. Fröberg, 1976, Shift work and health- interdisciplinary aspect, in P. G. Rentos, and R. D. Shepard, eds., Shift Work and Health: Washington, US Dept of Health, Education and Welfare, p. 179-197.

Åkerstedt, T., and M. Gillberg, 1981a, The circadian variation of experimentally displaced sleep: Sleep, v. 4, p. 159-169.

Åkerstedt, T., and M. Gillberg, 1981b, Sleep disturbances and shift work, in A. Reinberg, N. Vieux, and P. Andlauer, eds., Night and shift work: biological and social aspects: Oxford, Pergamon Press, p. 127138. 
Åkerstedt, T., and M. Gillberg, 1986, Sleep duration and the power spectral density of the EEG: Electroencephalogr Clin Neurophysiol, v. 64, p. 119-122.

Åkerstedt, T., and M. Gillberg, 1990, Subjective and objective sleepiness in the active individual: International Journal of Neuroscience, v. 52, p. 29-37.

Åkerstedt, T., K. Hume, D. Minors, and J. Waterhouse, 1994b, The meaning of good sleep: a longitudinal study of polysomnography and subjective sleep quality.: J Sleep Res, v. 3, p. 152-158.

Åkerstedt, T., K. Hume, D. Minors, and J. Waterhouse, 1994c, The subjective meaning of good sleep, an intraindividual approach using the Karolinska Sleep Diary: Percep Mot Skills, v. 79, p. 287-296.

Åkerstedt, T., G. Kecklund, and A. Knutsson, 1991, Spectral analysis of sleep electroencephalography in rotating three-shift work: Scandinavian Journal of Work Environment and Health, v. 17, p. 330-336.

Åkerstedt, T., J. Palmblad, B. de la Torre, M. Marana, and M. Gillberg, 1980, Adrenocortical and gondal steroids during sleep deprivation: Sleep, v. 3, p. 23-30.

Åkerstedt, T., and L. Torsvall, 1978, Experimental changes in shift schedules - their effects on well-being: Ergonomics, v. 21, p. 849-856.

Åkerstedt, T., and L. Torsvall, 1981a, Age, sleep, and adjustment to shift work, in W. Koella, ed., Sleep 1980: Basel, Karger, p. 190-194.

Åkerstedt, T., and L. Torsvall, 1981b, Shiftwork. Shift-dependent wellbeing and individual differences.: Ergonomics, v. 24, p. 265-273.

Åkerstedt, T., and L. Torsvall, 1985, Napping in shift work: Sleep, v. 8, p. 105-109.

Åkerstedt, T., L. Torsvall, and J. E. Fröberg, 1983, A questionnaire study of sleep/wake disturbances and irregular work hours: Sleep Res, v. 12, p. 358.

Åkerstedt, T., L. Torsvall, and M. Gillberg, 1982, Sleepiness and shift work: Field studies: Sleep, v. 5, p. 95106.

Åkerstedt, T., L. Torsvall, and M. Gillberg, 1987, Sleepiness in shiftwork. A review with emphasis on continuous monitoring of EEG and EOG: Chronobiol Int, v. 4, p. 129-140.

Åkerstedt, T., L. Torsvall, A. Kecklund, and A. Knutsson, 1990, The shift cycle and clinical indices of insomnia, in G. Costa, G. Cesana, K. Kogi, and A. Wedderburn, eds., Shift work: health, sleep and performance: Frankfurt am Main, Peter Lang, p. 421-426. 